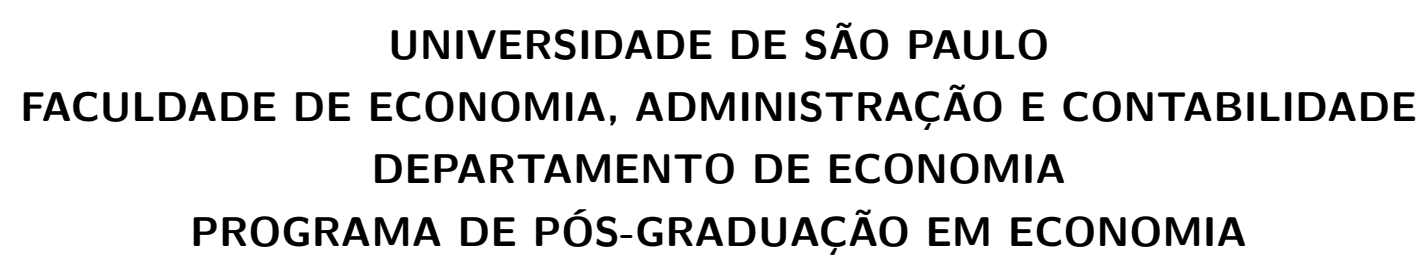

Efeitos adversos da legislação do seguro-desemprego: Evidência sobre o Brasil

\author{
Cristiano Costa Carvalho \\ Orientador: Renata Del Tedesco Narita
}

São Paulo - Brasil

2017 
Prof. Dr. Marco Antonio Zago

Reitor da Universidade de São Paulo

Prof. Dr. Adalberto Américo Fischmann

Diretor da Faculdade de Economia, Administração e Contabilidade

Prof. Dr. Eduardo Amaral Haddad

Chefe do Departamento de Economia

Prof. Dr. Ariaster Baumgratz Chimeli

Coordenador do Programa de Pós-Graduação em Economia 


\section{Efeitos adversos da legislação do seguro-desemprego: Evidência sobre o Brasil}

Trabalho de dissertação apresentado ao Departamento de Economia da Faculdade de Economia, Administração e Contabilidade da Universidade de São Paulo como requisito parcial para a obtenção do título de Mestre em Ciências

Orientador: Renata Del Tedesco Narita

Versão Corrigida

(versão original disponível na Biblioteca da Faculdade de Economia, Administração e Contabilidade)

São Paulo - Brasil

2017 
FICHA CATALOGRÁFICA

Elaborada pela Seção de Processamento Técnico do SBD/FEA/USP

Carvalho, Cristiano Costa

Efeitos adversos da legislação do seguro-desemprego: evidência sobre o Brasil / Cristiano Costa Carvalho. - São Paulo, 2017.

$102 \mathrm{p}$.

Dissertação (Mestrado) - Universidade de São Paulo, 2017.

Orientador: Renata Del Tedesco Narita.

1. Seguro-desemprego 2. Desemprego 3. Legislação trabalhista I. Universidade de São Paulo. Faculdade de Economia, Administração e Contabilidade. II. Título.

CDD -368.44 


\section{Agradecimentos}

Agradeço a minha orientadora, professora Renata Narita, e ao professor Raphael Corbi, que foram fundamentais no processo de construção deste trabalho. Também deixo meus agradecimentos ao professor Helio Zylberstajn e ao suporte financeiro fornecido pela CAPES e CNPq.

Agradeço aos meus amigos e colegas de mestrado por todas discussões ao longo do processo que contribuíram para minha aprendizagem e para a conclusão deste trabalho.

Por fim, agradeço principalmente aos meus pais, Sônia e Getúlio, aos meus irmãos, e à minha namorada, Bruna, pelo apoio incondicional e por sempre incentivar minhas escolhas. 

"A gente quer passar um rio a nado, e passa; mas vai dar na outra banda é num ponto muito mais embaixo, bem diverso do em que primeiro se pensou. Viver nem não é muito perigoso?" Grande Sertão: Veredas 



\section{Resumo}

O objetivo deste trabalho é investigar se a probabilidade dos trabalhadores do mercado formal serem demitidos aumenta quando esses são elegíveis ao recebimento do segurodesemprego. Utilizando da Relações Anuais de Informações Sociais (RAIS), a alteração na elegibilidade ao auxílio promovida pela MP665/2014 permitiu uma estimação de diferenças em diferenças a fim de identificar esse efeito. O resultado encontrado aponta uma queda de 0,73 p.p. na probabilidade de demissão sem justa causa dos grupos que eram elegíveis no período anterior à mudança e deixaram de ser após sua entrada em vigor, em comparação com os não-elegíveis nos dois períodos. A partir desse número, conclui-se que pelo menos $13 \%$ das demissões sem justa causa são induzidas. Os efeitos são maiores para os indivíduos empregados em firmas pequenas, que tenham baixa escolaridade e que não estejam no setor de serviços ou indústria. Utilizando a Pesquisa Mensal do Emprego (PME) em uma análise complementar, conclui-se que 34\% dos indivíduos que saem do formal para acessar o seguro-desemprego se empregam no setor informal no mês subsequente.

Palavras-chaves: seguro-desemprego, desemprego, legislação trabalhista. 



\section{Abstract}

This study investigates whether the probability of Brazilian formal workers being laid-off increases when they are elegible to receive the unemployment insurance. Using an administrative data, Relações Anuais de Informações Sociais (RAIS), for the universe of formal workers, we estimate the effect of a change in the elibility criteria on the probability of layoff for the workers using a diff-in-diff model. The results point out to a 0,73 p.p. decrease in this probability for groups who were elegible before the change and became inelegible afterwards, in comparison to the non-eligible workers in both periods. We conclude that fake layoffs accounts for at least $13 \%$ of total layoffs. The effects are more relevant for workers employed in small firms, with low education level and not employed in service or industrial sectors. In an additional analysis using a survey of labor force, Pesquisa Mensal de Emprego (PME), we find that $34 \%$ of workers engaged in fake layoffs are reemployed in the informal sector in the next month.

Key-words: unemployment insurance, unemployment, labor legislation. 



\section{Lista de ilustrações}

Figura 1 - Probabilidade de demissão sem justa causa nos meses de emprego . . . 30

Figura 2 - Proporção dos indivíduos por tempo de emprego dentre os segurados do programa seguro-desemprego . . . . . . . . . . . . . 30

Figura 3 - Linha do tempo . . . . . . . . . . . . . . . 34

Figura 4 - Tendência da probabilidade de demissão sem justa causa para o grupo dos tratados, 6 a 7 meses, e grupo dos controles, 4 a 5 meses . . . . . . 35

Figura 5 - Tendência da probabilidade de demissão sem justa causa para o grupo dos tratados, 6 a 7 meses, e grupo dos controles, 18 a 19 meses . . . 36

Figura 6 - Tendência da probabilidade de demissão sem justa para o grupo dos tratados, 6 a 7 meses, e grupo dos controles, 4 a 5 meses, contralada por efeito fixo mensal, dummy de tratamento e sazonalidade grupo . 36

Figura 7 - Tendência da probabilidade de demissão sem justa para o grupo dos tratados, 6 a 7 meses, e grupo dos controles, 18 a 19 meses, contralada por efeito fixo mensal, dummy de tratamento e sazonalidade grupo . . 37

Figura 8 - Gráfico dos coeficientes para o grupo dos tratados, 6 a 7 meses, e grupo dos controles, 4 a 5 meses - Demissão sem justa causa . . . . . . . . . . 48

Figura 9 - Gráfico dos coeficientes para o grupo dos tratados, 6 a 7 meses, e grupo dos controles, 18 a 19 meses - Demissão sem justa causa . . . . . . . . 48

Figura 10 - Gráfico dos coeficientes para o grupo dos tratados, 6 a 7 meses, e grupo dos controles, 4 a 5 meses - Saída por iniciativa do empregado . . . . . 51

Figura 11 - Gráfico dos coeficientes para o grupo dos tratados, 6 a 7 meses, e grupo dos controles, 18 a 19 meses - Saída por iniciativa do empregado . . . . 51

Figura 12 - Gráfico dos coeficientes para o grupo dos tratados, 6 a 7 meses, e grupo dos controles, 4 a 5 meses - Demissão com justa causa . . . . . . . . . 54

Figura 13 - Gráfico dos coeficientes para o grupo dos tratados, 6 a 7 meses, e grupo dos controles, 18 a 19 meses - Demissão com justa causa . . . . . . . . 54

Figura 14 - Gráfico dos coeficientes para o grupo dos tratados, 6 a 7 meses, e grupo dos controles, 4 a 5 meses - Outros tipos de quebra de vínculo . . . . . 55

Figura 15 - Gráfico dos coeficientes para o grupo dos tratados, 6 a 7 meses, e grupo dos controles, 18 a 19 meses - Outros tipos de quebra de vínculo . . . . 55

Figura 16 - Probabilidade de demissão com justa causa nos meses de emprego . . . 83

Figura 17 - Probabilidade de saída do emprego por iniciativa do trabalhador nos meses de emprego . . . . . . . . . . . . . . . . . . . . . . . . 84

Figura 18 - Probabilidade de quebra de vínculo por outros motivos nos meses de emprego . . . . . . . . . . . . . . . . . . . . 
Figura 19 - Proporção dos indivíduos por tempo de emprego dentre os segurados do programa seguro-desemprego que estavam até o segundo requerimento 86

Figura 20 - Proporção dos indivíduos por tempo de emprego dentre os segurados do programa seguro-desemprego que estavam até o segundo requerimento 87

Figura 21 - Tendência da probabilidade de demissão sem justa causa para o grupo dos tratados, 6 a 8 meses, e grupo dos controles, 3 a 5 meses . . . . . 87

Figura 22 - Tendência da probabilidade de demissão sem justa causa para o grupo dos tratados, 6 a 8 meses, e grupo dos controles, 18 a 20 meses . . . . 88

Figura 23 - Tendência da probabilidade de saída por iniciativa do trabalhador para o grupo dos tratados, 6 a 7 meses, e grupo dos controles, 4 a 5 meses . 88

Figura 24 - Tendência da probabilidade de saída por iniciativa do trabalhador para o grupo dos tratados, 6 a 7 meses, e grupo dos controles, 18 a 19 meses 89

Figura 25 - Tendência da probabilidade de demissão por justa causa para o grupo dos tratados, 6 a 7 meses, e grupo dos controles, 4 a 5 meses . . . . . 89

Figura 26 - Tendência da probabilidade de demissão por justa causa para o grupo dos tratados, 6 a 7 meses, e grupo dos controles, 18 a 19 meses .. . . 90

Figura 27 - Tendência da probabilidade de quebra de vínculo por outros motivos para o grupo dos tratados, 6 a 7 meses, e grupo dos controles, 4 a 5

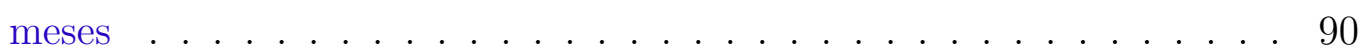

Figura 28 - Tendência da probabilidade de quebra de vínculo por outros motivos para o grupo dos tratados, 6 a 7 meses, e grupo dos controles, 18 a 19

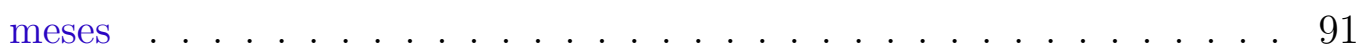




\section{Lista de tabelas}

Tabela 1 - Alteração na Legislação . . . . . . . . . . . . . . . . . . . 28

Tabela 2 - Teste de diferença de médias para covariadas controles de 4 a 5 meses no formal e tratados de 6 a $7 \ldots \ldots$. . . . . . . . . . 39

Tabela 3 - Teste de diferença de médias para covariadas controles de 18 a 19 meses no formal e tratados de 6 a $7 \ldots \ldots \ldots$. . . . . . . . 40

Tabela 4 - Resultado das regressões de diferenças em diferenças nas demissões sem justa causa - controles abaixo de 6 meses . . . . . . . . . . . . . . . 44

Tabela 5 - Resultado das regressões de diferenças em diferenças nas demissões sem justa causa - controles acima de 18 meses . . . . . . . . . . 45

Tabela 6 - Resultado das regressões de diferenças em diferenças nas saídas por iniciativa do empregado - controles abaixo de 6 meses . . . . . . . . . . 46

Tabela 7 - Resultado das regressões de diferenças em diferenças nas saídas por iniciativa do empregado - controles acima de 18 meses . . . . . . . . 47

Tabela 8 - Resultado das regressões de diferenças em diferenças nas demissões com justa causa - controles abaixo de 6 meses . . . . . . . . . . . . 49

Tabela 9 - Resultado das regressões de diferenças em diferenças nas demissões com justa causa - controles acima de 18 meses . . . . . . . . . . . 50

Tabela 10 - Resultado das regressões de diferenças em diferenças nas quebra por outros tipos - controles abaixo de 6 meses _ . . . . . . . . . . . . . 52

Tabela 11 - Resultado das regressões de diferenças em diferenças nas quebra por outros tipos - controles acima de 18 meses . . . . . . . . . . . 53

Tabela 12 - Resultado das regressões de diferenças em diferenças nas demissões sem justa causa - controles de 4 a 5 meses . . . . . . . . . . . . . 56

Tabela 13 - Resultado das regressões de diferenças em diferenças nas demissões sem justa causa - controles de 18 a 19 meses . . . . . . . . . . . . . 57

Tabela 14 - Resultado das regressões de diferenças em diferenças nas demissões sem justa causa . . . . . . . . . . . . . . . . . . . . . 59

Tabela 15 - Resultado das regressões de diferenças em diferenças nas demissões sem justa causa - Controles de 4 a 5 meses . . . . . . . . . . . . 60

Tabela 16 - Resultado das regressões de diferenças em diferenças nas demissões sem justa causa - Controles de 18 a 19 meses . . . . . . . . . . . . . . 61

Tabela 17 - Resultado das regressões de diferenças em diferenças nas demissões sem justa causa - controles abaixo de 6 meses . . . . . . . . . . . . . . 63

Tabela 18 - Resultado das regressões de diferenças em diferenças nas demissões sem justa causa - heterogeneidade para faixas de tamanho das firmas com controles abaixo de 6 meses . . . . . . . . . . . . . . . . 66 
Tabela 19 - Resultado das regressões de diferenças em diferenças nas demissões sem justa causa - heterogeneidade para faixas de tamanho das firmas com controles acima de 18 meses . . . . . . . . . . . . . . . 67

Tabela 20 - Resultado das regressões de diferenças em diferenças nas demissões sem justa causa - heterogeneidade para escolaridade com controles abaixo de 6 meses . . . . . . . . . . . . . . . . . . . . . . 68

Tabela 21 - Resultado das regressões de diferenças em diferenças nas demissões sem justa causa - heterogeneidade para escolaridade com controles acima de 18 meses . . . . . . . . . . . . . . . . . . . . . . . . .

Tabela 22 - Resultado das regressões de diferenças em diferenças nas demissões sem justa causa - heterogeneidade para setores de atividade com controles abaixo de 6 meses . . . . . . . . . . . . . . . . . . . . 70

Tabela 23 - Resultado das regressões de diferenças em diferenças nas demissões sem justa causa - heterogeneidade para setores de atividade com controles acima de 18 meses . . . . . . . . . . . . . . . . . . . . . . 71

Tabela 24 - Resultado das regressões de diferenças em diferenças nas saídas do setor formal - Controles com 3 meses e tratados com 6 em t-1 . . . . . . . . 74

Tabela 25 - Resultado das regressões de diferenças em diferenças nas saídas do setor formal - Controles com 3 meses e tratados com 6 em t-1 - Heterogeneidade de escolaridade . . . . . . . . . . . . . . . . 75

Tabela 26 - Resultado das regressões de diferenças em diferenças nas saídas do setor formal - Controles com 3 meses e tratados com 6 em t-1 - Heterogeneidade de tamanho da firma . . . . . . . . . . . . . . . . . . . 75

Tabela 27 - Resultado das regressões de diferenças em diferenças nas demissões sem justa causa por bimestre - controles abaixo de 6 meses . . . . . . . . . 93

Tabela 28 - Resultado das regressões de diferenças em diferenças nas demissões sem justa causa por bimestre - controles acima de 18 meses . . . . . . . . . 94

Tabela 29 - Resultado das regressões de diferenças em diferenças nas saídas por iniciativa do empregado por bimestre - controles abaixo de 6 meses . . 95

Tabela 30 - Resultado das regressões de diferenças em diferenças nas saídas por iniciativa do empregado por bimestre - controles acima de 18 meses . . 96

Tabela 31 - Resultado das regressões de diferenças em diferenças nas demissões com justa causa por bimestre - controles abaixo de 6 meses . . . . . . . 97

Tabela 32 - Resultado das regressões de diferenças em diferenças nas demissões com justa causa por bimestre - controles acima de 18 meses . . . . . . 98

Tabela 33 - Resultado das regressões de diferenças em diferenças nas quebra por outros tipos por bimestre - controles abaixo de 6 meses . . . . . . . . . 99

Tabela 34 - Resultado das regressões de diferenças em diferenças nas quebra por outros tipos por bimestre - controles acima de 18 meses . . . . . . . . 100 
Tabela 35 - Resultado das regressões de diferenças em diferenças nas saídas do setor informal - Controles com 3 meses e tratados com 6 em t-1 . . . . . . . 101

Tabela 36 - Resultado das regressões de diferenças em diferenças nas saídas do setor informal - Controles com 3 meses e tratados com 6 em t-1 Heterogeneidade de escolaridade . . . . . . . . . . . . . . . . . . . 101

Tabela 37 - Resultado das regressões de diferenças em diferenças nas saídas do setor informal - Controles com 3 meses e tratados com 6 em t-1 Heterogeneidade de tamanho da firma . . . . . . . . . . . . . . . . . 102 



\section{Sumário}

INTRODUÇÃO $\ldots \ldots \ldots \ldots \ldots \ldots \ldots \ldots$

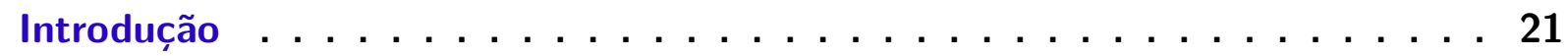

2 CARACTERIZAÇÃO DAS LEIS TRABALHISTAS . . . . . . 25

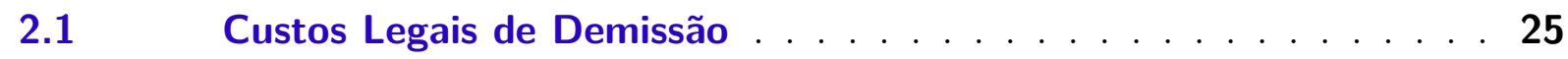

2.2 Mudança da Lei do Seguro-Desemprego . . . . . . . . . . . . 26

$3 \quad$ BASE DE DADOS $\ldots \ldots \ldots \ldots \ldots \ldots \ldots \ldots$

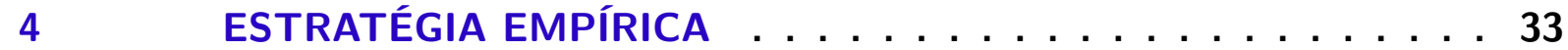

$4.1 \quad$ Hipóteses de Identificação $\ldots \ldots \ldots \ldots \ldots$

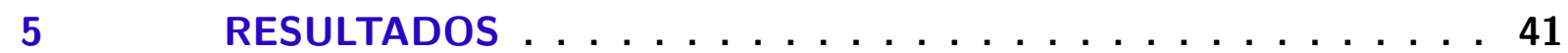

$5.1 \quad$ Avaliação de Impacto . . . . . . . . . . . . . . . . 41

5.2 Testes de Falseamento e Placebos . . . . . . . . . . . . . 43

$5.3 \quad$ Robustez . . . . . . . . . . . . . . . . . . 55

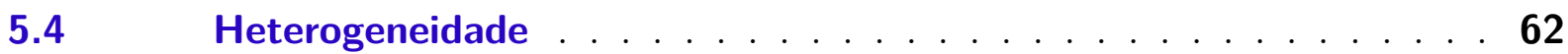

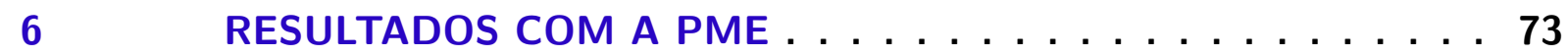

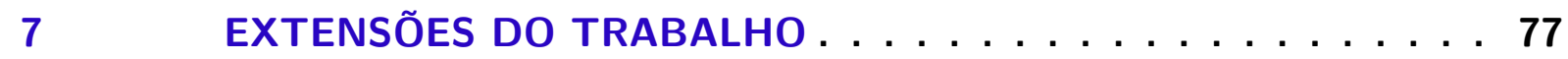

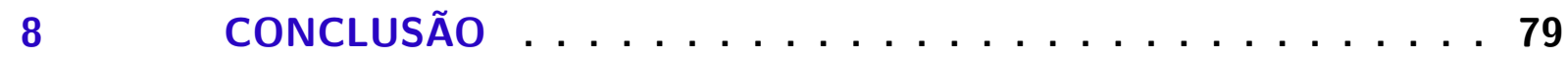

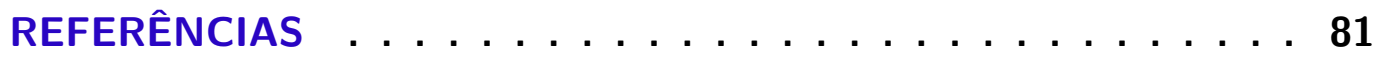

APÊNDICE A-GRÁFICOS . . . . . . . . . 83

APÊNDICE B - EFEITO POR BIMESTRE . . . . . . 93

APÊNDICE C - RESUltAdOS PME . . . . . . . . 101 



\section{Introdução}

O seguro-desemprego é um mecanismo de proteção social amplamente utilizado em diversos países e tem como objetivo proteger o trabalhador das flutuações do mercado de trabalho. O mecanismo é direcionado aos trabalhadores do mercado de trabalho formal em situação de desemprego involuntário. No Brasil, segundo dados do Ministério do Trabalho e Emprego (MTE), depois de um período de grande crescimento, os recursos gastos com o seguro-desemprego atingiram $\mathrm{R} \$ 33,2$ bilhões e atenderam cerca de 8,4 milhões de trabalhadores em 2014. ${ }^{1} \mathrm{O}$ crescimento do benefício ocorreu em um contexto de queda no desemprego, valorização do salário mínimo e formalização.

Apesar da dimensão atingida pelo programa, poucos estudos buscam avaliar os possíveis impactos do seguro-desemprego sobre os fluxos no mercado de trabalho brasileiro. Este projeto se propõe a investigar se os trabalhadores do mercado formal são capazes de induzir a própria demissão a fim de obter o benefício do seguro-desemprego. A Medida Provisória n 665/2014 (doravante, MP665), que alterou o tempo mínimo de trabalho exigido para a concessão do benefício, fornece a variação exógena necessária para identificação desse efeito.

Há uma considerável literatura teórica e empírica que avalia os possíveis incentivos gerados pelos seguros sociais e as condições necessárias para obter-se a política ótima. No contexto do seguro-desemprego, os trabalhos empíricos avaliam como mudanças no nível e na extensão dos programas afetam o mercado de trabalho, particularmente a busca por emprego quando o trabalhador ainda está recebendo o benefício (HOPENHAYN; NICOLINI, 1997; PAVONI; VIOLANTE, 2007; PAVONI, 2007; PAVONI, 2009). Contudo, encontram-se na literatura poucos estudos recentes que avaliam se políticas de segurodesemprego afetam as taxas de demissão das firmas, ou se geram incentivos ao trabalhador induzir a própria demissão a fim de auferir o benefício (CHETTY; FINKELSTEIN, 2013).

Uma possível explicação para esta aparente lacuna na literatura internacional seriam as especificidades do mercado de trabalho brasileiro, marcado por baixa qualificação da mão-de-obra, elevada rotatividade da força de trabalho e elevada participação do mercado informal $^{2}$, que poderiam gerar maiores incentivos para indução da demissão do que em outros países. Adicionalmente, ao contrário de outros países, as firmas que operam no Brasil não contribuem para o financiamento do seguro-desemprego de forma proporcional à quatidade de demissões involuntárias que produzem.

1 No Brasil, esse benefício foi instituído a partir do decreto lei $\mathrm{n}^{\circ}$ 2.284/1986 e passou a integrar o Programa do Seguro-Desemprego após a Constituição de 1988.

2 Segundo informações do IBGE, 43,1\% dos trabalhadores brasileiros estavam no mercado informal em 2012. 
Segundo o WorldBank (2002), um terço da força de trabalho brasileira muda de emprego todos os anos, o que pode ser efeito de um baixo investimento em capital humano, gerando empregos de baixa qualidade e, consequentemente, pouco duradouros (GONZAGA; MALONEY; MIZALA, 2003). Barros, Corseuil e Foguel (2009) argumentam que a existência de mecanismos de proteção ao trabalhador, como o próprio seguro-desemprego e o Fundo de Garantia por Tempo de Serviço (FGTS), também podem explicar a elevada rotatividade do mercado de trabalho brasileiro. Segundo os autores, ambos os benefícios podem gerar incentivos para demissões induzidas dado que os trabalhadores somente podem acessá-los caso sejam demitidos involuntariamente.

A relativa facilidade de inserção no mercado informal também pode contribuir com a elevada rotatividade no mercado formal. Uma vez que os mecanismos de proteção ao trabalhador só podem ser acessados em caso de desemprego involuntário e sem justa causa, poderia haver incentivos para o trabalhador induzir sua demissão no trabalho formal e se inserir no mercado informal. Esta é a hipótese a ser testada no presente estudo.

Levando em conta justamente as especificidades do mercado de trabalho brasileiro, em particular a existência de oportunidades no mercado informal, Gerard e Gonzaga (2016) estimam os efeitos em termos de eficiência e os efeitos comportamentais do recebimento de uma parcela a mais do seguro-desemprego sobre o mercado formal. Os resultados mostram que a extensão do benefício resultou em queda das taxas de reemprego no setor formal e aumento no emprego informal. Contudo, como as taxas de reemprego no setor formal são baixas, a maioria dos benefícios extras foram efetivamente recebidos por requerentes que não mudariam seu comportamento na busca por emprego. Assim, os autores concluem que uma pequena fração do custo da extensão do benefício foi gerada por incentivos perversos da medida.

É importante destacar que os autores mostram que há uma descontinuidade na densidade de demitidos quando os trabalhadores completam 6 meses de trabalho, período mínimo para elegibilidade ao benefício, indicando que há possibilidade de indução ou atraso, como neste caso, da demissão pelo trabalhador. Contudo os autores não exploram essa possibilidade porque focam na extensão do seguro-desemprego para trabalhadores com elevado tempo de emprego no setor formal. Assim, Gerard e Gonzaga puderam avaliar apenas os efeitos comportamentais dos beneficiários do seguro-desemprego sobre a busca por emprego.

Além do período mínimo de 6 meses no trabalho formal, um outro critério importante de elegibilidade para o seguro-desemprego é o período de carência entre uma demissão e outra. Caso tenham acessado o seguro-desemprego na última demissão, os indivíduos somente são elegíveis ao benefício depois de 16 meses transcorridos dessa data. Analisando este critério, Gerard, Rokkanen e Rothe (2016) tratam explicitamente da manipulação do tempo de emprego do trabalhador na data em que é demitido. Os autores 
verificam um salto na densidade de demitidos imediatamente quando o período de carência, 16 meses, se encerra. Os autores também acham evidência de manipulação ao redor dos 6 meses, mas curiosamente não exploram esta descontinuidade.

Apesar da importância dada as descontinuidades nos critérios de elegibilidade, Gerard, Rokkanen e Rothe (2016) têm como foco estimar o efeito do seguro-desemprego no tempo de retorno do trabalhador demitido ao setor formal. Os autores estão interessados em propor um novo método de regressão descontínua que considera o problema de viés de seleção nos casos em que existe manipulação da regra. As descontinuidades na densidade de demissão, entretanto, podem indicar uma questão mais ampla no mercado de trabalho brasileiro, se existe uma relação causal entre elegibilidade e rotatividade no emprego formal. Tal relação pode ser traduzida em um efeito adverso da política do seguro-desemprego que não é testado pelos autores.

O trabalho seminal de Mortensen (1976) foi pioneiro por avaliar os incentivos gerados pelo seguro-desemprego ao relacioná-lo com a literatura de job search. O autor mostra de forma teórica que a existência do seguro-desemprego gera incentivos para que os trabalhadores não elegíveis encontrem trabalho mais rápido, diminuindo o salário de reserva ou aumentando os esforços de busca. Por outro lado, desempregados beneficiários tendem a acelerar o processo de busca por emprego quando há limite temporal do benefício, especialmente no período próximo à exaustão.

Card e Levine (2000) avaliam os impactos de uma extensão temporária do tempo máximo de recebimento do seguro-desemprego no estado de Nova Jersey, nos Estados Unidos, ocorrida em maio de 1996. Os autores encontram que as taxas de saída do segurodesemprego diminuíram significativamente após a extensão do benefício: treze semanas de extensão aumentam a taxa de exaustão do benefício em sete pontos percentuais ${ }^{3}$.

Na Áustria, a reforma do seguro-desemprego em 1989 permitiu que Lalive, Ours e Zweimüller (2006) verificassem o impacto do aumento nas taxas de reposição e na duração máxima do benefício na probabilidade de saída do desemprego. Os autores encontram que as mudanças no potencial de duração do benefício afetam mais fortemente o tempo de desemprego do que mudanças na taxa de reposição, sendo que ambas aumentam o tempo de desemprego. Além disso, a magnitude dos efeitos é diferente para trabalhadores jovens e trabalhadores mais velhos.

Ours e Vodopivec (2006) utilizam como experimento natural a reforma da lei de seguro-desemprego na Eslovênia em 1998, que encurtou o tempo potencial do benefício do seguro-desemprego para a maior parte dos grupos de trabalhadores. Os autores verificam que a redução do tempo potencial de recebimento do benefício aumentou a probabilidade de encontrar um emprego, ou seja, facilitou a saída dos trabalhadores da situação

3 A taxa de exaustão é a proporção de beneficiários que usufruem do benefício até a última parcela. 
de desemprego. Em outro paper (OURS; VODOPIVEC, 2008), os mesmos autores encontram que a diminuição do tempo do seguro-desemprego não afetou a qualidade dos novos matches. As medidas utilizadas para aferir estes resultados foram o impacto da reforma nos salários, nos proporção dos tipos de contratos (temporário ou permanente) e na probabilidade dos indivíduos perderem seus empregos pós reforma.

Os trabalhos citados, que se enquadram na literatura de job search, analisam os efeitos do seguro-desemprego sobre a reinserção do trabalhador como empregado. O foco está nos incentivos colocados aos trabalhadores após terem sido demitidos. Este trabalho tem como enfoque um momento anterior: quando os indivíduos ainda estão empregados no setor formal. A contribuição para a literatura está em analisar se os trabalhadores agem estrategicamente, enquanto empregados, para receber o seguro-desemprego. Estima-se qual o efeito causal do seguro-desemprego sobre a rotatividade no mercado de trabalho brasileiro e encontra-se que pelo menos $13 \%$ das demissões sem justa causa são causadas pela elegibilidade ao seguro-desemprego. Em um trabalho desenvolvido de forma independente e paralela, Doornik, Schoenherr e Skrastins (2017) encontram um número similar.

Além desta introdução, este trabalho está organizado como segue. A seção 2 detalha a legislação trabalhista e a MP665. A seção 3 descreve a base de dados utilizada. A seção 4 apresenta a estratégia empírica e as hipóteses de identificação, enquanto a seção 5 apresenta os resultados, os testes falseamento e placebos, as análises de robustez e de efeitos heterogêneos. A seção 6 apresenta resultados complementares. A seção 7 discute as extensões e a seção 8 conclui o trabalho. 


\section{Caracterização das Leis Trabalhistas}

No Brasil, as relações de emprego formais são regidas pela Consolidação das Leis de Trabalho (CLT) e pela Constituição de 1988. O emprego formal é definido pela posse da carteira de trabalho. Aos empregados que possuem a carteira de trabalho assinada, são garantidos vários benefícios, tais como: direito ao salário mínimo, recebimento do $13^{\circ}$ salário, 30 dias de férias remuneradas com adicional de $1 / 3$ do salário médio mensal, licença maternidade de 120 dias, pagamento de horas extras com adicional mínimo de $50 \%$. Adicionalmente, as firmas ficam obrigadas a realizar algumas contribuições sobre os salários dos empregados formais, sendo que as principais são as contribuições para a Previdência Social (20\%) e para as contas individuais do Fundo de Garantia por Tempo de Serviço, FGTS ( $8 \%$ ).

\subsection{Custos Legais de Demissão}

As políticas de proteção ao emprego são definidas pela legislação brasileira, de modo que a demissão involuntária é considerada de forma distinta de outros tipos de encerramento de vínculos contratuais. Para os casos de demissão sem justa causa, as firmas são obrigadas a pagar uma multa de $50 \%$ do montante acumulado na conta do FGTS enquanto o empregado esteve no mesmo vínculo ${ }^{1}$. O FGTS é um fundo no qual os empregados formais possuem contas individuais. Para cada trabalhador, são depositados mensalmente $8 \%$ de seu salário. O valor total dos depósitos é remunerado a uma taxa inferior à inflação, e podem ser acessados mediante demissão sem justa causa ou aposentadoria.

Adicionalmente, nos casos de demissão involuntária, as firmas devem obrigatoriamente informar o trabalhador com certo período de antecedência. A partir de $2011^{2}$, os empregados devem ser avisados da demissão com ao menos um mês de antecedência, sendo que são acrescidos a este período 3 dias para cada ano trabalhado no mesmo vínculo, não podendo o tempo total ultrapassar 90 dias. Após a notificação, as firmas podem demitir o trabalhador imediatamente e pagar o salário do tempo restante (aviso prévio indenizado), ou manter o trabalhador com jornada reduzida em $25 \%$ até o término do período do aviso (aviso prévio trabalhado). Para fins de recebimento de outros benefícios, o tempo do aviso prévio é contabilizado para a contagem do tempo de emprego, independentemente se o aviso foi trabalhado ou indenizado.

Vale ressaltar que o pagamento de multa recissória e do aviso prévio não são neces-

1 A partir de 2001, 40\% da multa é pago diretamente ao trabalhador e $10 \%$ ao governo.

2 Lei $\mathrm{n}^{\mathrm{o}} 12.506$ de 11 de outubro de 2011 
sários caso a firma encerre o vínculo com trabalhadores recém contratados. A legislação define um período de experiência para todos os empregados contratados por tempo indeterminado. O contrato de experiência oferecido ao trabalhador admitido tem duração máxima de 3 meses, sendo que, ao seu final, a firma escolhe entre contratá-lo por tempo indeterminado ou encerrrar o contrato de trabalho.

Os términos de contrato ocorridos após 12 meses de tempo no emprego devem ser homologados no sindicato da categoria ou perante o Ministério do Trabalho e Previdência Social. No ato da homologação, é verificado se o trabalhador recebeu todos os benefícios a que tinha direito. Tal procedimento impõe custos sobre as firmas que não seguem estritamente as regras, dado que estas devem regularizar sua situação.

\subsection{Mudança da Lei do Seguro-Desemprego}

O seguro-desemprego no Brasil foi regulamentado a partir da Lei $n^{\circ} 7.998$ de 1990, que instituiu o Fundo de Amparo ao Trabalhador (FAT). Este Fundo, além de financiar o benefício, deu suporte a outras políticas voltadas ao mercado de trabalho. Apesar de existirem diversas modalidades do seguro-desemprego, que visam abranger tipos específicos de trabalhadores, este estudo se restringirá somente ao benefício concedido aos trabalhadores dispensados involuntariamente do setor formal sem justa causa.

Os trabalhadores formais, urbanos ou rurais, de empresas privadas que possuem contrato de trabalho por tempo indeterminado ${ }^{3}$, caso sejam demitidos involuntariamente com um tempo mínimo no emprego formal, possuem direito a receber de 3 a 5 parcelas do benefício. A duração do benefício depende do tempo de emprego acumulado no histórico dos empregos formais dos últimos 36 meses anteriores à demissão. O trabalhador é elegível a três, quatro ou cinco parcelas do seguro-desemprego caso tenha de 6 a 11, de 12 a 23 ou mais que 24 meses de emprego, respectivamente, incluindo o tempo do aviso prévio. Vale ressaltar que, no cálculo do tempo de emprego, para fins de recebimento do benefício, 15 dias trabalhados no mesmo mês equivalem a um mês completo.

O requerimento do seguro-desemprego deve ser realizado pessoalmente entre o $7^{\circ}$ e o $120^{\circ}$ dia contado da data da dispensa. Além do tempo mínimo de emprego, é necessário para o recebimento do benefício que o trabalhador não esteja reempregado. $\mathrm{O}$ monitoramento, entretanto, somente é realizado para os empregos formais, sendo que o benefício é cancelado se o nome do trabalhador aparecer no Cadastro Geral de Empregados e Desempregados (CAGED), base administrativa do Ministério do Trabalhado que engloba todos os trabalhadores formais admitidos e demitidos nos mês. A falta de fiscalização permite que os trabalhadores reempregados no setor informal continuem recebendo o

3 Servidores públicos estatutários e trabalhadores temporários não possuem direito ao seguro desemprego. Além disso, empregados públicos em regime CLT raramente são demitidos sem justa causa. 
seguro-desemprego.

O valor do benefício depende da média dos salários recebidos nos três meses anteriores à data de demissão. O pagamento das parcelas varia entre o salário mínimo, menor valor possível, e um teto estabelecido anualmente, sendo que em 2015 este correspondia a aproximadamente 1,7 salário mínimo. Nota-se que a taxa de reposição é máxima (100\%) para quem recebe o salário mínimo e decai conforme o salário aumenta. Em 2015, por exemplo, a taxa de reposição era aproximadamente $58 \%$ para o indivíduo que ganhava 3 salários mínimos.

A Medida Provisória 665, promulgada em 30 de dezembro de 2014, alterou alguns aspectos fundamentais dessa legislação, especialmente no que se refere aos critérios de elegibilidade para o recebimento do benefício. Conforme ilustrado na Tabela 1, pela lei anterior, o trabalhador com seis meses ininterruptos de emprego era considerado elegível para obter o $1^{\circ}$ acesso ao auxílio. Para os demais acessos, eram exigidos seis meses de trabalho nos últimos trinta e seis meses. A partir da MP665, para obter o benefício pela primeira vez, o trabalhador precisa ter dezoito meses trabalhados nos últimos vinte e quatro meses anteriores à dispensa. $\mathrm{Na} 2^{\mathrm{a}}$ solicitação, são exigidos doze meses de trabalho nos últimos dezesseis, e para as demais solicitações são necessários seis meses consecutivos de trabalho no período pré-demissão. Note que a MP665 não alterou o critério para a obtenção do $3^{\circ}$ acesso. O período de carência entre um requerimento e outro se manteve constante, sendo de dezesseis meses.

No âmbito do direito, Medida Provisória (MP) é um mecanismo que permite ao presidente promulgar atos unipessoais com força de lei. Em geral, as MPs são válidas imediatamente após a data de suas promulgações. No caso da MP665, este critério foi alterado, de modo que esta passou a ter poder de lei apenas 60 dias após a data de sua promulgação, no dia 28 de fevereiro de 2015. Além disso, por, a princípio, não ser submetida à intervenção legislativa, não houve discussões anteriores à divulgação da medida sobre as mudanças nela contidas.

É importante ressaltar que, segundo o DIEESE (2015), a justificativa oficial para essa alteração é de que a medida iria auxiliar no ajuste das contas públicas e entraria como parte integrante do esforço fiscal iniciado em 2015. Uma outra razão é de que a medida contribuiria para evitar fraudes e distorções nos benefícios alterados. Ambas explicações não se relacionam diretamente com flutuações no mercado de trabalho brasileiro.

A não antecipação do conteúdo da medida, assim como sua preponderância como parte integrante do esforço fiscal, podem ser verificadas em trechos de notícias divulgadas na época: "As medidas foram anunciadas após encontro dos ministros com representantes de centrais sindicais, na tarde de hoje (29), no Palácio do Planalto. Elas começam a valer a partir de amanhã, mas precisam ser aprovadas pelos deputados e senadores para virarem lei."(Carta Capital, 29/12/2014). "Numa reunião com empresários, em Campinas, 
durante a campanha eleitoral, a então candidata à reeleição Dilma Rousseff se saiu com a frase 'nem que a vaca tussa' para deixar claro que não mexeria nos direitos trabalhistas. (...) Passadas as eleições, o primeiro anúncio feito pelo governo para cortar gastos atingiu justamente o trabalhador. Foram seis medidas com projeção de $\mathrm{R} \$ 18$ bilhões de economia por ano, a partir de 2015, três delas com impacto direto nos direitos dos trabalhadores." (O Globo, 31/12/2014).

A discussão dos novos prazos necessários para o requerimento do seguro-desemprego teve início, em comissão legislativa, apenas no mês de abril de 2015. A MP665 teve seu conteúdo alterado quando, por fim, foi submetida à apreciação lesgislativa obrigatória, e resultou em lei específica. Conforme ilustrado pela tabela 1, a Lei $n^{\circ} 13.134$, de 16 de junho de 2015, consolidou as alterações na Lei $\mathrm{n}^{\circ} 7.998$ e revogou os prazos estabelecidos pela MP665 para a obtenção do seguro-desemprego, tornando-os mais flexíveis. Para obter o benefício pela primeira vez, o trabalhador precisa ter 12 meses trabalhados dos últimos 18 meses anteriores à dispensa. Na $2^{\mathrm{a}}$ solicitação, são exigidos 9 meses dos últimos 12, e, para as demais solicitações, não foi alterado o critério estabelecido na MP665.

Tabela 1 - Alteração na Legislação

\begin{tabular}{|c|c|c|c|}
\hline & Lei 7.998 - Até $02 / 2015$ & MP665 - Válida em 03/2015 & Lei $n^{\circ} 13.134$ - Válida em 06/2015 \\
\hline $1^{\circ}$ acesso & $\begin{array}{l}\text { seis meses ininterruptos } \\
\text { de trabalho }\end{array}$ & $\begin{array}{l}\text { dezoito meses de trabalho nos últimos } \\
\text { vinte e quatro anteriores à dispensa }\end{array}$ & $\begin{array}{l}\text { doze meses de trabalho nos últimos } \\
\text { dezoito anteriores à dispensa }\end{array}$ \\
\hline $2^{\circ}$ acesso & $\begin{array}{l}\text { mínimo de seis meses de trabalho nos } \\
\text { últimos trinta e seis para os demais acessos }\end{array}$ & $\begin{array}{l}\text { doze meses de trabalho nos últimos } \\
\text { dezesseis anteriores à dispensa }\end{array}$ & $\begin{array}{c}\text { nove meses de trabalho no últimos } \\
\text { doze anteriores à dispensa }\end{array}$ \\
\hline $\begin{array}{l}3^{\circ} \text { e demais } \\
\text { acessos }\end{array}$ & $\begin{array}{l}\text { mínimo de seis meses de trabalho nos } \\
\text { últimos trinta e seis para os demais acessos }\end{array}$ & $\begin{array}{l}\text { seis meses ininterruptos } \\
\text { de trabalho }\end{array}$ & $\begin{array}{l}\text { seis meses ininterruptos } \\
\text { de trabalho }\end{array}$ \\
\hline
\end{tabular}

As alterações legislativas que ocorreram em 2015, MP665 e Lei no 13.134, podem ser consideradas mudanças exógenas que permitem inferir o efeito da elegibilidade ao seguro-desemprego nas demissões no emprego formal. Ambas restringiram o acesso ao benefício, deslocando, para uma parcela significativa dos indivíduos ${ }^{4}$, o tempo mínimo de emprego formal exigido para acessar o seguro-desemprego. Desse modo, as novas regras alteram a descontinuidade na elegibilidade ao seguro-desemprego que existia na proximidade dos 6 meses de tempo de emprego formal. Caso exista alguma relação causal entre o benefício e rotatividade, é esperado que tanto a MP665 quanto a Lei 13.134 aproximem as taxas de demissão sem justa causa para os indivíduos acima e abaixo do corte de 6 meses em pequenas janelas de tempo de emprego.

A figura 1, elaborada com dados da Relação Anual de Informações Sociais (RAIS) dos anos de 2012 a 2015, apresenta a probabilidade mensal de demissão sem justa causa. As probabilidades são calculadas separadamente para intervalos de um mês de tempo de emprego tanto para o período anterior à publicação da MP665 quanto para o período

4 Segundo dados administrativos do programa seguro-desemprego, $62 \%$ dos segurados em 2014 haviam requerido o benefício até 2 vezes. 
posterior a sua entrada em vigor. A descontinuidade na probabilidade de demissão nos seis meses de emprego relatada em outros trabalhos é observada para o período prévio às alterações legislativas (GERARD; GONZAGA, 2016; GERARD; ROKKANEN; ROTHE, 2016). A partir da data em que a medida provisória começa a vigorar, o tamanho da descontinuidade decresce. A elevação do tempo mínimo necessário para acessar o seguro homogeniza a probabilidade de demissão em pequenas janelas de tempo de emprego no entorno dos seis meses, dando indícios da existência de uma relação causal entre segurodesemprego e rotatividade no setor formal. A mesma relação não é encontrada para demissão com justa causa e saída do emprego por parte do trabalhador (Figura 16 e Figura 17 no Apêndice A).

Em uma análise inicial, a baixa probabilidade de demissão sem justa causa entre indivíduos com pouco tempo de emprego pode parecer pouco intuitiva. Entretanto, este fato pode ser explicado pela existência do contrato de experiência para empregados com pouco tempo de emprego. A legislação permite às firmas proporem contratos de até 90 dias para os trabalhadores admitidos. O período de experiência se assimila a um contrato de trabalho temporário, terminado o prazo estipulado neste, a firma decide entre contratar o trabalhador por tempo indeterminado ou não renovar o contrato de trabalho. A figura 18, apresentada no Apêndice A, mostra que a probabilidade de quebra de vínculo por outras causas, que inclui o motivo término de contrato, é mais alta para os indivíduos com menos tempo de emprego formal.

A figura 2, construída com base nos dados administrativos do seguro-desemprego, apresenta a proporção das pessoas até 9 e 12 meses de tempo de emprego dentre os segurados ao longo dos meses em que foram demitidas, dos anos de 2012 a 2015. A partir de sua análise, é possível obter evidência de que houve enforcement da mudança legislativa na concessão do seguro-desemprego aos trabalhadores demitidos. O período de maior queda na série histórica da proporção dos indivíduos até 9 meses e até 12 meses coincide com janela de meses em que a MP665 estava em vigor, de março a junho de 2015. Com a flexibilização dos critérios de elegibilidade ocasionada pela Lei $\mathrm{n}^{\circ}$ 13.134, de 16 de junho de 2015, a proporção dos indivíduos até 12 meses cresce suavemente. Note que as informações sobre qual o requerimento em que os indivíduos se encontram não são utilizadas na construção dessa figura. As figuras 19 e 20, no Apêndice A, apresentam as proporções para os indivíduos até o segundo requerimento. 
Figura 1 - Probabilidade de demissão sem justa causa nos meses de emprego

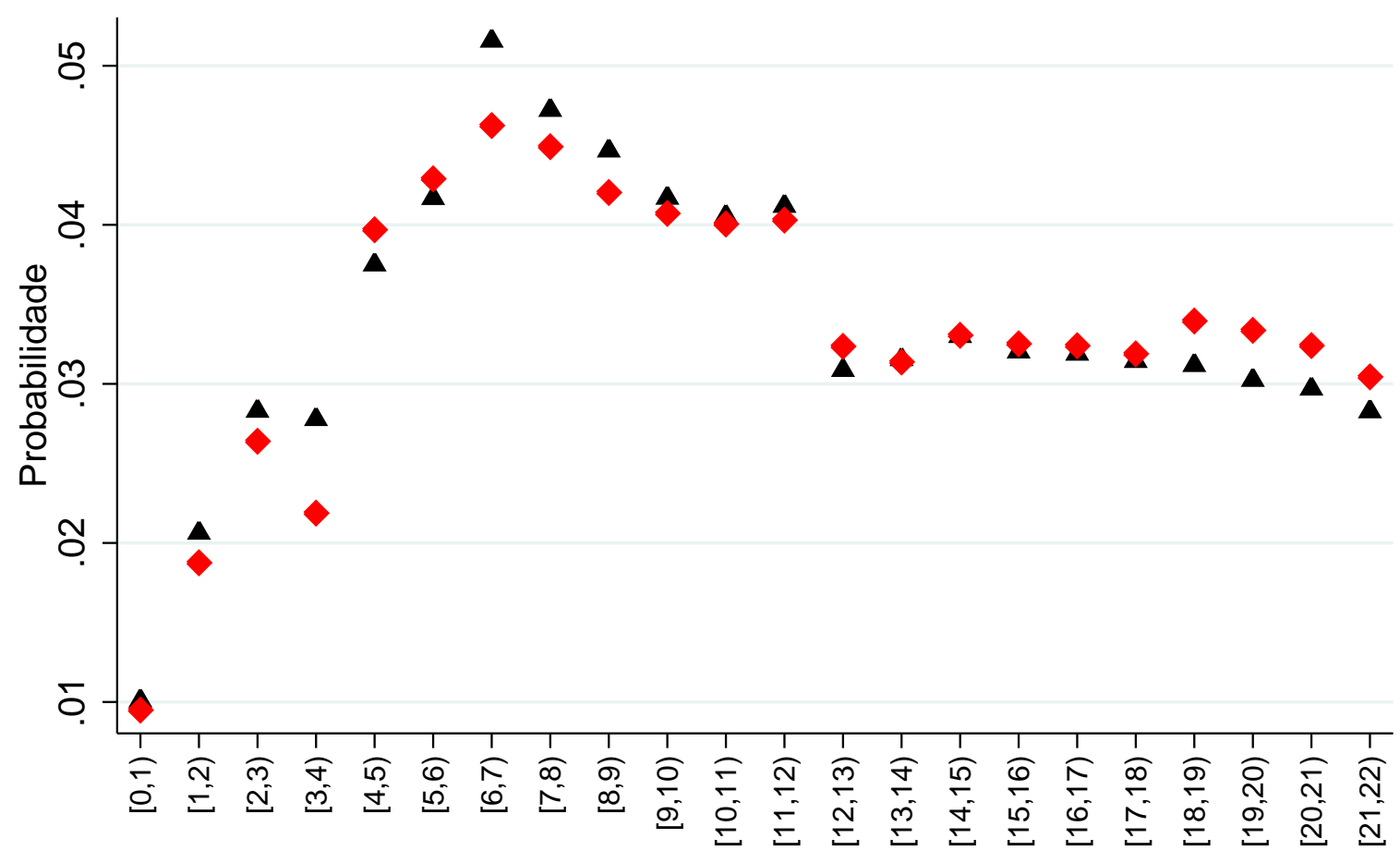

Tempo de emprego em meses

\section{A Antes da MP665 entrar em vigor $\diamond$ Depois da MP665 entrar em vigor}

Fonte: RAIS 2012 a 2015.

Os meses anteriores à março de 2015 são definidos como o período "Antes da MP665 entrar em vigor". O período "Depois da MP665 entrar em vigor" compreende os meses após março de 2015. A probabilidade de demissão é calculada como uma média da probabilidade mensal de demissão sem justa causa para intervalos de um mês de tempo de emprego.

Figura 2 - Proporção dos indivíduos por tempo de emprego dentre os segurados do programa seguro-desemprego

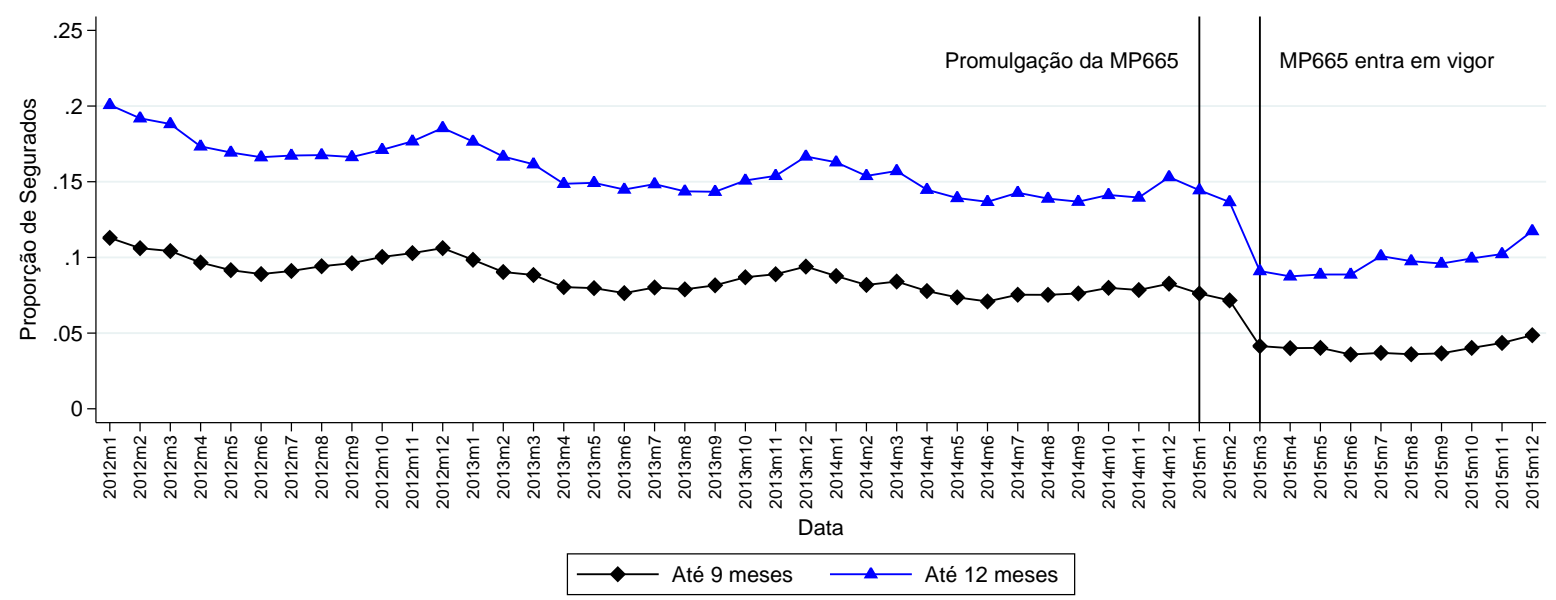

Fonte: Base administrativa do seguro-desemprego 2012 a 2015.

O gráfico apresenta a proporção das pessoas até 9 e 12 meses de tempo de emprego dentre os segurados ao longo dos meses de demissão. O período considerado inicia-se em janeiro de 2012 indo até dezembro de 2015, englobando os meses em que a MP665 foi promulgada, dezembro de 2014, e que passou a vigorar, fevereiro de 2015 . Tendo em vista que tanto o dia da promulgação quanto o dia em que a medida passou a vigorar estão no final do mês, 30 de dezembro e 28 de fevereiro, respectivamente, opta-se por traçar a linha vertical nos meses subsequentes, janeiro e março de 2015. 


\section{Base de Dados}

Para avaliar o efeito do seguro-desemprego nas demissões sem justa causa, este trabalho faz uso de dados da Relação Anual de Informações Sociais (RAIS), uma base administrativa dos vínculos entre empresas e trabalhadores que engloba todo o universo dos empregos formais. As empresas registradas devem declarar anualmente informações sobre cada trabalhador empregado. As observações da RAIS representam cada vínculo de emprego formal existente entre as firmas e os empregados, contendo informações sobre o salário anual, idade, gênero, nível de educação, setor de atividade, tempo de emprego no mesmo vínculo até a data de demissão ou, caso não demitido, 31 de dezembro do ano considerado, mês de admissão e separação, motivo da quebra do vínculo, quantidade de horas contratadas, tipo de contrato, tamanho e município de localização das firmas. Com base nas informações de mês de admissão e demissão, é possível criar cross-sections mensais empilhadas dos fluxos no emprego formal. No entanto, as informações disponíveis não permitem identificar unicamente os indivíduos nem as firmas na base de dados. Também não é possível identificar os mesmos vínculos ano a ano.

As estimações são realizadas com base em uma amostra aleatória retirada da RAIS dos anos de 2012 a 2015. A princípio, são mantidos na base apenas os indivíduos contratados por tempo indeterminado, urbanos ou rurais, em empresas privadas. Para cada indivíduo, o tempo de emprego é calculado retroativamente para cada mês do ano. A partir disso, são excluídos da análise: empregados afastados por qualquer razão, abaixo de 18 anos, com mais de 22 meses de tempo de emprego e que possuam remuneração média igual a 0 . Com base nos vínculos restantes, é retirada uma amostragem aleatória de $10 \%$ dos vínculos que mantêm as mesmas distribuições dos indivíduos por tempo de emprego e nos meses do ano observadas na base original.

Para verificar se, após deixarem o emprego, os indivíduos se inserem no setor informal, este trabalho também faz uso de dados da Pesquisa Mensal de Emprego (PME), um painel rotativo mensal que entrevista residentes das seis maiores regiões metropolitanas brasileiras: Belo Horizonte, Porto Alegre, Recife, Rio de Janeiro, Salvador e São Paulo. A pesquisa é realizada por meio de uma amostra probabilística de domicílios.

O Instituto Brasileiro de Geografia e Estatística (IBGE) é o órgão responsável pela produção e divulgação dos dados da PME, que ocorre mensalmente. A pesquisa colhe informações das características da força de trabalho, como cor, gênero, escolaridade, emprego e renda. Todas as informações são de cunho autodeclaratório. É importante salientar que as informações de cada domicílio são oriundas de um único respondente, ou seja, uma única pessoa do domicílio é quem responde o questionário. Cada domicílio é 
seguido por quatro meses consecutivos em dois anos diferentes, sendo o intervalo entre as rodadas anuais de oito meses. É importante ressaltar que a pesquisa seleciona o domicílio. Caso os indivíduos residentes mudem de domicílio após o início das entrevistas, estes não serão mais encontrados.

Para o fim de analisar o destino dos trabalhadores que deixam o setor formal, será utilizado na Pesquisa Mensal de Emprego o mesmo período considerado na análise principal, janeiro de 2012 a dezembro de 2015. Neste exercício, são desconsiderados trabalhadores formais com contrato de trabalho temporário ${ }^{1}$, ou que se enquadram no regime contratual dos servidores públicos ${ }^{2}$, ou que estejam afastados do emprego durante o mês da entrevista. Para captar os fluxos do setor formal, entre os indivíduos restantes, são deixados na amostra os que são observados em ao menos dois meses subsequentes, $t-1 \mathrm{e}$ $t$, e que sejam formais em $t-1$. Além disso, vale ressaltar que a PME foi descontinuada em 2015, sendo que a partir de fevereiro deste ano não é possível observar domicílios na primeira entrevista, e a partir de maio somente são observados domicílios da quinta à oitava entrevista. Por esta razão, a análise é concentrada nos indivíduos que se encontram no intervalo da quinta à oitava entrevista, segunda rodada de acompanhamento dos domicílios. É importante notar que o atrito amostral é elevado para este grupo, no período considerado, 2012 a 2015, aproximadamente $33 \%$ dos indivíduos que são trabalhadores formais na primeira entrevista não são encontrados na quinta.

$\overline{1}$ Os contratos de trabalho temporários são usalmente celebrados por 3 meses e, ao término do contrato, o trabalhador não é habilitado a receber o seguro-desemprego.

2 Trabalhadores que tenham o contrato no regime dos servidores públicos não possuem o direito de receber o seguro-desemprego. 


\section{Estratégia Empírica}

Para analisar o impacto das mudanças do critério de elegibilidade ao segurodesemprego, MP665 e Lei $n^{\circ}$ 13.134, especifica-se um modelo econométrico de diferenças em diferenças para a probabilidade de demissão dos trabalhadores sem justa causa que explora as alterações como fonte de variação exógena. Mais especificamente, assumimos:

$$
y_{i, t}=\delta \cdot L_{t \geq \operatorname{março~de~} 2015} \cdot T_{i}+\lambda \cdot T_{i}+\mu_{t}+\gamma \cdot T_{i} \cdot \text { Mês }+\tau \cdot T_{i} \cdot t+\beta \cdot X_{i, t}+\varepsilon_{i, t}
$$

onde $y_{i, t}$ é uma variável binária igual a 1 caso o trabalhador i seja demitido sem justa

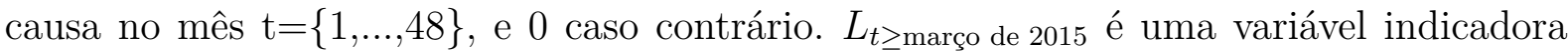
que assume valor igual a 1 quando $t$ é maior ou igual a março de 2015, mês em que a mudança passa a vigorar, e 0 quando $t$ é menor que março de 2015. $T_{i}$ é uma variável binária igual a 1 se o indivíduo pertence ao grupo dos tratados que é definido por: $6 \leq$ tempo de emprego ${ }_{i}$ (em meses $) \leq 6+\xi$. Dois grupos de controles distintos são utilizados em análises separadas, de modo que $T_{i}$ assume valor igual a 0 se o indivíduo possui: (i) 5 - $\xi \leq$ tempo de emprego ${ }_{i} \leq 5 ;^{1}$ (ii) $18 \leq$ tempo de emprego ${ }_{i} \leq 18+\xi .^{2} \mathrm{Na}$ apresentação dos resultados varia-se a janela de meses de tempo no emprego, $\xi$, que define $T_{i}$. Essa assume valores iguais a 1 ou a $2 . \mu_{t}$ é um vetor de efeito fixo mês/ano que controla pelas condições macroeconômicas que afetam o mercado de trabalho, tais como sazonalidade, flutuações da atividade e da política econômica. $T_{i}$. Mês controla por fatores sazonais que afetam de modo distinto o desempenho de cada grupo no mercado de trabalho em cada mês do ano. $T_{i} \cdot t$ capta diferentes tendências lineares da probabilidade de demissão entre os grupos, permitindo que, por exemplo, o agravamento da crise econômica afete os grupos de forma distinta. $X_{i, t}$ é um grupo de covariadas, descrito nas tabelas 2 e 3, que controla para idade, faixa de escolaridade, gênero, cor, efeito fixo de estado brasileiro, ocupação, setor de atividade, tamanho do estabelecimento e quantidade de horas contratadas, e $\varepsilon_{i, t}$ é um termo de erro idiossincrático.

A figura 3 descreve a sequência dos acontecimentos entre a publicação da MP665 e a data da aprovação da Lei $n^{\circ}$ 13.134. Os tratados são aqueles que haviam completado pelo menos 6 meses e estavam nas janelas de tempo de emprego definidas anteriormente (1 ou 2 meses), sendo assim elegíveis para receber o seguro-desemprego. Contudo, a partir

1 A RAIS não identificada não apresenta os dias de demissão e admissão. Logo, não é possível definir precisamente a elegibilidade para os indivíduos com tempo de emprego entre 5 e 6 meses. Isto porque segundo a regra do seguro-desemprego, para o cômputo de tempo de emprego, 15 dias trabalhados em um mesmo mês equivalem a um mês inteiro.

2 Caso demitidas sem justa causa, as pessoas com menos que 6 meses de tempo no emprego formal não acessam o seguro-desemprego nem antes nem após a mudança. As pessoas com mais de 18 meses, por sua vez, são elegíveis nos dois períodos 
Figura 3 - Linha do tempo

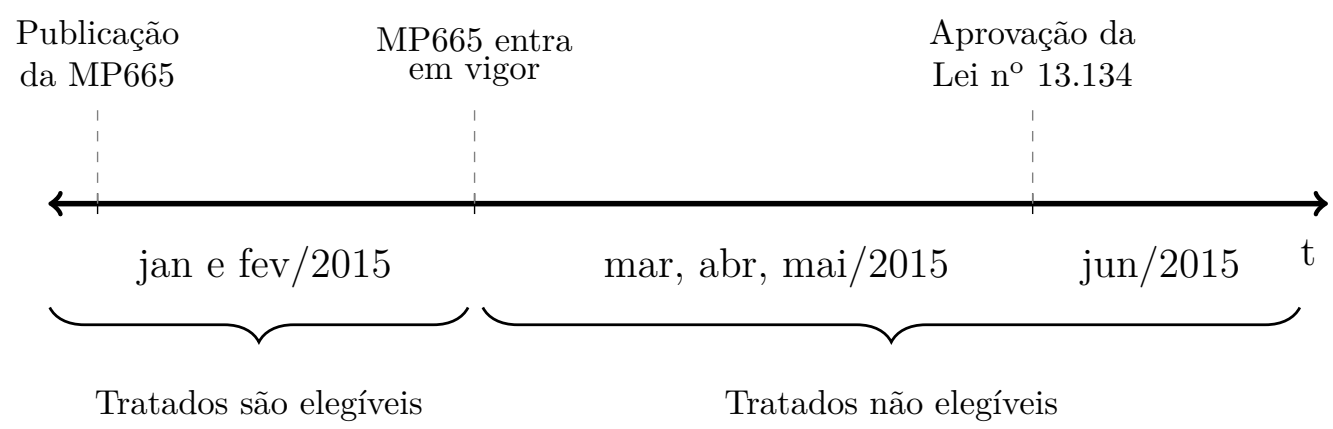

de março, com a efetivação da MP665, detalhada na seção 2.1 deste trabalho, os trabalhadores não mais teriam direito ao recebimento deste benefício ${ }^{3}$. Note que, para as janelas de tempo de emprego definidas, a aprovação da lei ainda exclui os tratados da elegibilidade. O grupo de controle, por sua vez, é formado pelos trabalhadores do setor formal que estão próximos de completar seis meses de trabalho ou que possuem mais de dezoito meses de emprego formal. Logo, estes não são induzidos pela MP665 a forçarem sua própria demissão, dodo que a situação de elegibilidade não se altera para eles.

O estimador de diferenças em diferenças em (1) identifica o efeito da elegibilidade ao seguro-desemprego nas demissões sem justa causa. Contudo, este impacto não pode ser obtido de maneira direta. Considerando que os trabalhadores elegíveis induzem sua demissão para acessar o benefício, o sinal esperado do parâmetro $\delta$ é negativo, dado que as alterações legislativas fecham este canal.

\subsection{Hipóteses de Identificação}

Para que o estimador do efeito de diferenças em diferenças capture o verdadeiro efeito da mudança, deve ser respeitada uma hipótese fundamental de que na ausência das alterações legislativas, MP665 e Lei n 13.134, a probabilidade de demissão dos trabalhadores elegíveis e não elegíveis teria evoluido de maneira semelhante, também conhecida como hipótese de tendências paralelas.

Com o objetivo de avaliar a razoabilidade da hipótese de tendências paralelas no contexto dos grupos analisados, a figura 4 apresenta a evolução da probabilidade de demissão sem justa causa para os grupos dos tratados e controles ao longo do tempo. Alguns padrões podem ser notados de imediato, as tendências pré-tratamento avançam de forma similar ao longo dos meses. Além disso, após o período em que a MP665 passa a vigorar, a probabilidade de demissão dos tratados se aproxima das probabilidades para

3 É importante destacar que essa regra vale apenas para os trabalhadores que não estejam no $3^{\circ}$ requerimento do programa. Logo, os trabalhadores possivelmente afetados pela MP665 são aqueles no $1^{\circ}$ ou $2^{\circ}$ requerimento. 
o grupo de controle, pessoas abaixo de 6 meses de emprego. A figura 5 exibe o gráfico de tendência paralela utilizando o grupo de controle alternativo, pessoas acima de 18 meses de tempo de emprego. A verificação do mesmo padrão na probabilidade de demissão, observado ao se comparar os tratados com indivíduos com poucos e muitos meses de emprego, reforça a hipótese de efeito causal do seguro-desemprego sobre demissão, sendo menos provável que a influência de fatores conjunturais seja determinante.

Figura 4 - Tendência da probabilidade de demissão sem justa causa para o grupo dos tratados, 6 a 7 meses, e grupo dos controles, 4 a 5 meses

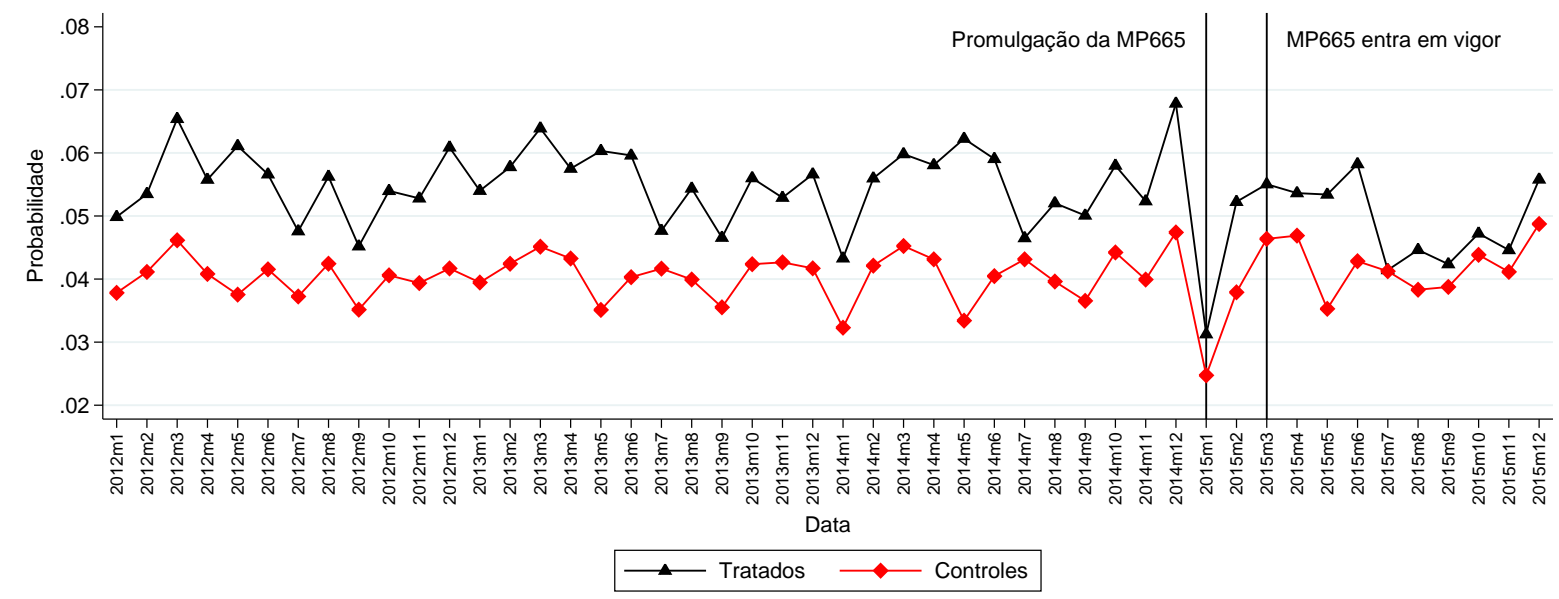

Fonte: RAIS 2012 a 2015.

Os gráfico apresentam as probabilidades de demissão sem justa causa mensais para o grupo dos tratados, indivíduos de 6 a 7 meses completos no trabalho formal, e para o grupo dos controles, pessoas que possuem de 4 a 5 meses completos de trabalho no setor formal. O período considerado inicia-se em janeiro de 2012 indo até dezembro de 2015, englobando os meses em que a MP665 foi promulgada, dezembro de 2014, e que passou a vigorar, fevereiro de 2015. Tendo em vista que tanto o dia da promulgação quanto o dia em que a medida passou a vigorar estão no final do mês, 30 de dezembro e 28 de fevereiro, respectivamente, opta-se por traçar a linha vertical nos meses subsequentes, janeiro e março de 2015.

Apesar das tendências de probabilidade de demissão serem visualmente similares entre o grupo dos tratados e o dos controles, é possível notar a existência de um componente sazonal que afeta os grupos de forma diferente. As figuras 6 e 7 apresentam as probabilidade de demissão sem justa causa após controlar para sazonalidade mensal específica para cada grupo ${ }^{4}$. O efeito do tratamento pode ser observado de forma mais clara com o descolamento das tendências dos grupos a partir de março de 2015, mês em que a MP665 passa a vigorar.

É necessário garantir que outros fatores não estejam influenciando o padrão encontrado nas probabilidades de demissão. A princípio, é preciso verificar se os indivíduos se antecipam frente às mudanças na legislação. As antecipações podem ocorrer de dois modos distintos. O primeiro decorre do comportamento estratégico dos indivíduos elegíveis ao seguro-desemprego para serem demitidos em janeiro ou fevereiro de 2015, período

4 São estimadas regressões da variável de demissão sem justa causa no efeito fixo mês/ano, na variável de grupo de tratados e na interação entre dummies de meses do ano com o grupo dos tratados e, em seguida, as médias mensais dos resíduos são apresentadas por grupos ao longo dos meses 
Figura 5 - Tendência da probabilidade de demissão sem justa causa para o grupo dos tratados, 6 a 7 meses, e grupo dos controles, 18 a 19 meses

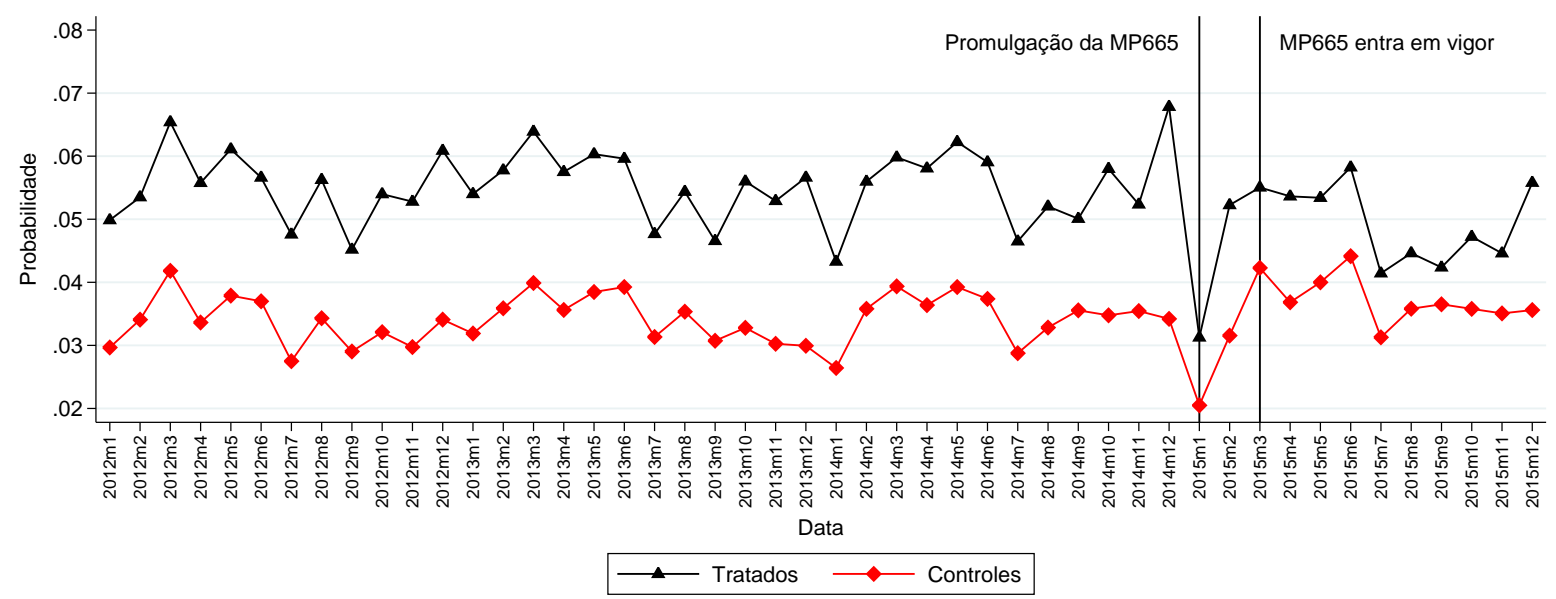

Fonte: RAIS 2012 a 2015.

O gráfico apresenta as probabilidades de demissão sem justa causa mensais para o grupo dos tratados, indivíduos de 6 a 7 meses completos no trabalho formal, e para o grupo dos controles, pessoas que possuem de 18 a 19 meses completos de trabalho no setor formal. O período considerado inicia-se em janeiro de 2012 indo até dezembro de 2015, englobando os meses em que a MP665 foi promulgada, dezembro de 2014, e que passou a vigorar, fevereiro de 2015. Tendo em vista que tanto o dia da promulgação quanto o dia em que a medida passou a vigorar estão no final do mês, 30 de dezembro e 28 de fevereiro, respectivamente, opta-se por traçar a linha vertical nos meses subsequentes, janeiro e março de 2015.

Figura 6 - Tendência da probabilidade de demissão sem justa para o grupo dos tratados, 6 a 7 meses, e grupo dos controles, 4 a 5 meses, contralada por efeito fixo mensal, dummy de tratamento e sazonalidade grupo

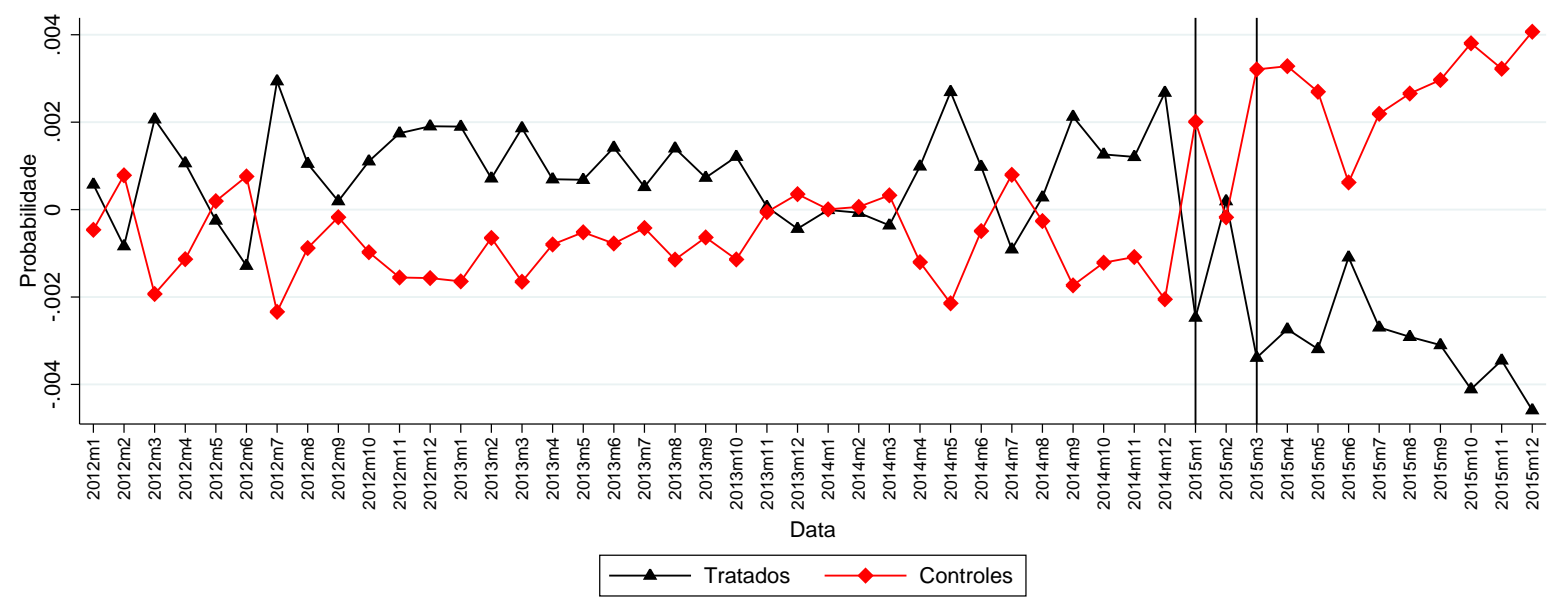

Fonte: RAIS 2012 a 2015.

O gráfico apresenta os resíduos preditos da regressão da variável de demissão sem justa causa no efeito fixo mês/ano, na variável de grupo de tratados e na interação entre dummies de meses do ano com o grupo dos tratados. As médias mensais dos resíduos por grupo são apresentadas para o grupo dos tratados, indivíduos de 6 a 7 meses completos no trabalho formal, e para o grupo dos controles, pessoas que possuem de 4 a 5 meses completos de trabalho no setor formal. O período considerado inicia-se em janeiro de 2012 indo até dezembro de 2015, englobando os meses em que a MP665 foi promulgada, dezembro de 2014, e que passou a vigorar, fevereiro de 2015. Tendo em vista que tanto o dia da promulgação quanto o dia em que a medida passou a vigorar estão no final do mês, 30 de dezembro e 28 de fevereiro, respectivamente, opta-se por traçar a linha vertical nos meses subsequentes, janeiro e março de 2015. 
Figura 7 - Tendência da probabilidade de demissão sem justa para o grupo dos tratados, 6 a 7 meses, e grupo dos controles, 18 a 19 meses, contralada por efeito fixo mensal, dummy de tratamento e sazonalidade grupo

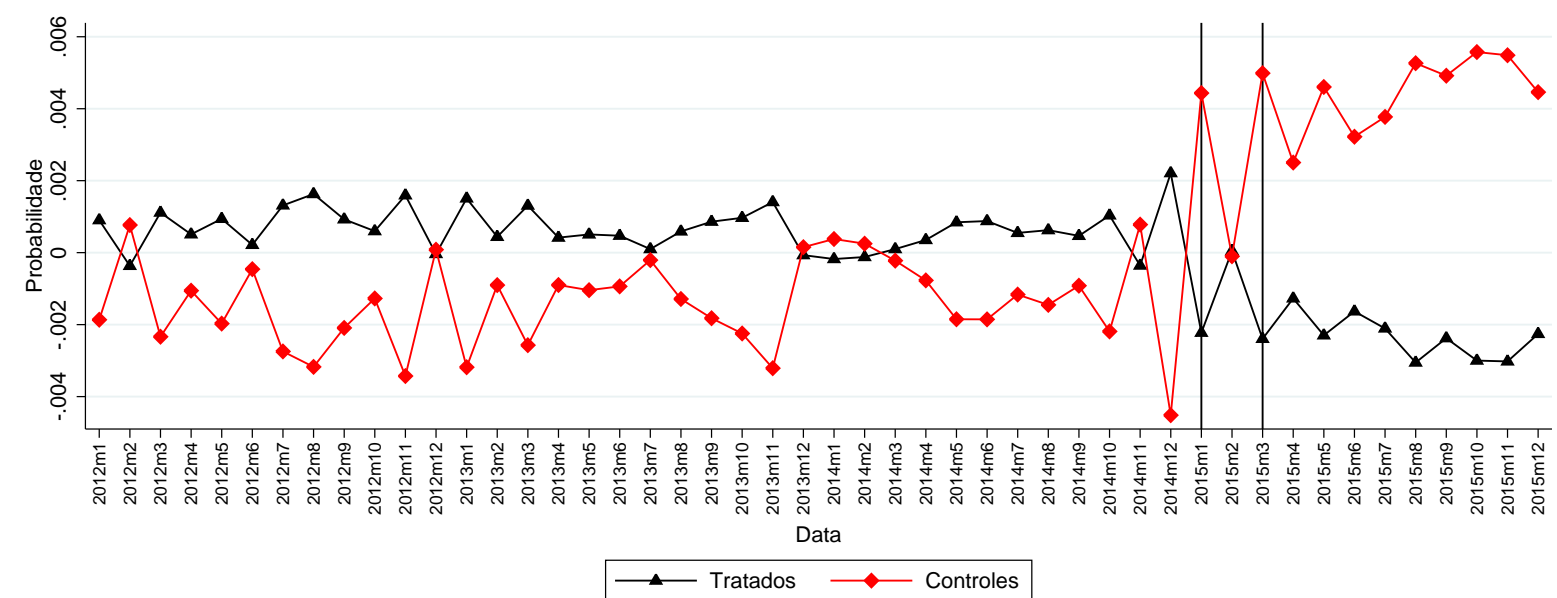

Fonte: RAIS 2012 a 2015.

O gráfico apresenta os resíduos preditos da regressão da variável de demissão sem justa causa no efeito fixo mês/ano, na variável de grupo de tratados e na interação entre dummies de meses do ano com o grupo dos tratados. As médias mensais dos resíduos por grupo são apresentadas para o grupo dos tratados, indivíduos de 6 a 7 meses completos no trabalho formal, e para o grupo dos controles, pessoas que possuem de 18 a 19 meses completos de trabalho no setor formal. O período considerado inicia-se em janeiro de 2012 indo até dezembro de 2015, englobando os meses em que a MP665 foi promulgada, dezembro de 2014, e que passou a vigorar, fevereiro de 2015. Tendo em vista que tanto o dia da promulgação quanto o dia em que a medida passou a vigorar estão no final do mês, 30 de dezembro e 28 de fevereiro, respectivamente, opta-se por traçar a linha vertical nos meses subsequentes, janeiro e março de 2015.

anterior à vigoração da MP665. Tal comportamento não impõe restrição à análise, apenas reforça a hipótese de que os indivíduos possuem algum tipo de controle sobre suas demissões sem justa causa que, a princípio, deveriam ser exógenas.

O segundo modo de antecipação, caso ocorra, impõe uma maior restrição à avaliação do efeito da mudança legislativa. Os indivíduos não elegíveis ao seguro-desemprego em janeiro e fevereiro de 2015 podem optar por deixar o emprego formal pois não terão a oportunidade de acessá-lo após 28 de fevereiro, data em que a MP665 passa a vigorar. Logo, é possível que ocorra uma seleção de pessoas mais estáveis no emprego, o que no decorrer dos meses ocasionaria em uma diminuição na probabiliade de demissão sem justa causa dos grupos com maior tempo de emprego. Entretanto, na seção dos resultados será verificado que ambos os modos de antecipação não são comprovados.

Além disso, apesar de não ser uma das hipóteses fundamentais do modelo de diferenças em diferenças, é possível testar se os fatores observáveis são diferentes entre os indivíduos dos grupos dos tratados e dos controles. As tabelas 2 e 3 trazem as estatísticas descritivas para as amostras que foram utilizadas nas regressões. Nelas também é possível visualizar os resultados dos testes de diferenças de médias das covariadas incluídas em (1) e de outras características observáveis para os grupos definidos na menor janela considerada na análise, um mês de tempo de emprego. 
Analisando a tabela 2 e 3, verifica-se que para a maior parte das variáveis, os indivíduos utilizados como tratados e como controles são semelhantes. Entretanto, os testes de diferenças de médias são significantes devido à elevada quantidade de observações amostrais. Destaca-se que a amostra é predominantemente de trabalhadores urbanos, da região sudeste e que possuem até o ensino médio completo. Dentre os tipos possíveis de quebra dos vínculos, a demissão sem justa causa é a mais comum, representando pelo menos $54 \%$ do total dos desligamentos. Nota-se também que, entre os dois grupos de controle, aquele com indivíduos com mais de 18 meses de tempo de emprego difere mais nas covariadas do grupo dos tratados. Em especial, são mais estáveis no emprego e possuem uma remuneração média maior.

Por fim, com as variáveis presentes na RAIS não identificada, não é possível verificar se o trabalhador requereu o seguro desemprego e em qual requerimento se encontra. Como há distinção na MP665 e na Lei nº 13.134 de acordo com o número do requerimento, o grupo de tratado abarca trabalhadores que não são afetados pela medida. Levando em consideração os últimos dois pontos, o $\delta$ capta um efeito atenuado da MP665, correspondendo a um upper bound. De outra maneira, os requerentes pela terceira vez não serão compelidos a mudarem o comportamento. Além disso, dentre os indivíduos elegíveis podem existir pessoas que não receberiam o seguro-desemprego caso demitidas e pessoas que não fizeram o requerimento ${ }^{5}$.

5 O período de carência entre o requerimento consecutivo do benefício é de 16 meses. Caso o indivíduo seja demitido durante esse período, ele apesar de ser elegível não poderá receber o benefício. Este é o único caso em que um requerente elegível não recebe o benefício. 
Tabela 2 - Teste de diferença de médias para covariadas controles de 4 a 5 meses no formal e tratados de 6 a 7

\begin{tabular}{|c|c|c|c|c|c|}
\hline \multirow[b]{2}{*}{ Variáveis } & \multicolumn{2}{|c|}{ Controles } & \multicolumn{2}{|c|}{ Tratados } & \multirow[b]{2}{*}{ Diferença } \\
\hline & Observações & Média & Observações & Média & \\
\hline Idade & 4852486 & 31,82 & 4112615 & 32,08 & $-0,264^{* * *}$ \\
\hline Horas de Jornada & 4852486 & 42,64 & 4112615 & 42,61 & $0,036^{* * *}$ \\
\hline Remuneração Média & 4852486 & 1465 & 4112615 & 1500 & $-35,286 * * *$ \\
\hline \multicolumn{6}{|l|}{ Faixa de escolaridade } \\
\hline Analfabeto & 4852486 & 0,004 & 4112615 & 0,004 & $0,000^{* * *}$ \\
\hline Fundamental Incompleto & 4852486 & 0,135 & 4112615 & 0,13 & $0,005^{* * *}$ \\
\hline Fundamental Completo & 4852486 & 0,21 & 4112615 & 0,207 & $0,002^{* * *}$ \\
\hline Médio Completo & 4852486 & 0,558 & 4112615 & 0,56 & $-0,002^{* * *}$ \\
\hline Superior Completo & 4852486 & 0,091 & 4112615 & 0,096 & $-0,005^{* * *}$ \\
\hline Mestrado ou Doutorado & 4852486 & 0,003 & 4112615 & 0,003 & $-0,000^{* * *}$ \\
\hline Proporção de Homens & 4852486 & 0,622 & 4112615 & 0,618 & $0,004^{* * *}$ \\
\hline \multicolumn{6}{|l|}{ Raça } \\
\hline Proporção de Brancos & 4852486 & 0,499 & 4112615 & 0,507 & $-0,008 * * *$ \\
\hline Proporção de Negros & 4852486 & 0,053 & 4112615 & 0,052 & $0,001^{* * *}$ \\
\hline Proporção de Pardos & 4852486 & 0,354 & 4112615 & 0,349 & $0,005^{* * *}$ \\
\hline Outros & 4852486 & 0,095 & 4112615 & 0,093 & $0,002^{* * *}$ \\
\hline \multicolumn{6}{|l|}{ Tipo de Contrato } \\
\hline Clt Urbano & 4852486 & 0,985 & 4112615 & 0,986 & $-0,001^{* * *}$ \\
\hline Clt Rural & 4852486 & 0,015 & 4112615 & 0,014 & $0,001^{* * *}$ \\
\hline \multicolumn{6}{|l|}{ Setor de Atividade } \\
\hline Indústria & 4852486 & 0,172 & 4112615 & 0,177 & $-0,004^{* * *}$ \\
\hline Serviço & 4852486 & 0,401 & 4112615 & 0,406 & $-0,005^{* * *}$ \\
\hline Comércio & 4852486 & 0,264 & 4112615 & 0,267 & $-0,003^{* * *}$ \\
\hline Construção & 4852486 & 0,139 & 4112615 & 0,128 & $0,011^{* * *}$ \\
\hline \multicolumn{6}{|l|}{ Região } \\
\hline Norte & 4852486 & 0,051 & 4112615 & 0,051 & $0,000^{* *}$ \\
\hline Nordeste & 4852486 & 0,168 & 4112615 & 0,169 & $-0,001^{* * *}$ \\
\hline Sudeste & 4852486 & 0,52 & 4112615 & 0,522 & $-0,002^{* * *}$ \\
\hline Sul & 4852486 & 0,175 & 4112615 & 0,174 & $0,001^{* * *}$ \\
\hline Centro-Oeste & 4852486 & 0,086 & 4112615 & 0,084 & $0,002^{* * *}$ \\
\hline \multicolumn{6}{|l|}{ Número de Empregados na Firma } \\
\hline Até 9 & 4852486 & 0,246 & 4112615 & 0,248 & $-0,002^{* * *}$ \\
\hline De 10 até 49 & 4852486 & 0,282 & 4112615 & 0,28 & $0,002^{* * *}$ \\
\hline De 50 até 249 & 4852486 & 0,218 & 4112615 & 0,217 & $0,001^{* * *}$ \\
\hline Mais que 249 & 4852486 & 0,254 & 4112615 & 0,255 & $-0,001^{* * *}$ \\
\hline \multicolumn{6}{|l|}{ Proporção Mensal de Quebra dos Vínculos } \\
\hline Todas Tipos de Quebra & 4852486 & 0,074 & 4112615 & 0,081 & $-0,007 * * *$ \\
\hline Demissão sem Justa Causa & 4852486 & 0,04 & 4112615 & 0,054 & $-0,014^{* * *}$ \\
\hline Demissão com Justa Causa & 4852486 & 0,002 & 4112615 & 0,001 & $0,000^{* * *}$ \\
\hline Quebra por Iniciativa do Empregado & 4852486 & 0,027 & 4112615 & 0,02 & $0,007 * * *$ \\
\hline Outros & 4852486 & 0,006 & 4112615 & 0,006 & $0,000 * * *$ \\
\hline
\end{tabular}

Fonte: RAIS 2012 a fevereiro de 2015. Níveis de significância: $\quad *: 10 \% \quad * *: 5 \% \quad * * *: 1 \%$. Os controles são indivíduos que possuem de 4 a 5 meses de tempo de emprego, já os tratados possuem de 6 a 7 . 
Tabela 3 - Teste de diferença de médias para covariadas controles de 18 a 19 meses no formal e tratados de 6 a 7

\begin{tabular}{|c|c|c|c|c|c|}
\hline \multirow[b]{2}{*}{ Variáveis } & \multicolumn{2}{|c|}{ Controles } & \multicolumn{2}{|c|}{ Tratados } & \multirow[b]{2}{*}{ Diferença } \\
\hline & Observações & Média & Observações & Média & \\
\hline Idade & 1941186 & 33,51 & 4112615 & 32,08 & $1,432^{* * *}$ \\
\hline Horas de Jornada & 1941186 & 42,46 & 4112615 & 42,61 & $-0,150 * * *$ \\
\hline Remuneração Média & 1941186 & 1707 & 4112615 & 1500 & $206,684^{* * *}$ \\
\hline \multicolumn{6}{|l|}{ Faixa de escolaridade } \\
\hline Analfabeto & 1941186 & 0,002 & 4112615 & 0,004 & $-0,001^{* * *}$ \\
\hline Fundamental Incompleto & 1941186 & 0,115 & 4112615 & 0,13 & $-0,015^{* * *}$ \\
\hline Fundamental Completo & 1941186 & 0,201 & 4112615 & 0,207 & $-0,006^{* * *}$ \\
\hline Médio Completo & 1941186 & 0,562 & 4112615 & 0,56 & $0,001^{* * *}$ \\
\hline Superior Completo & 1941186 & 0,116 & 4112615 & 0,096 & $0,020^{* * *}$ \\
\hline Mestrado ou Doutorado & 1941186 & 0,004 & 4112615 & 0,003 & $0,001^{* * *}$ \\
\hline Proporção de Homens & 1941186 & 0,607 & 4112615 & 0,618 & $-0,012^{* * *}$ \\
\hline \multicolumn{6}{|l|}{ Raça } \\
\hline Proporção de Brancos & 1941186 & 0,544 & 4112615 & 0,507 & $0,038^{* * *}$ \\
\hline Proporção de Negros & 1941186 & 0,049 & 4112615 & 0,052 & $-0,002^{* * *}$ \\
\hline Proporção de Pardos & 1941186 & 0,324 & 4112615 & 0,349 & $-0,025 * * *$ \\
\hline Outros & 1941186 & 0,082 & 4112615 & 0,093 & $-0,011^{* * *}$ \\
\hline \multicolumn{6}{|l|}{ Tipo de Contrato } \\
\hline Clt Urbano & 1941186 & 0,991 & 4112615 & 0,986 & $0,005^{* * *}$ \\
\hline Clt Rural & 1941186 & 0,009 & 4112615 & 0,014 & $-0,005^{* * *}$ \\
\hline \multicolumn{6}{|l|}{ Setor de Atividade } \\
\hline Indústria & 1941186 & 0,204 & 4112615 & 0,177 & $0,027^{* * *}$ \\
\hline Serviço & 1941186 & 0,425 & 4112615 & 0,406 & $0,019 * * *$ \\
\hline Comércio & 1941186 & 0,272 & 4112615 & 0,267 & $0,005^{* * *}$ \\
\hline Construção & 1941186 & 0,08 & 4112615 & 0,128 & $-0,047^{* * *}$ \\
\hline \multicolumn{6}{|l|}{ Região } \\
\hline Norte & 1941186 & 0,049 & 4112615 & 0,051 & $-0,002^{* * *}$ \\
\hline Nordeste & 1941186 & 0,168 & 4112615 & 0,169 & $-0,001^{* * *}$ \\
\hline Sudeste & 1941186 & 0,533 & 4112615 & 0,522 & $0,011^{* * *}$ \\
\hline Sul & 1941186 & 0,174 & 4112615 & 0,174 & 0 \\
\hline Centro-Oeste & 1941186 & 0,077 & 4112615 & 0,084 & $-0,007^{* * *}$ \\
\hline \multicolumn{6}{|l|}{ Número de Empregados na Firma } \\
\hline Até 9 & 1941186 & 0,239 & 4112615 & 0,248 & $-0,009^{* * *}$ \\
\hline De 10 até 49 & 1941186 & 0,276 & 4112615 & 0,28 & $-0,004^{* * *}$ \\
\hline De 50 até 249 & 1941186 & 0,216 & 4112615 & 0,217 & $-0,001^{*}$ \\
\hline Mais que 249 & 1941186 & 0,269 & 4112615 & 0,255 & $0,014^{* * *}$ \\
\hline \multicolumn{6}{|l|}{ Proporção Mensal de Quebra dos Vínculos } \\
\hline Todas Tipos de Quebra & 1941186 & 0,046 & 4112615 & 0,081 & $-0,035^{* * *}$ \\
\hline Demissão sem Justa Causa & 1941186 & 0,034 & 4112615 & 0,054 & $-0,021^{* * *}$ \\
\hline Demissão com Justa Causa & 1941186 & 0,001 & 4112615 & 0,001 & $-0,001^{* * *}$ \\
\hline Quebra por Iniciativa do Empregado & 1941186 & 0,008 & 4112615 & 0,02 & $-0,012^{* * *}$ \\
\hline Outros & 1941186 & 0,004 & 4112615 & 0,006 & $-0,002^{* * *}$ \\
\hline
\end{tabular}

Fonte: RAIS 2012 a fevereiro de 2015. Níveis de significância: $\quad *: 10 \% \quad * *: 5 \% \quad * * *: 1 \%$. Os controles são indivíduos que possuem de 18 a 19 meses de tempo de emprego, já os tratados possuem de 6 a 7 . 


\section{Resultados}

\subsection{Avaliação de Impacto}

A equação (1) estimada por um modelo de probabilidade linear tem seus resultados expostos nas tabelas 4 e 5 para os dois grupos de controles utilizados, pessoas abaixo de 6 meses e acima de 18 meses de emprego, respectivamente. As colunas representam estimações distintas nas quais foram utilizadas diferentes janelas de tempo de emprego, iguais a um ou dois meses. Todas estimações foram realizadas com efeitos fixos mensais. Adicionalmente, algumas delas foram realizadas com a adição da interação entre tratados e os meses do ano, de tendência linear específica para os tratados, e covariadas de forma que o modelo controla para variáveis de efeito fixo mensal, idade, faixa de escolaridade, gênero, cor, efeito fixo de estado brasileiro, ocupação, setor de atividade, tamanho do estabelecimento e quantidade de horas contratadas.

Optou-se pela não inclusão da variável renda média mensal, pois diferenças entre grupos nessa variável seguem diretamente de como estes foram construídos: seleção de indivíduos utilizando o critério de meses trabalhados no formal. Controlar por essa variável seria afirmar que indivíduos do grupo dos controles são contrafactuais para indivíduos do grupo dos tratados desde que tenham a mesma renda, mesmo que tenham sido definidos com base em diferentes critérios de tempo de emprego. Além disso, é provável que renda seja afetada pela MP665, algo que não será testado neste trabalho.

Analisando os coeficientes do efeito da MP665 nas estimações é possível notar que esses têm sinal negativo para todos os grupos utilizados, confirmando a hipótese apresentada nas seções anteriores. A adição de covariadas, da interação entre tratados e os meses do ano e da tendência linear específica para os tratados pouco altera a magnitude dos coeficientes estimados. Adicionalmente, nota-se que ao aumentar a janela de tempo de emprego, o coeficiente se torna menos negativo e com menor erro padrão. Quanto mais distante do corte de seis meses, menores são os incentivos para os elegíveis, pois são compostos por indivíduos que já se mantiveram no emprego frente à possibilidade de acessar o seguro-desemprego anteriormente.

Vale ressaltar que o decréscimo no efeito encontrado é mais evidente nas estimações em que os indivíduos com menos de seis meses de tempo de emprego são utilizados como grupo de controle. Para este, a expansão na janela de meses de emprego é especialmente problemática, pois passa a englobar indivíduos cada vez mais próximos ao tempo limite do contrato de experiência, até três meses de tempo de emprego. O período de experiência é similar a um contrato de trabalho por tempo determinado, sendo que as firmas escolhem 
entre terminar a relação de trabalho ou contratar o trabalhador por tempo indeterminado ao seu final. Dessa forma, as demissões sem justa causa perdem importância relativa para os indivíduos com baixo tempo de emprego, sendo que os términos de contrato passam a ser preponderantes.

Os resultados indicam que os trabalhadores do setor formal que podem acessar o seguro-desemprego conseguem e induzem a sua própria demissão em alguma medida. Tendo como base o sinal dos coeficientes estimados do efeito das mudanças na lei, os trabalhores formais afetados pela MP665 têm suas probabilidades de serem demitidos diminuída a partir de março de 2015, mês que configura o início do período em que os requisitos de tempo mínino no formal foram aumentados. Considerando que as estimações realizadas permitem isolar o efeito das alterações legislativas, a diferença de probabilidade da demissão está exclusivamente ligada ao fato dos trabalhadores formais elegíveis serem mais propensos à demissão sem justa causa pois podem acessar o seguro-desemprego. Para os indivíduos mais comparáveis, contidos na janela de um mês de tempo de emprego, o efeito é de aproximadamente 0,73 pontos percentuais, o que significa $13 \%$ das demissões dos indivíduos elegíveis no período anterior à mudança legislativa.

Para melhor analisar se o efeito nas demissões sem justa causa acontece no exato período em que a MP665 começa a vigorar, estima-se a equação (4.1) desagregando o coeficiente de interesse do modelo de diferenças em diferenças. Ao invés de estimar apenas um coeficiente para o efeito da mudança, estima-se o efeito para cada bimestre dos anos de 2014 e $2015^{1}$. Os coeficientes estimados para cada bimestre e seus intervalos de confiança são apresentados nas figuras 8 e $9^{2}$. A partir da análise dessas, nota-se que a queda nas demissões sem justa causa ocorre no bimestre em que a MP665 entrou em vigor, março e abril de 2015, e se mantêm ao longo deste ano. Vale ressaltar que não é possível observar antecipação por parte dos indivíduos elegíveis no período entre a promulgação e a entrada da MP665 em vigor, janeiro e fevereiro de 2015. A estimativa pontual para este bimestre é negativa para os dois grupos de controle utilizados. Dessa forma, a inclusão dos meses de janeiro e fevereiro não compromete a avaliação do impacto da alteração dos critérios de elegibilidade, de modo que o efeito seria maior se esses meses fossem excluídos da análise.

Adicionalmente, é necessário avaliar o efeito das alterações legislativas na probabilidade dos empregados deixarem o emprego. Os acordos podem ser realizados de duas formas distintas. Na primeira, as firmas podem adiar as demissões que já ocorreriam na-

1 Estima-se

$$
y_{i, t}=\sum_{\tau=0}^{5} \delta_{+\tau} \cdot \mathbb{1}_{t=\tau} \cdot T_{i}+\sum_{\tau=1}^{7} \delta_{-\tau} \cdot \mathbb{1}_{t=-\tau} \cdot T_{i}+\lambda \cdot T_{i}+\mu_{t}+\gamma \cdot T_{i} \cdot \text { Mês }+\tau \cdot T_{i} \cdot t+\beta \cdot X_{i, t}+\varepsilon_{i, t}
$$

, onde $\tau=0$ representa o bimestre em que a MP665 passou a vigorar, março e abril de 2015. As interações são estimadas para todos os bimestres de 2014 e 2015.

2 As regressões estão contidas nas tabelas 27 e 28 no Apêndice B. 
turalmente com o objetivo de tornar o empregado elegível ao seguro-desemprego. Neste caso, o efeito seria encontrado apenas nas demissões sem justa causa. Na segunda, caso quisessem deixar o emprego, os empregados poderiam negociar suas demissões sem justa causa com as firmas. Assim, a mudança na elegibilidade ao seguro-desemprego deveria aumentar a probabilidade de saída do emprego por iniciativa do trabalhador, dado que o canal para o segundo tipo de acordo foi encerrado.

Os resultados expostos nas tabelas 6 e 7 mostram que a probabilidade de saída do emprego por iniciativa do trabalhador aumenta com as alteração dos critérios de elegibilidade. Entretanto, o aumento na probabilidade de saída do emprego não compensa a diminuição na probabilidade de demissão observada na regressão principal. O efeito é encontrado apenas quando os indivíduos com baixo tempo de emprego são utilizados como grupo de controle, não sendo robusto a utilização dos indivíduos com mais de 18 meses de emprego. Dessa forma, é possível que os acordos por adiamento sejam predominantes. Os gráficos para verificação de tendência paralela das probabilidades de saída estão contidos no Apêndice A.

O mesmo resultado pode ser visualizado com os gráficos dos efeitos para os bimestres de 2014 e 2015. A partir da análise das figuras 10 e $11^{3}$, é possível notar que os efeitos não são robustos ao grupo de controle utilizado. Vale ressaltar que não é possível visualizar um efeito antecipatório para os indivíduos que possuem pouco tempo de emprego no setor formal. O coeficiente estimado para o bimestre de janeiro e fevereiro de 2015 é positivo e não significante.

\subsection{Testes de Falseamento e Placebos}

Para tentar avaliar se os resultados encontrados são fruto de uma relação causal, é necessário distinguir os efeitos das mudanças legislativas, MP665 e Lei 13.134, de elementos conjunturais do mercado de trabalho brasileiro. A legislação do seguro-desemprego impõe como um dos critérios diretos para a elegibilidade a demissão involuntária do empregado. Somente têm direito a acessar os benefícios, os trabalhadores formais demitidos sem justa causa do emprego. Este requisito formal da legislação permite realizar testes de falseamento em outros tipos de quebra de vínculos, de modo que as alterações legislativas não deveriam ter efeito sobre elas se o mecanismo de queda nas demissões sem justa causa está bem identificado.

A mesma especificação descrita na equação (1) é estimada utilizando como variável depedente tipos alternativos de desligamento do empregado. As tabelas 8, 9, 10 e 11 apresentam os testes de falseamento para as variáveis de demissão com justa causa e de outros tipos de desligamento. A variável "Outros tipos" de desligamento engloba quebras

$\overline{3}$ As regressões estão contidas nas tabelas 29 e 30 do Apêndice B. 


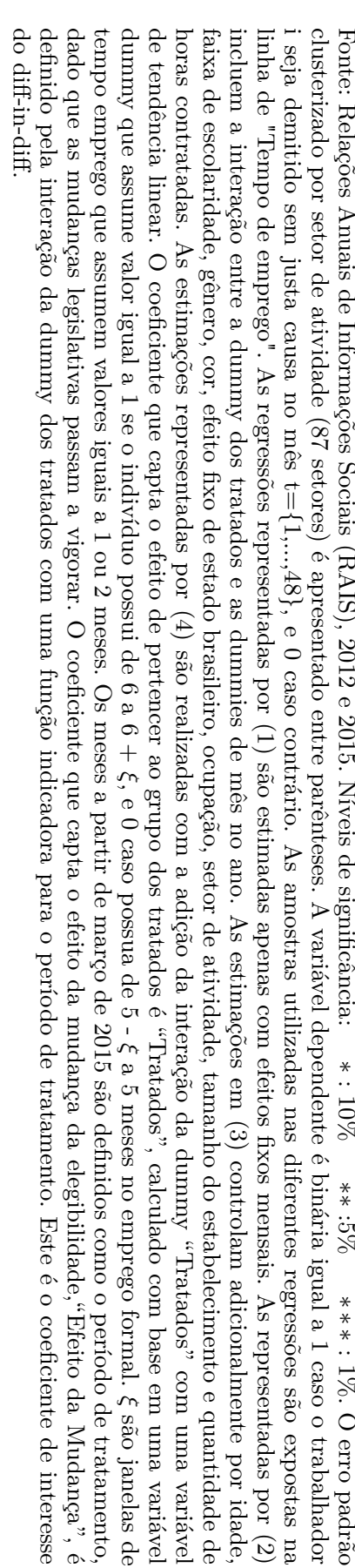

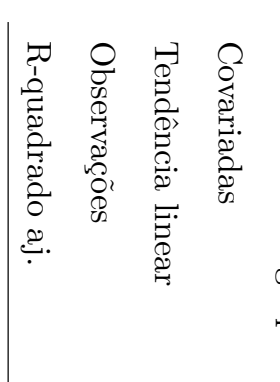

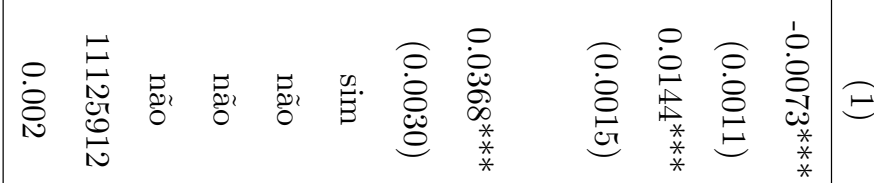

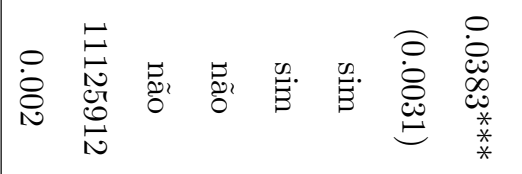

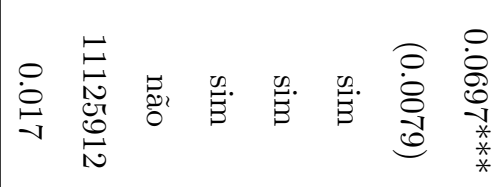

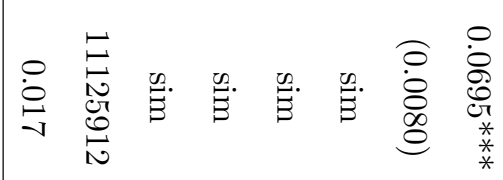

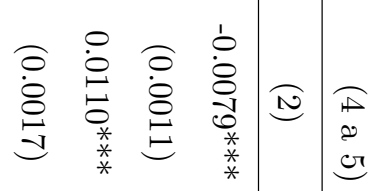

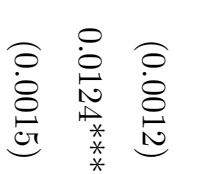

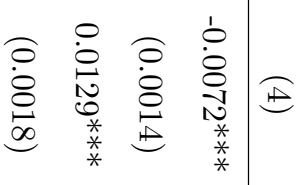

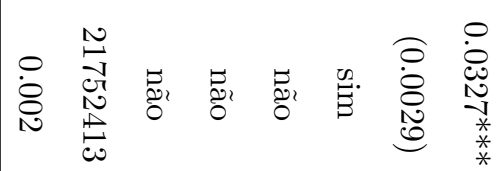

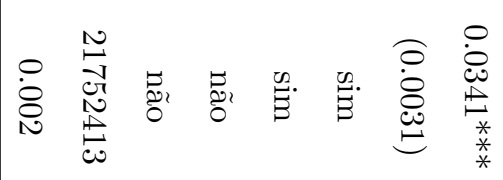

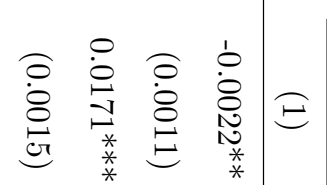

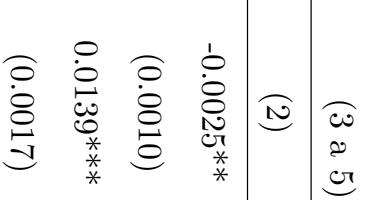

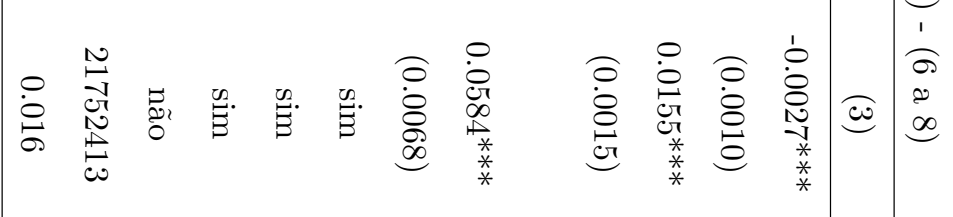

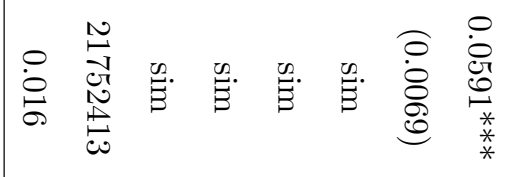

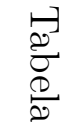

in

(1)

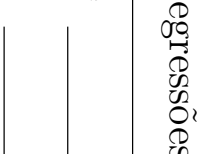

क)

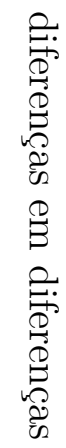

है

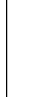

2
0
3
$:$
0
0
0
0
0

莡

Е.

نें

章

:

के

0
3
8
8
0 


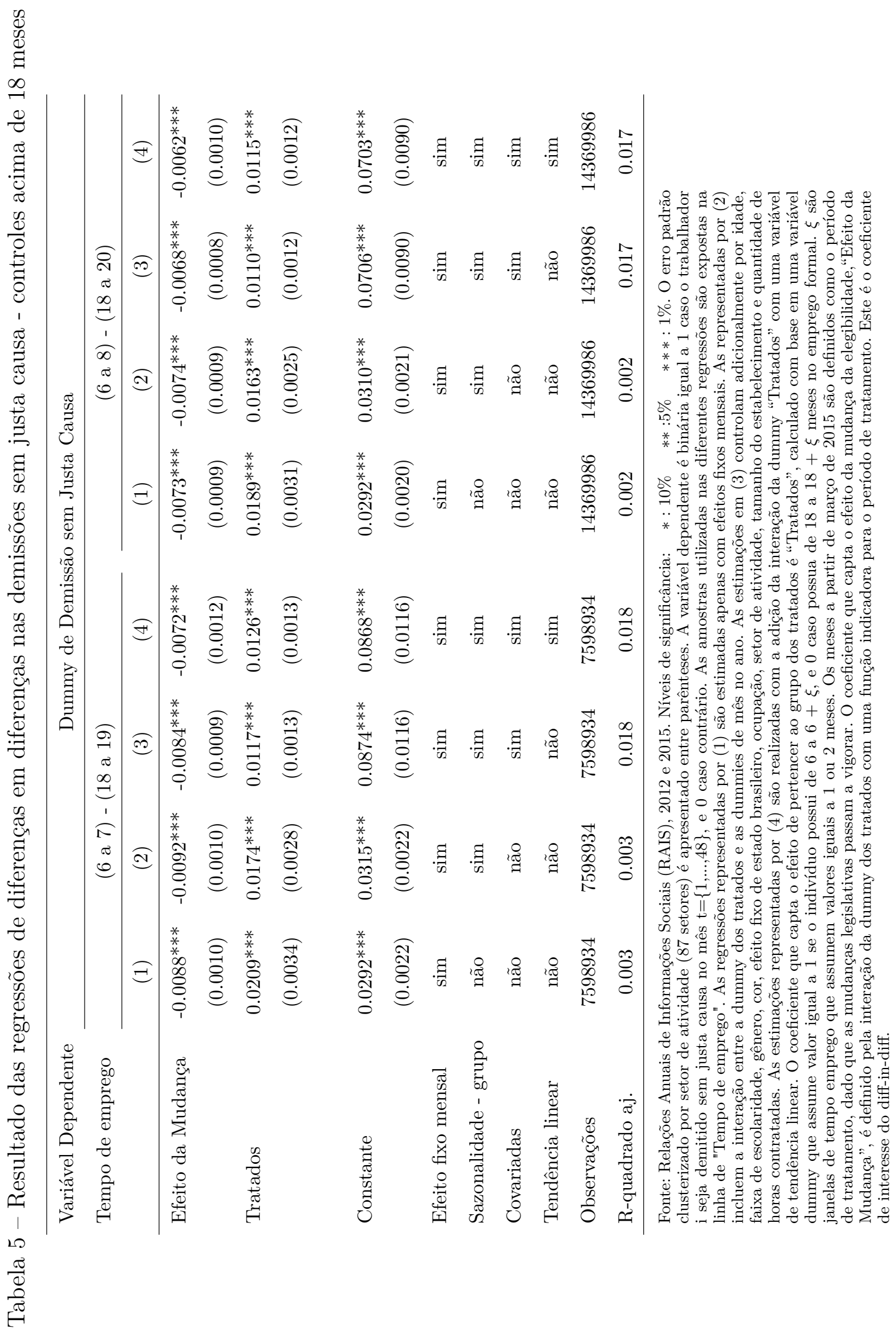




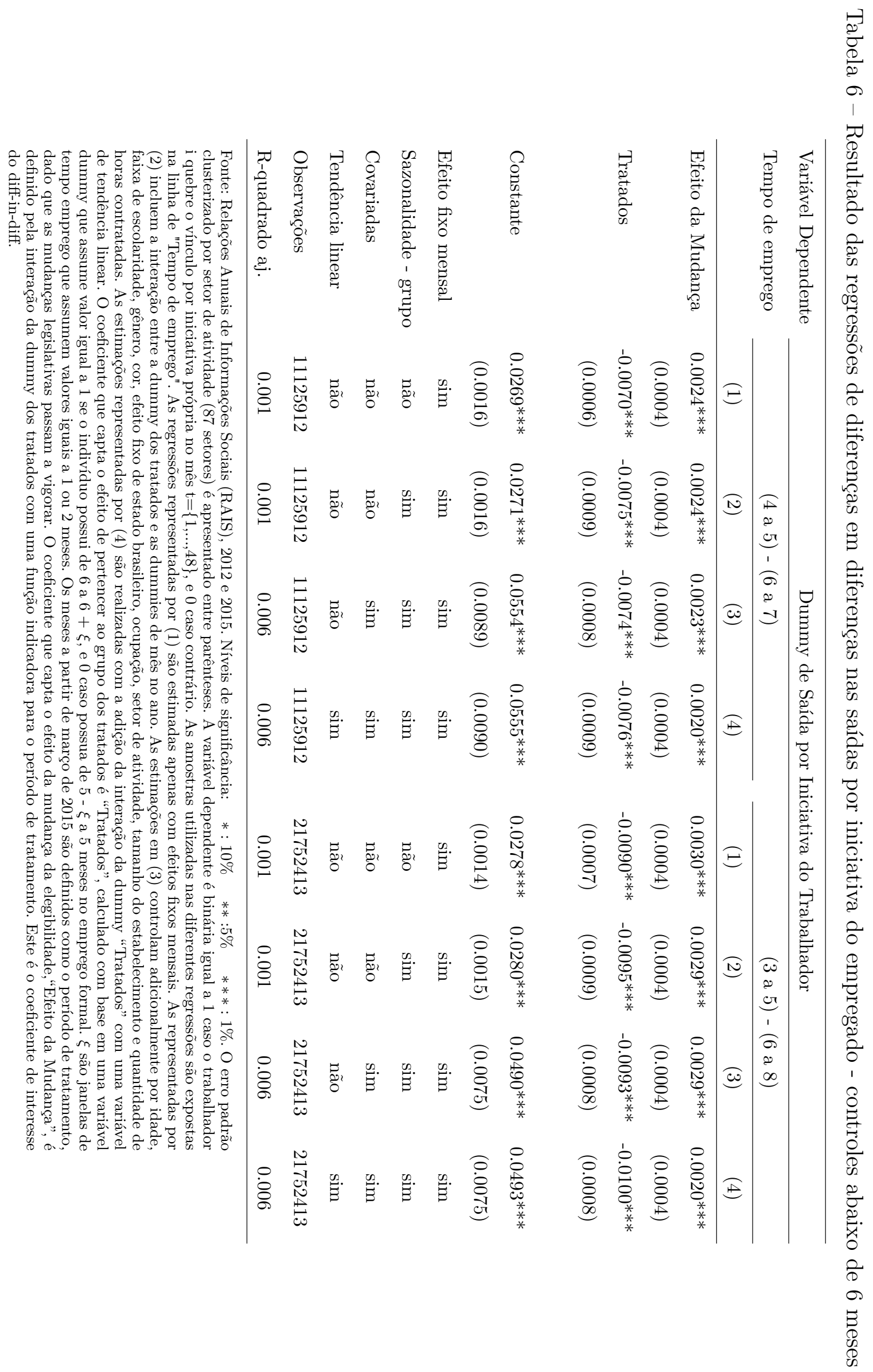




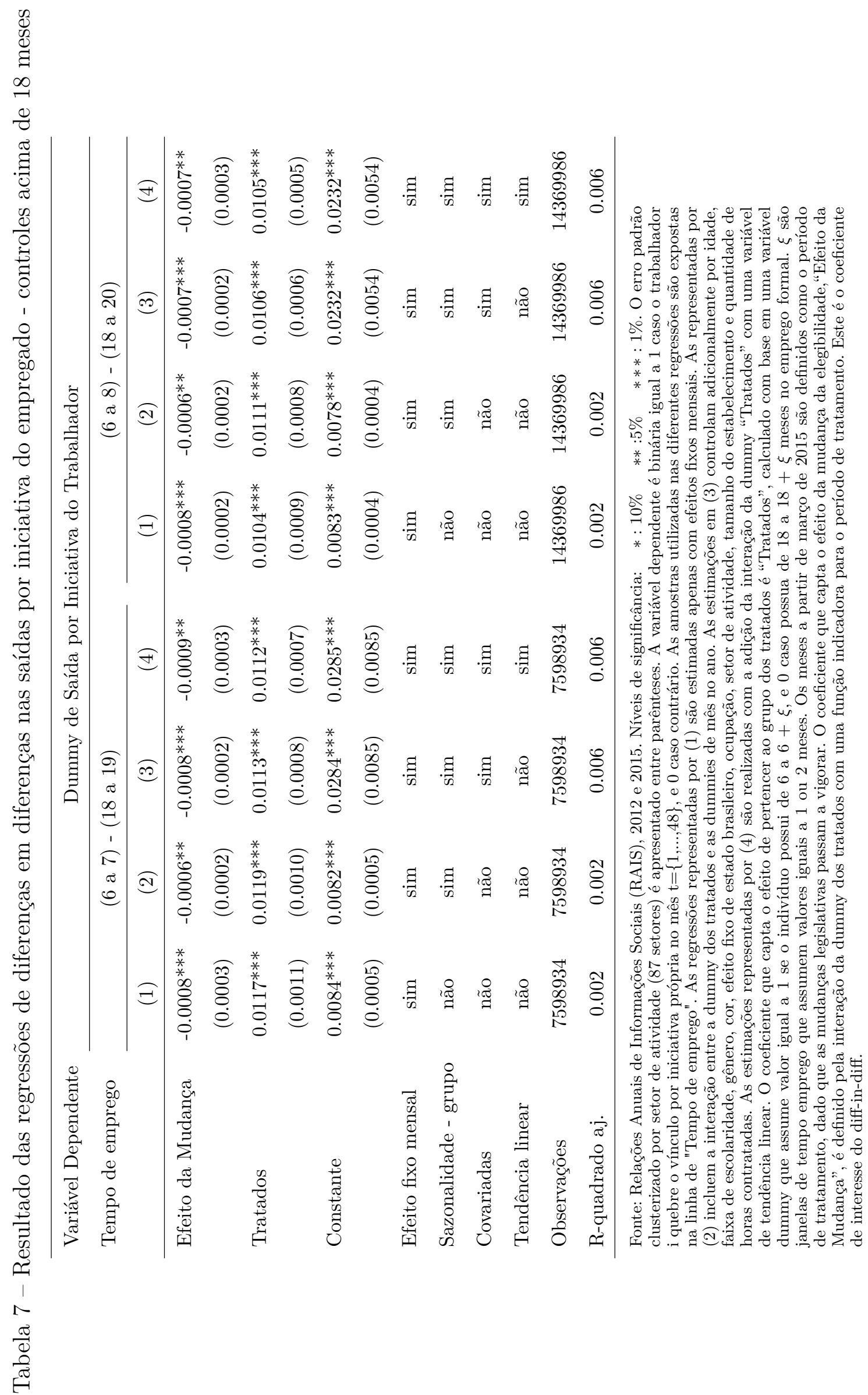


Figura 8 - Gráfico dos coeficientes para o grupo dos tratados, 6 a 7 meses, e grupo dos controles, 4 a 5 meses - Demissão sem justa causa

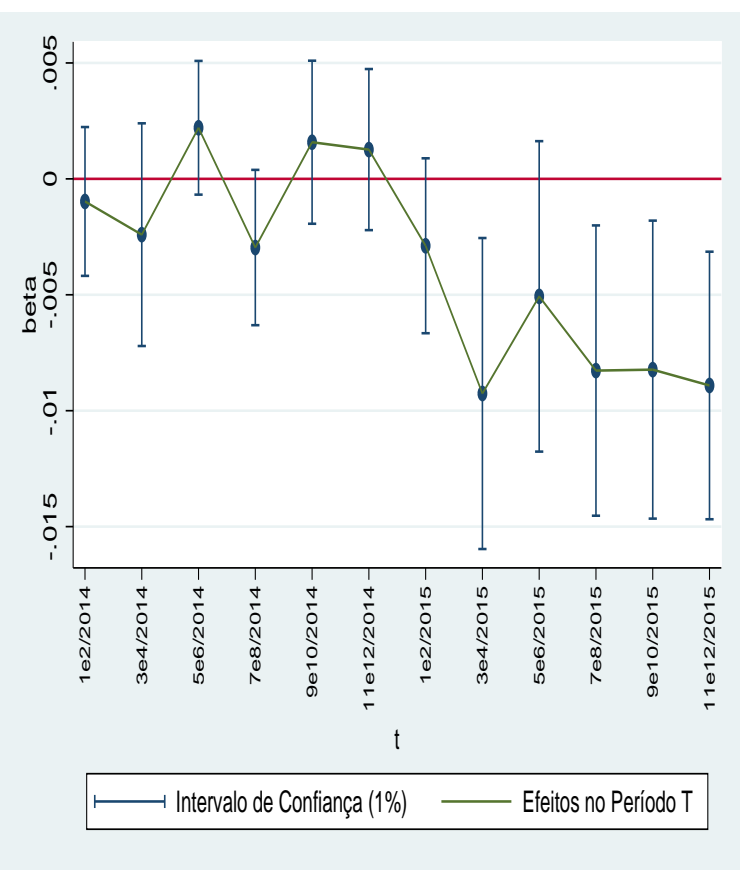

Figura 9 - Gráfico dos coeficientes para o grupo dos tratados, 6 a 7 meses, e grupo dos controles, 18 a 19 meses - Demissão sem justa causa

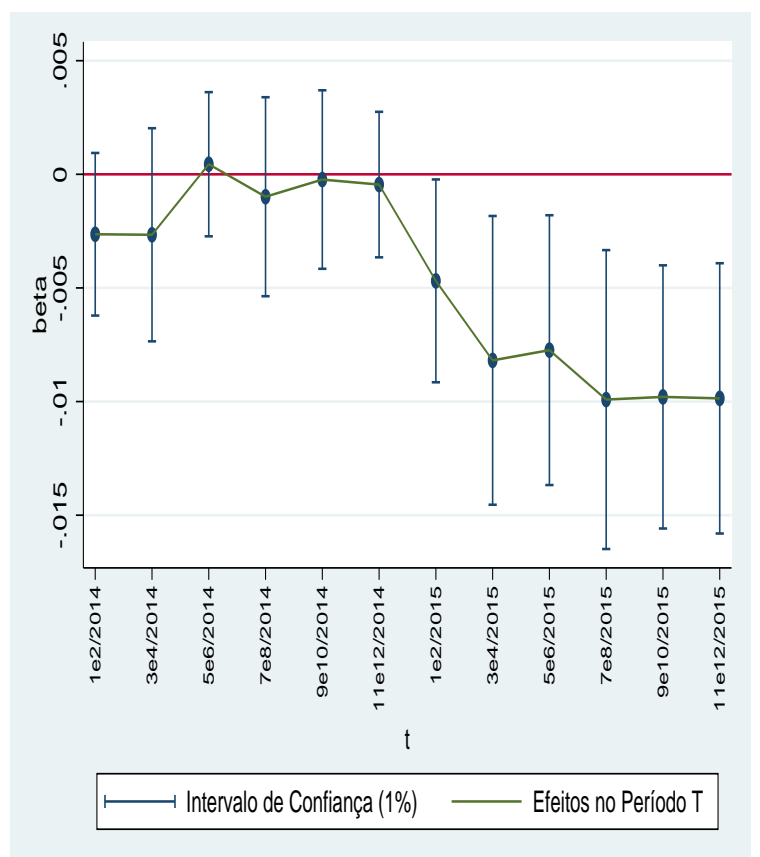

Utilizando a RAIS dos anos de 2012 até 2015, estima-se (5.1) para as demissões sem justa causa. As interações são estimadas para todos os bimestres de 2014 e 2015 e plotadas na figura junto com o intervalo de confiança de $1 \%$.

dos vínculos por término do contrato, recisão com justa causa por iniciativa do empregado, transferência, falecimento e aposentadoria. Note que ambos os tipos de encerramento dos vínculos não devem ser afetados diretamente pelos novos critérios do seguro-desemprego. No Apêndice A, os gráficos de tendência entre os grupos são apresentados para essas duas variáveis. A hipótese de tendências paralelas é um pressuposto para a validade dos testes de falseamento.

Analisando os coeficientes estimados contidos nas tabelas 8 e 9 é possível verificar que as alterações legislativas que ocorreram em 2015 aumentam a probabilidade de demissão com justa causa para as estimações realizadas utilizando os grupos de controle com baixo tempo de emprego. Entretanto, com base no modelo mais completo, que inclui tendência linear específica para o grupo dos tratados, não é possível rejeitar que o coeficiente seja estatísticamente diferente de 0 . Adicionalmente, os coeficiente estimados são não significantes ao utilizar-se os indivíduos com mais de 18 meses como grupo de controle contidos na janela de um mês de tempo de emprego.

O oposto acontece para outros tipos de quebra dos vínculos. A partir da análise das estimativas apresentadas nas tabelas 10 e 11, é possível visualizar que as mudanças nas regras do seguro-desemprego diminuem a probabilidade de quebra de vínculo por 


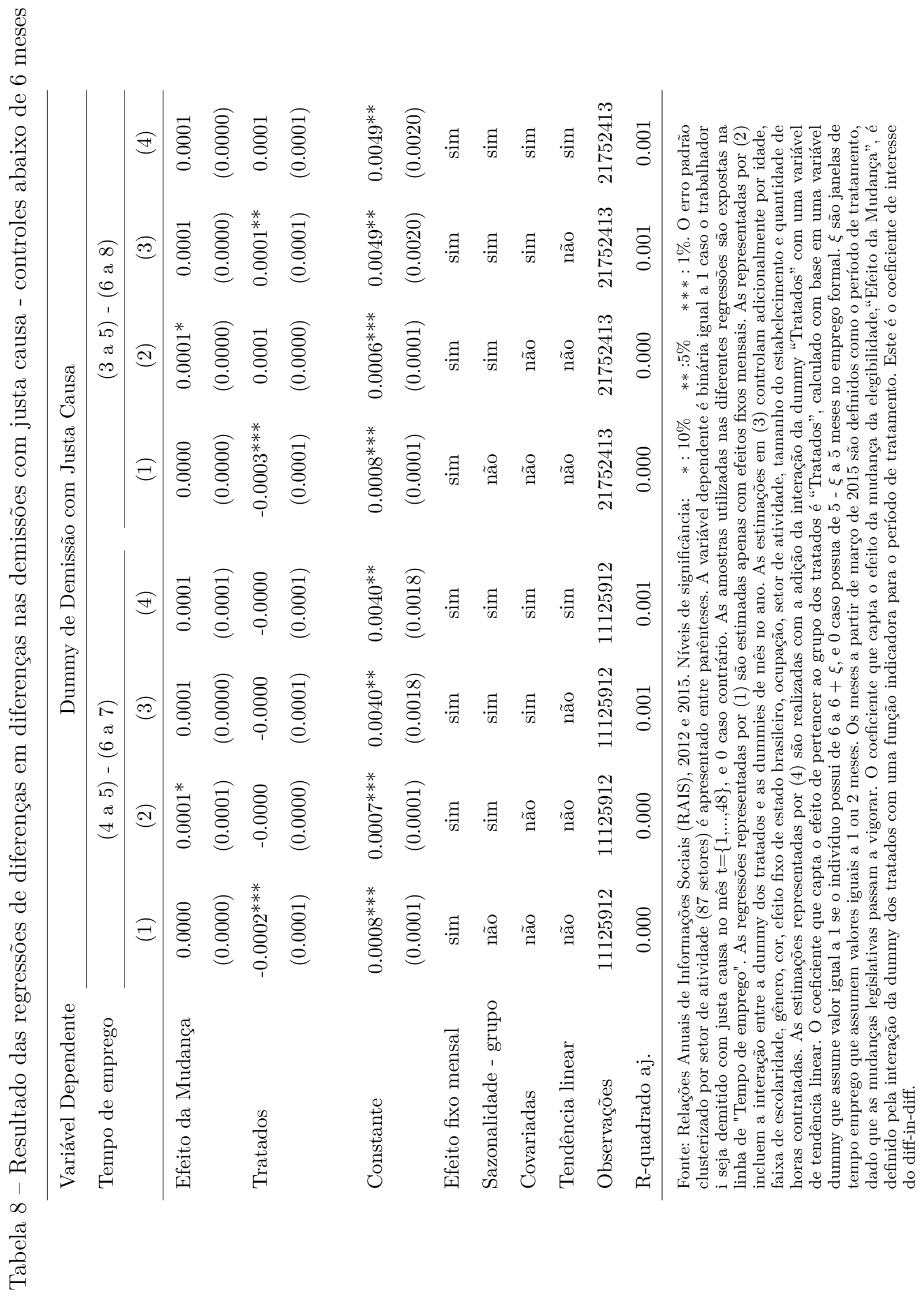




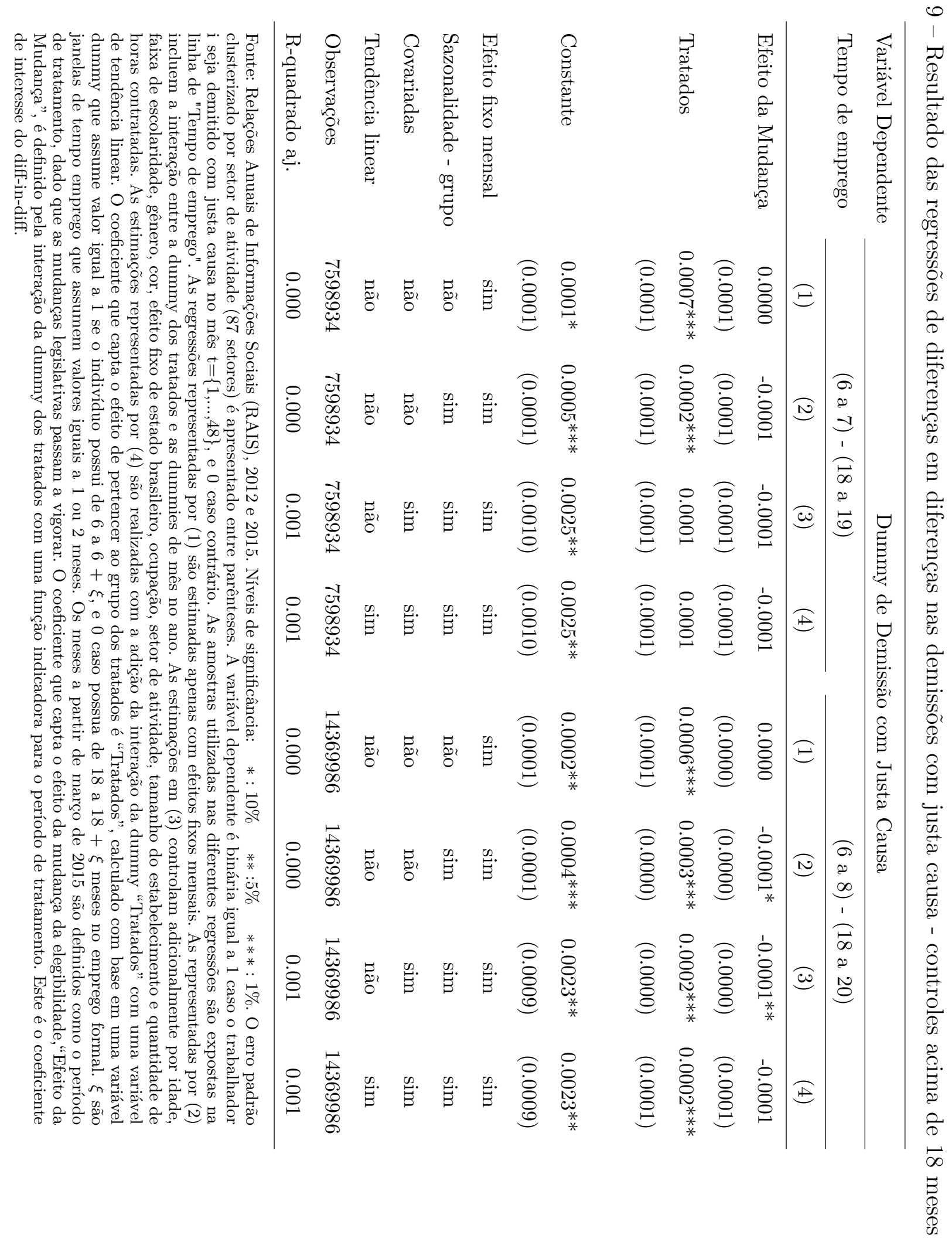


Figura 10 - Gráfico dos coeficientes para o grupo dos tratados, 6 a 7 meses, e grupo dos controles, 4 a 5 meses - Saída por iniciativa do empregado

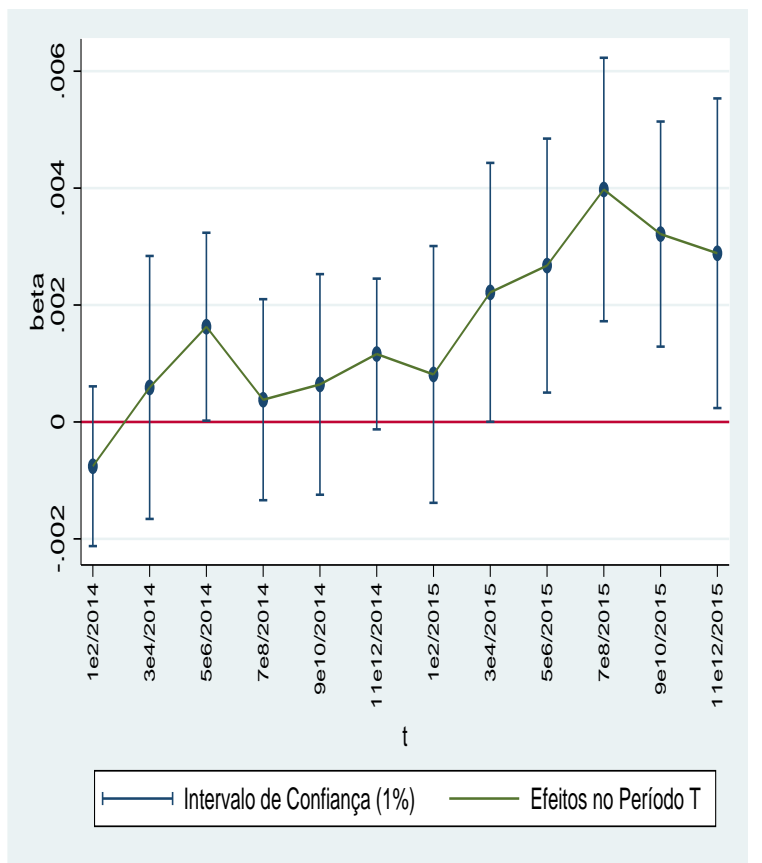

Figura 11 - Gráfico dos coeficientes para o grupo dos tratados, 6 a 7 meses, e grupo dos controles, 18 a 19 meses - Saída por iniciativa do empregado

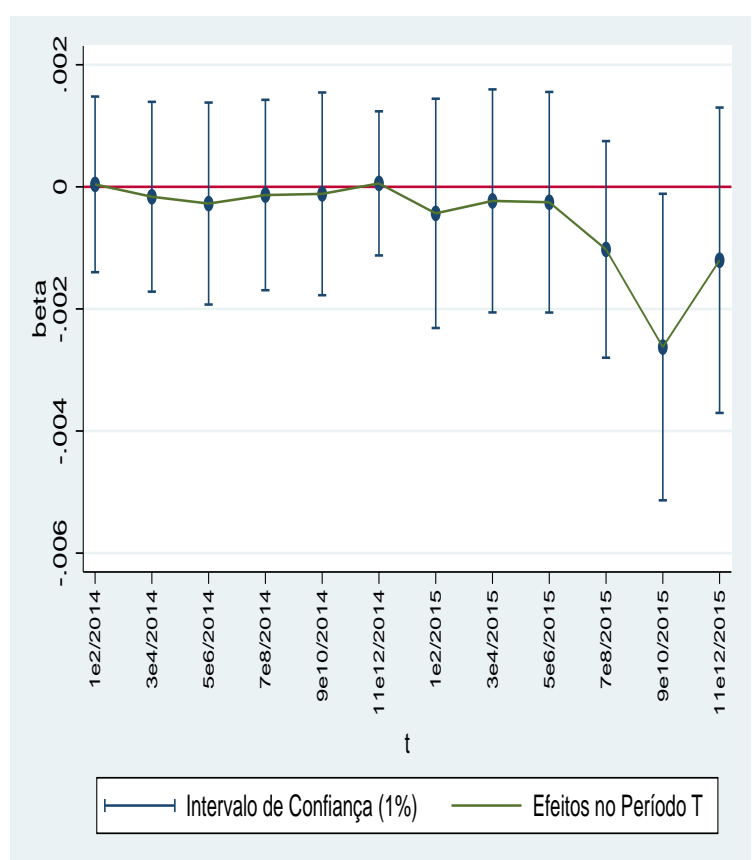

Utilizando a RAIS dos anos de 2012 até 2015, estima-se (5.1) para as saídas por iniciativa do empregado. As interações são estimadas para todos os bimestres de 2014 e 2015 e plotadas na figura junto com o intervalo de confiança de $1 \%$.

outros modos. O efeito, entretanto, é encontrado apenas quando os indivíduos com baixo tempo de emprego são utilizados como o grupo de controle, o que pode ser explicado pela maior incidência de quebras de vínculo por término de contrato entre eles. Adicionalmente, quando o modelo completo é utilizado, o efeito deixa de ser significante para o grupo de controle com baixo tempo de emprego.

O desligamento do trabalhador por término de contrato é uma característica do período de experiência. Aos trabalhadores admitidos, são propostos contratos de experiência, que possuem limite máximo de 3 meses. Após o término deste período, as firmas decidem entre não renovar o contrato de trabalho, ou contratar o indivíduo por tempo indeterminado. Na RAIS, é possível verificar que a probabilidade de término do contrato é maior para os indivíduos com menos tempo de emprego, mesmo que já tenham excedido o tempo limite do contrato de experiência de 3 meses. Dessa forma, a rejeição no teste não é problemática, dado que não ocorre para as estimações em que o grupo de controle tem mais de 18 meses de emprego.

Os gráficos dos efeitos para os bimestres de 2014 e 2015 corroboram os resultados encontrados para ambas as variáveis, demissão sem justa causa e quebra dos vínculos por 


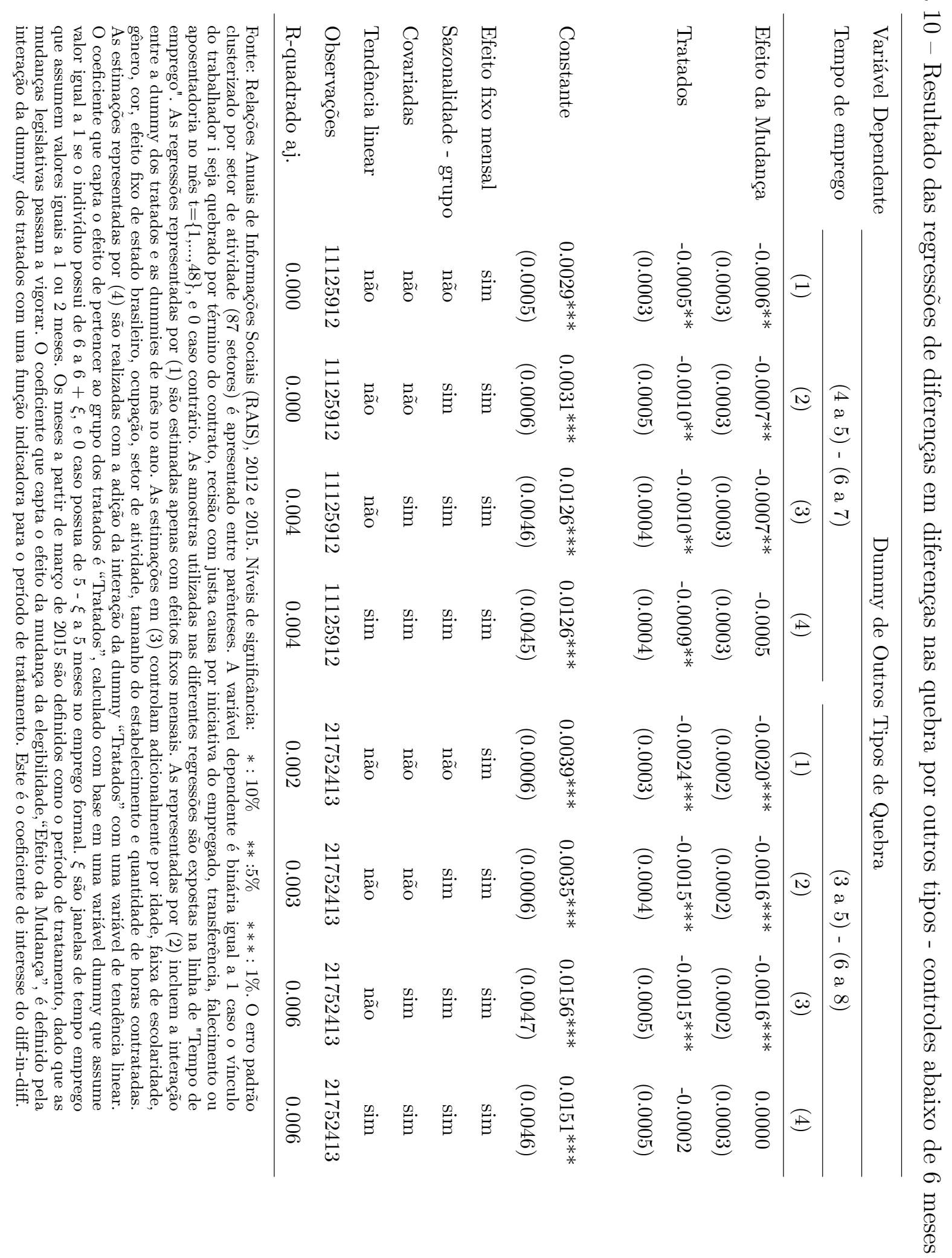




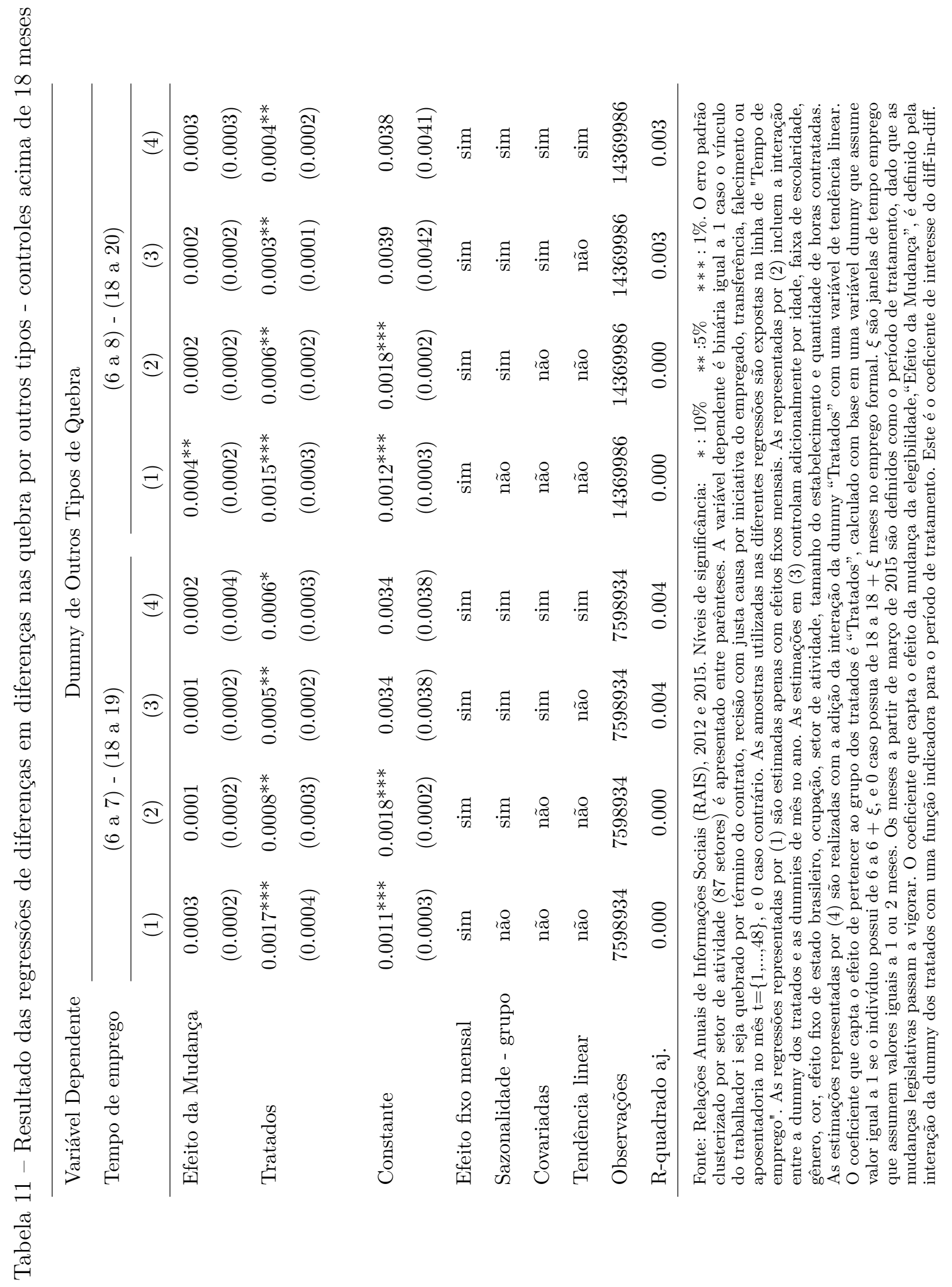


outros motivos. A partir da análise das figuras 12, 13, 14 e 15² , é possível observar que os efeitos bimestrais não são significantes para o período após a vigorção da MP665.

A partir dos resultados dos testes de falseamento realizados, é possível concluir que os efeitos das alterações legislativas nas demissões sem justa causa não são observados nos demais tipos de quebra dos vínculos. Os coeficientes estimados do modelo mais completo, com tedência linear, não são significantes nas estimações para os dois grupos de controle considerados independentemente da janela de tempo de emprego utilizada, 1 ou 2 meses.

Figura 12 - Gráfico dos coeficientes para o grupo dos tratados, 6 a 7 meses, e grupo dos controles, 4 a 5 meses - Demissão com justa causa

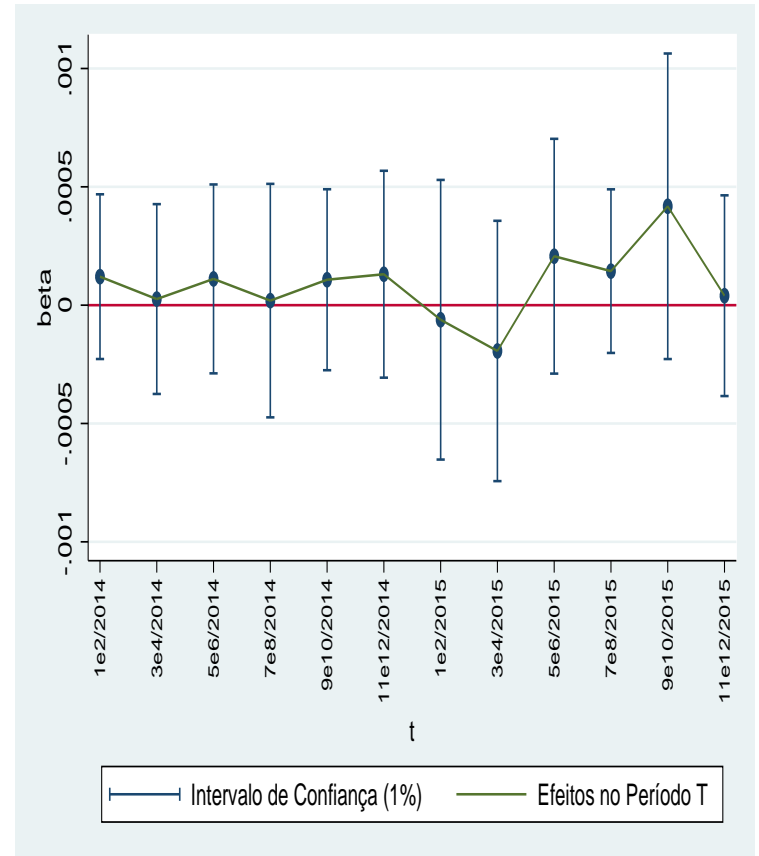

Figura 13 - Gráfico dos coeficientes para o grupo dos tratados, 6 a 7 meses, e grupo dos controles, 18 a 19 meses - Demissão com justa causa

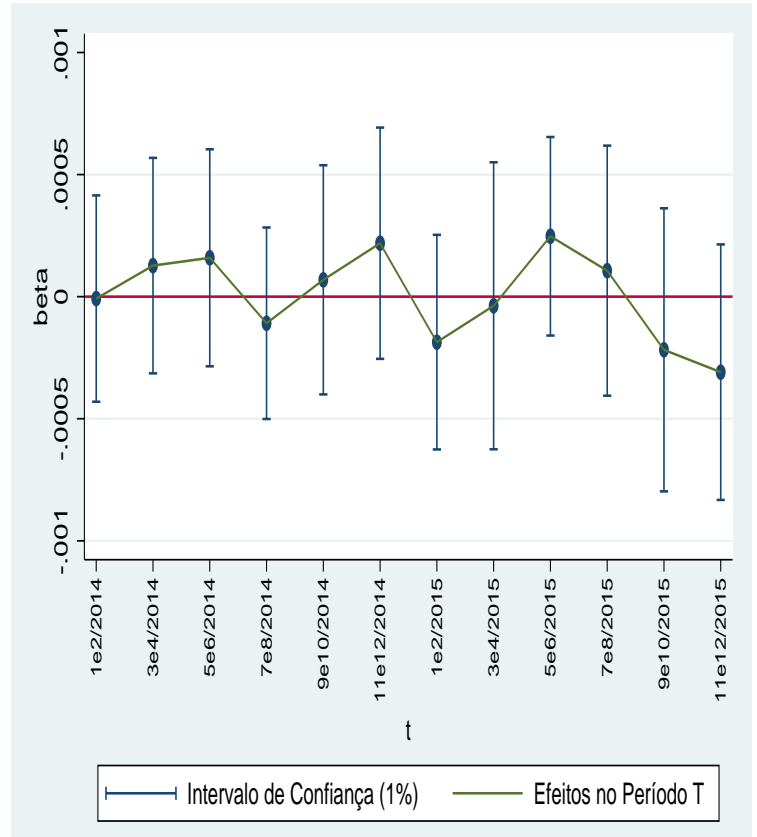

Utilizando a RAIS dos anos de 2012 até 2015, estima-se (5.1) para as demissões com justa causa. As interações são estimadas para todos os bimestres de 2014 e 2015 e plotadas na figura junto com o intervalo de confiança de $1 \%$.

Além dos testes de falseamento, para confimar que os resultados são válidos, é necessário verificar se os padrões observados nas demissões sem justa causa, no período pós-alterações, são similares aos observados em anos em que a política não estava em vigor. Dessa forma, são realizados testes placebos que simulam a aplicação das mudanças para períodos anteriores à real modificação.

As tabelas 12 e 13 apresentam as estimações que simulam separadamente a mudança nos critérios de elegibilidade para março de 2013 e 2014. O tratamento é considerado a partir do mês em que a mudança simulada até dezembro de 2014. O ano de 2015 é excluído da análise por ser o período em que as alterações legislativas ocorreram de fato.

$\overline{4}$ As regressões estão contidas nas tabelas $31,32,33$ e 34 no Apêndice B. 
Figura 14 - Gráfico dos coeficientes para o grupo dos tratados, 6 a 7 meses, e grupo dos controles, 4 a 5 meses - Outros tipos de quebra de vínculo

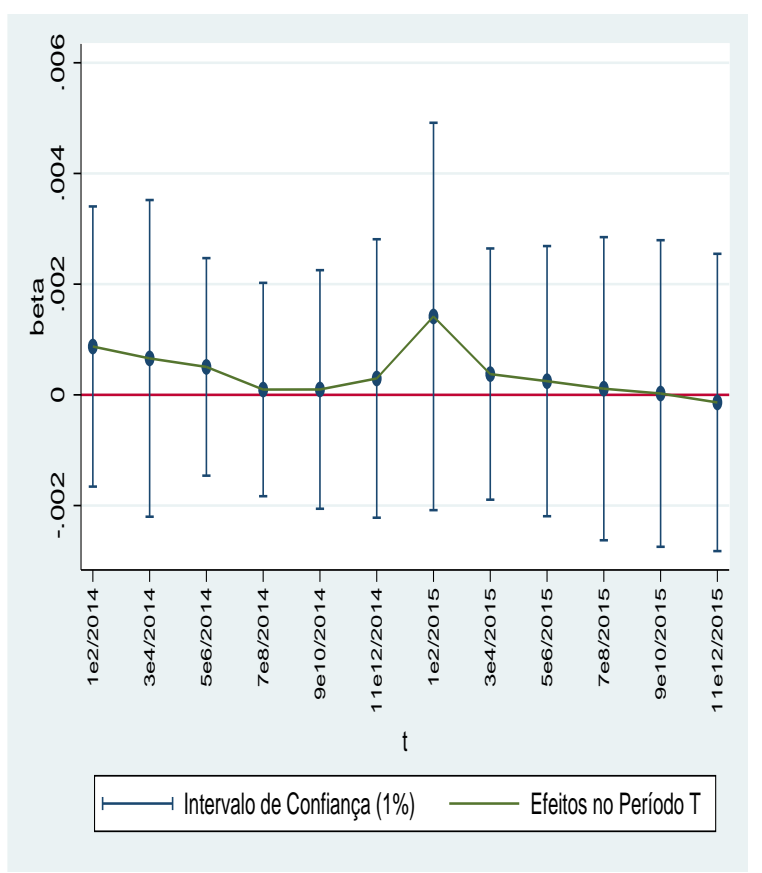

Figura 15 - Gráfico dos coeficientes para o grupo dos tratados, 6 a 7 meses, e grupo dos controles, 18 a 19 meses - Outros tipos de quebra de vínculo

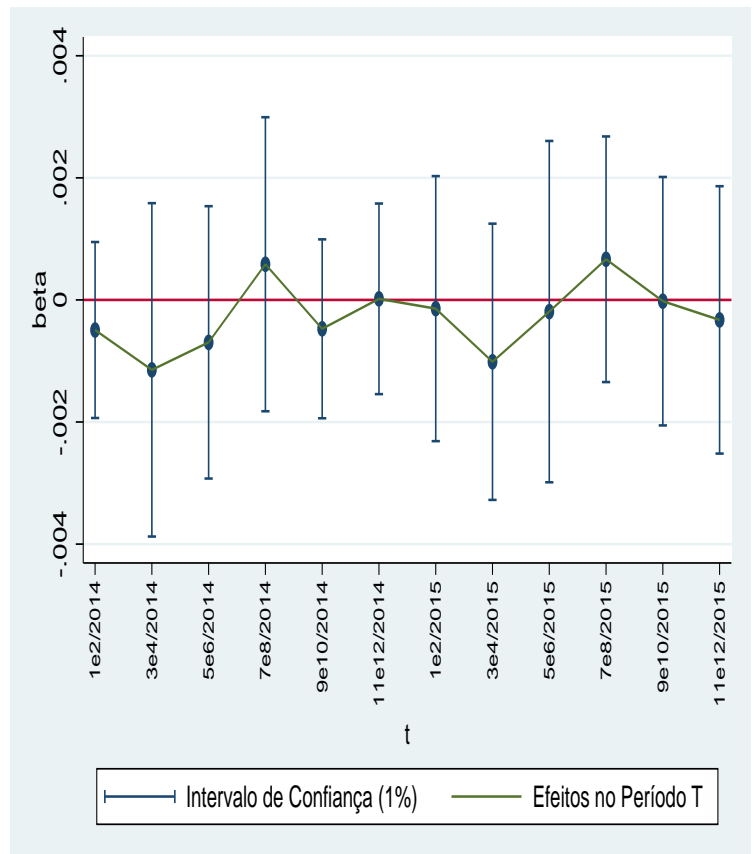

Utilizando a RAIS dos anos de 2012 até 2015, estima-se (5.1) para outros tipos de quebra de vínculo que englobam término de contrato, recisão com justa causa por iniciativa do empregado, transferência, falecimento ou aposentadoria. As interações são estimadas para todos os bimestres de 2014 e 2015 e plotadas na figura junto com o intervalo de confiança de $1 \%$.

Adicionalmente, as regressões são apresentadas apenas para a janela de um mês de tempo de emprego, considerando os dois grupos de controles.

Analisando os coeficiente dos efeitos simulados, nota-se que, para o ano de 2014, estes são insignificantes. Entretanto, o mesmo não ocorre para o ano de 2013, de modo que o coeficiente é negativo e significante a 5\%. O teste somente é rejeitado quando tendência linear é incluída no modelo, padrão que diverge do observado para o período após a MP665 entrar em vigor. Conclui-se, portanto, que é improvável que o efeito calculado para 2015 seja decorrente de algum padrão pré-existente das demissões sem justa causa no mercado de trabalho formal brasileiro.

\subsection{Robustez}

Alguns aspectos são importantes na análise dos efeitos das alterações legislativas, MP665 e Lei 13.134, sobre as demissões sem justa causa. Caso os efeitos encontrados sejam causados pela mudança da legislação, estes devem ser imunes a janela temporal utilizada. Uma análise de robustez é realizada diminuindo a janela temporal na verificação do efeito. 


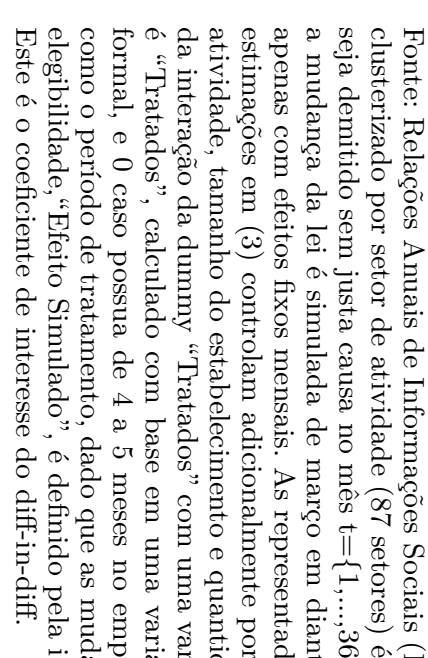

E.

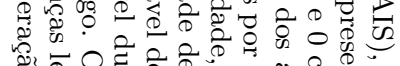

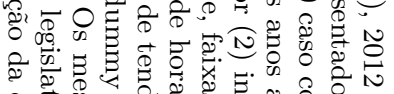

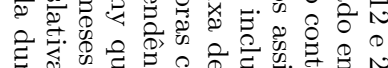

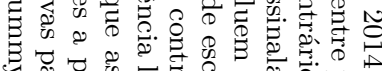

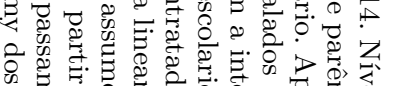
\& 20 \% 邪.

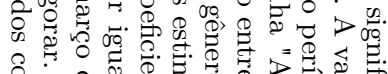
В 08 \%

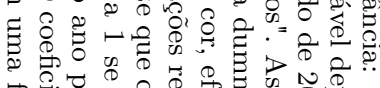
䒠密.

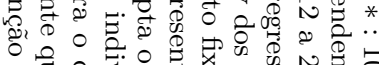
.

:

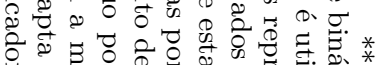

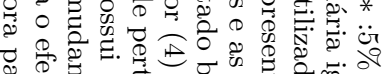

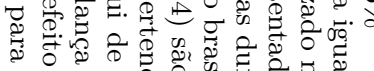
(2.) $0.0 \%$

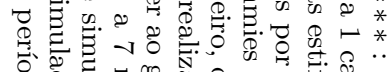

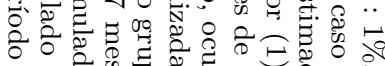

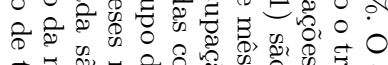

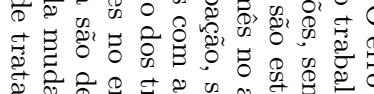

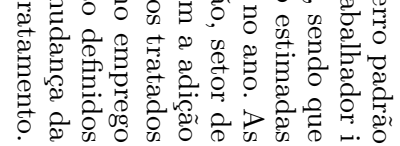

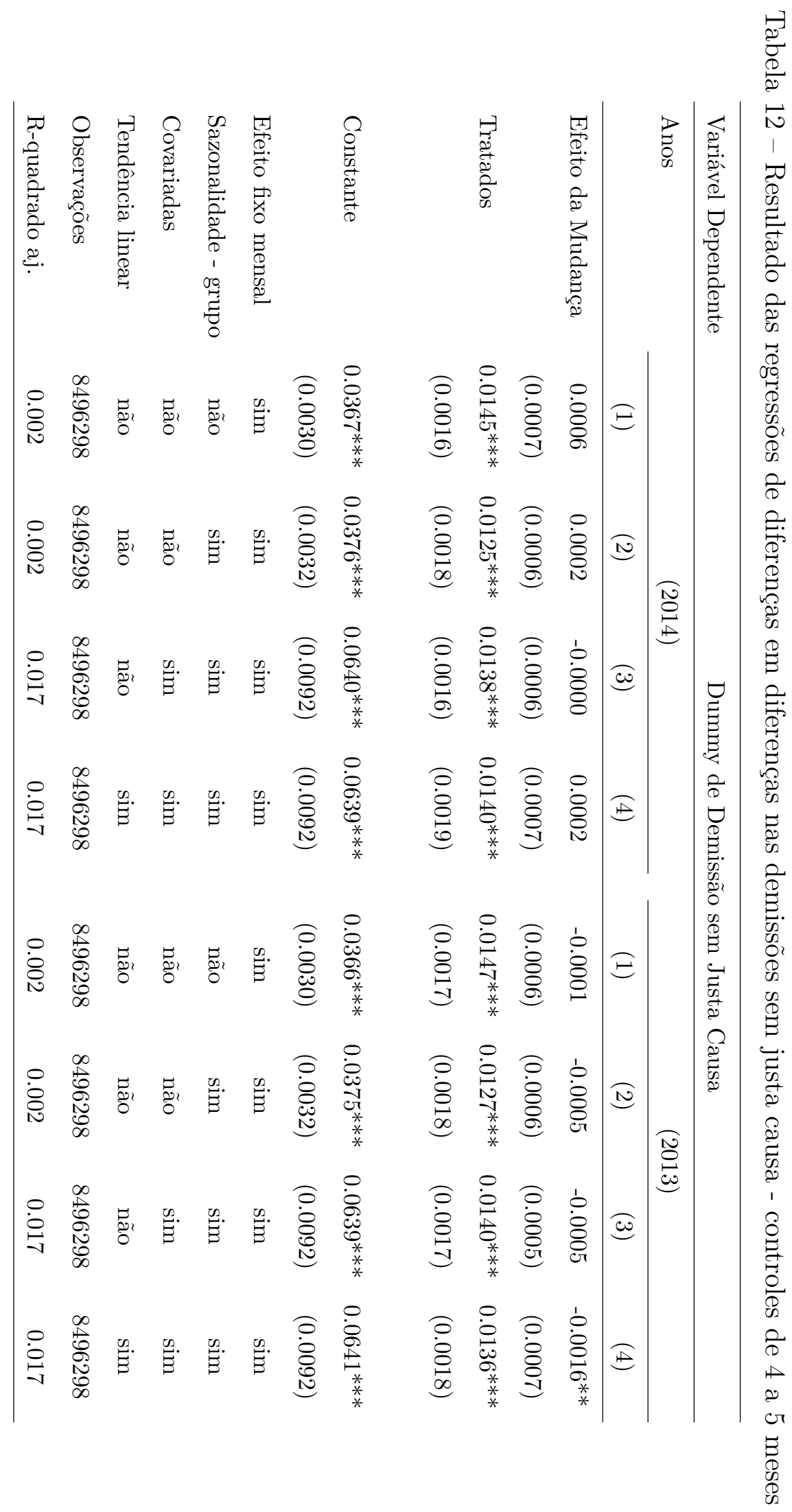




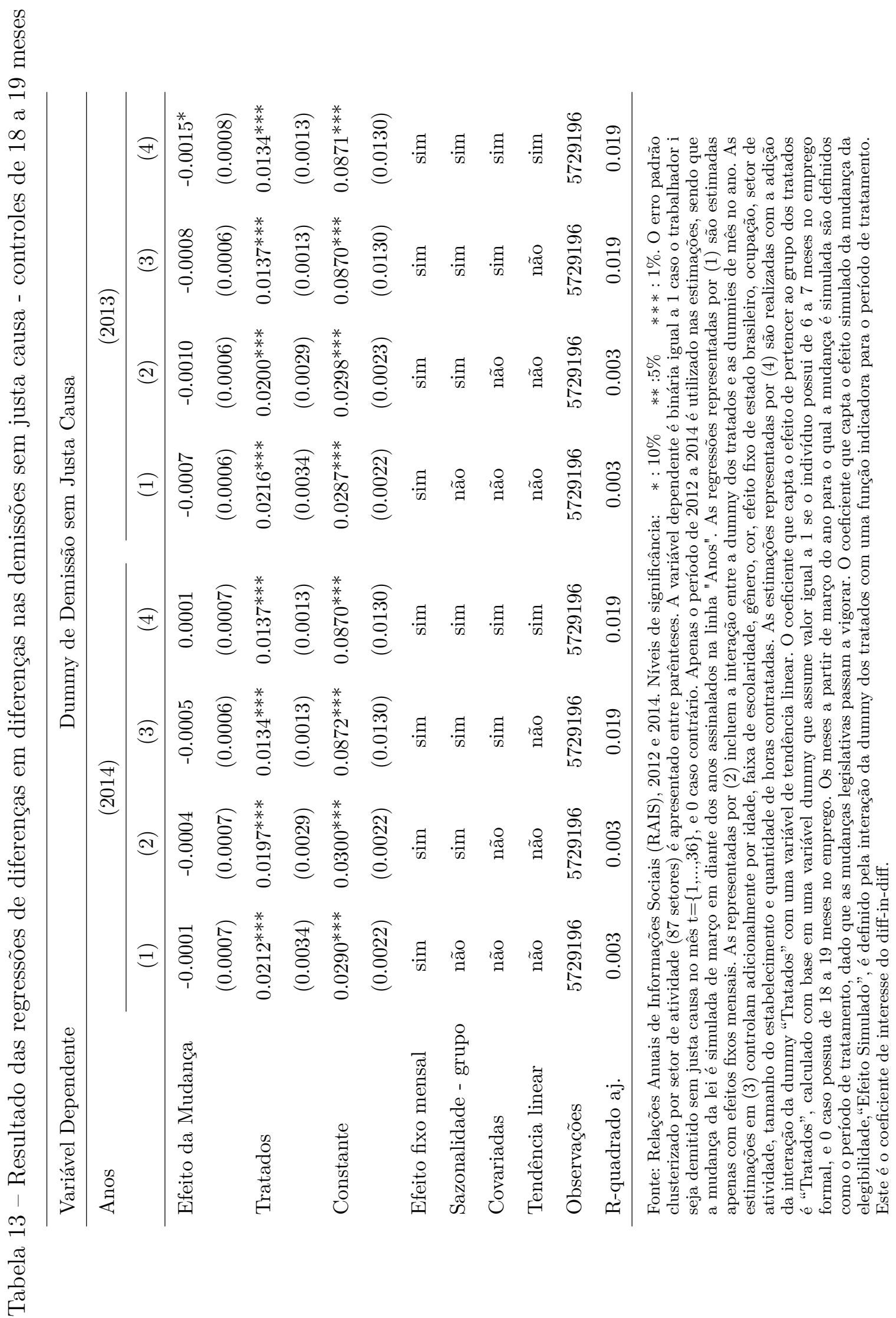


Utiliza-se apenas dois meses como janela temporal, sendo o mês de fevereiro de 2015 o período pré tratamento; e, março de 2015, o período pós tratamento. Dessa forma, a definição dos grupos com base no tempo de emprego não permite que, neste exercício, a promulgação da MP665 determine a escolha de entrada dos indivíduos no emprego formal, dado que eles já estavam empregados no momento.

As estimações utilizando apenas dois meses de janela temporal são apresentadas na tabela 14. Analisando os coeficiente estimados é possível notar que os efeitos encontrados diminuem ao reduzir a análise para apenas dois meses. A magnitude dos coeficientes é menor que a encontrada para a especificação principal, utilizando dados de 2012 a 2015, porém os coeficientes continuam com sinal negativo e são significantes.

Ao restringir para apenas dois meses os períodos considerados na análise, é necessário verificar que os resultados encontrados não são fruto de variações sazonais que afetam de modo distinto os grupos dos controles e dos tratados. Caso os fatores sazonais sejam determinantes na análise, espera-se que o mesmo efeito seja encontrado utilizando os meses de fevereiro e março dos anos anteriores às alterações dos critérios de elegibilidade ao seguro-desemprego.

As tabelas 15 e 16 apresentam os resultados das estimações replicadas para os anos anteriores às mudanças legislativas, utilizando como controles os indivíduos abaixo de 6 meses e acima de 18 como grupo de controle, respectivamente. As estimações são realizadas apenas para a janela de um mês de tempo de emprego. Nota-se que os padrões encontados para 2015 não são visualizados para os anos anteriores, de modo que é possível descartar que os resultados são determinados por fatores sazonais.

Adicionalmente, outra análise de robustez é possível com base no modo como as alterações legislativas foram implementadas. A mudança na legislação modificou a elegibilidade de forma distinta para os diferentes acessos ao seguro-desemprego. O tempo mínimo de emprego necessário para acessar o benefício passou a ser maior para os indivíduos que nunca acessaram o seguro-desemprego anteriormente. Entretanto, para os trabalhadores que já receberam o benefício por pelo menos três vezes, o tempo mínimo não foi alterado (tabela 1). Logo, espera-se uma redução maior na probabilidade de demissão sem justa causa para os indivíduos que nunca receberam o seguro.

Apesar de não ter informações sobre qual o requerimento em que o indivíduo se encontra, é possível, através das variáveis contidas na RAIS, saber o tipo de admissão para os empregados admitidos. Dentre os tipo de admissão, observa-se os indivíduos que foram admitidos em primeiro emprego, sendo que é possível inferir que, caso venham acessar o seguro-desemprego, estarão no primeiro requerimento. Entretanto, as informações sobre o modo de admissão somente estão disponíveis para os indivíduos no ano em que são admitidos. Por exemplo, no ano de 2015 não é possível saber o tipo de admissão dos empregados admitidos em 2014. Isso acontece porque não possuímos um identificador dos 


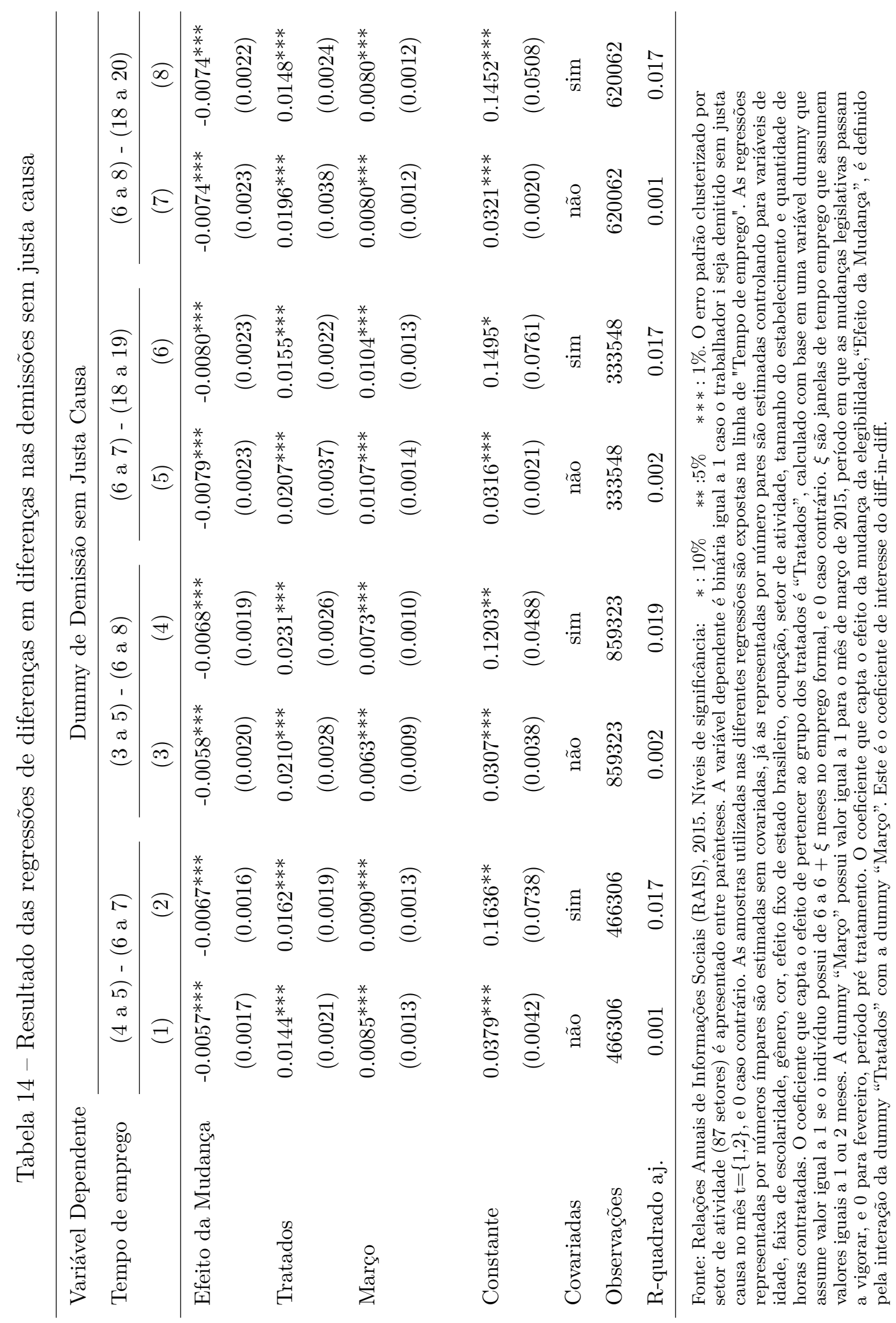




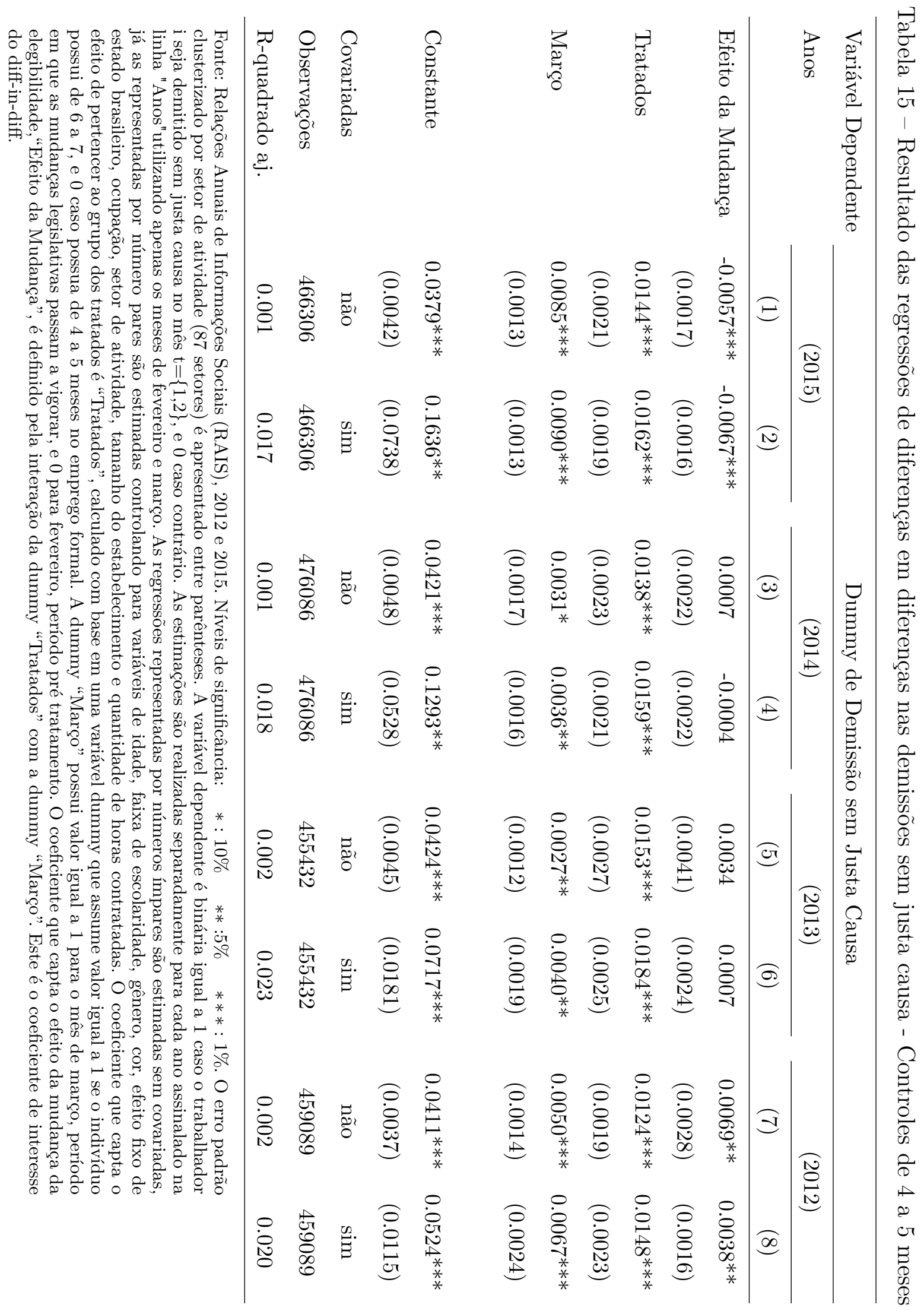




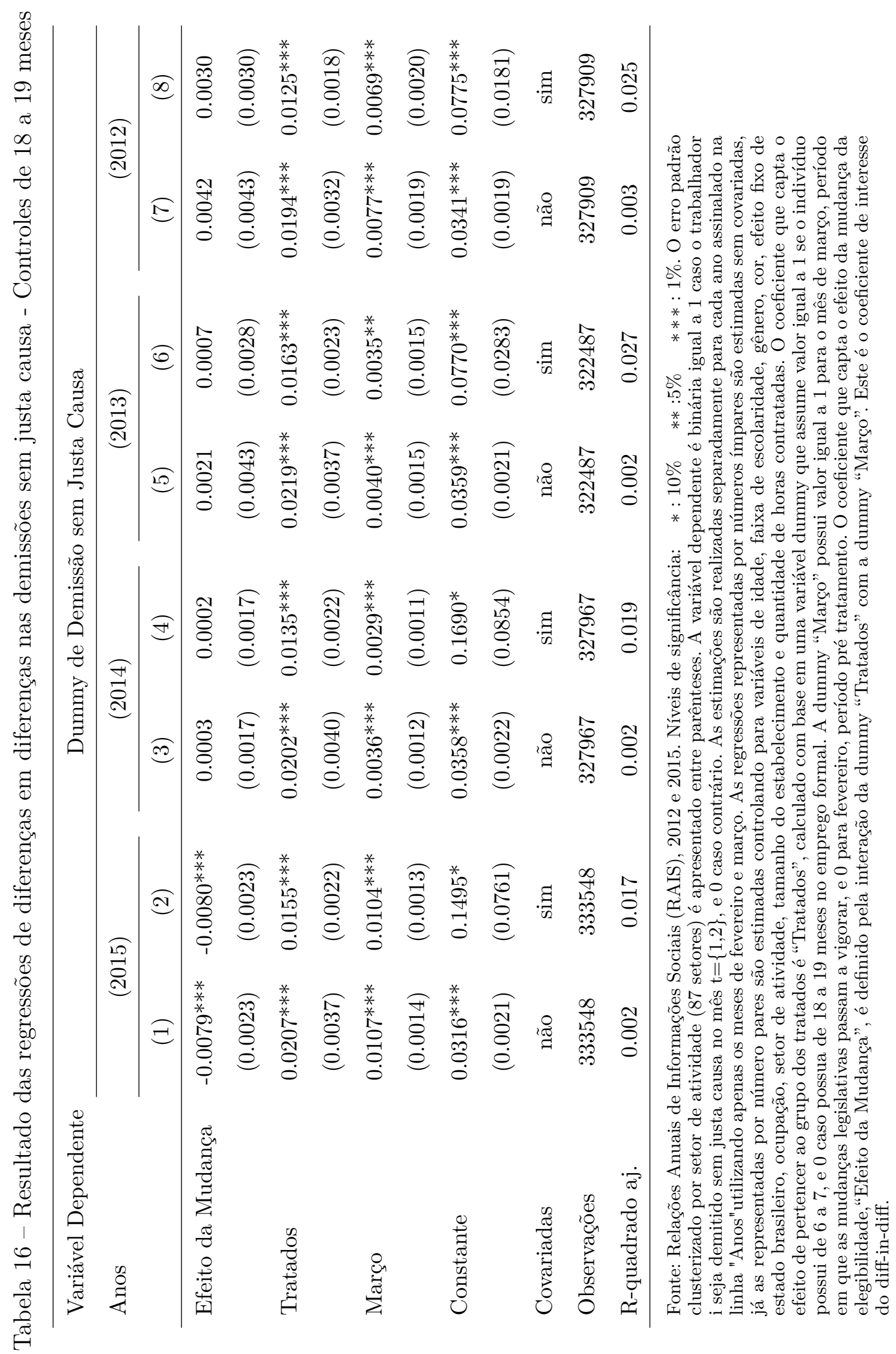


mesmos indivíduos ano a ano.

As estimações utilizadas para a análise de robustez no tipo de admissão são apresentadas na tabela 17. Os resultados são apresentados utilizando como grupo de controle os indivíduos com tempo de emprego de 4 a 5 meses no formal; e, como tratados, os indivíduos de 6 a 7 meses no formal. Tendo em vista que a informação de tipo de admissão somente está disponível para os admitidos no ano, a análise somente pode ser realizada utilizando os meses de agosto a dezembro de todos os anos. Os efeitos encontrados são maiores para os indivíduos que estão em seu primeiro emprego, as alterações legislativas diminuem em aproximadamente $24 \%$ a probabilidade de demissão dos que eram elegíveis ao seguro-desemprego. Em contrapartida, este número é de $15 \%$ para os trabalhadores admitidos em reemprego. Os resultados estão de acordo com o argumentado, sendo que os indivíduos no primeiro emprego são os mais afetados pelos novos critérios de elegibilidade.

\subsection{Heterogeneidade}

Para melhor compreender os efeitos da alteração dos critérios de elegibilidade sobre os fluxos no mercado de trabalho formal, é necessário realizar algumas análises de heterogeneidade. A princípio, é possível observar como os impactos da lei variam de acordo com o tamanho da firma na qual o trabalhador está empregado. Segundo Cardoso e Lage (2007), as inspeções dos fiscais do trabalho são direcionadas a observar o seguimento das normas nas firmas formais, e podem ser ocasionadas por denúncias anônimas. Dessa forma, é provável que a probabilidade da firma ser inspecionada aumente de acordo com o número de empregados desta.

Por terem uma probabilidade maior de inspeção, os acordos entre firmas e trabalhadores para demissão sem justa causa seriam mais custosos para as firmas maiores. As firmas com muitos empregados não conseguem deixar de pagar os valores da multa do FGTS e do aviso prévio. Além disso, após a demissão, os incentivos para recontratar os empregados sem carteira de trabalho são menores, sendo que a probabilidade de detecção é maior para essas firmas. Logo, espera-se que os efeitos das alteração nos critérios de elegibilidade sejam menores para as firmas que possuem um número maior de empregados.

As estimações foram realizadas de forma que os efeitos das alterações legislativas pudessem variar de acordo com o tamanho da firma. Foram considerados 4 tipos de empresas de acordo com o número de empregados, são eles: firmas de até 9 empregados, de 10 a 49, de 50 a 249, e acima de 249 empregados. Um das limitações é que a variável que define o número de trabalhadores das firmas é calculada posteriormente, 31 de dezembro do ano analisado, de forma que algumas firmas possuem 0 trabalhadores. Dessa forma, essa variável pode não estar livre dos efeitos da lei.

As tabelas 18 e 19 apresentam os efeitos da mudança na legislação de acordo com 


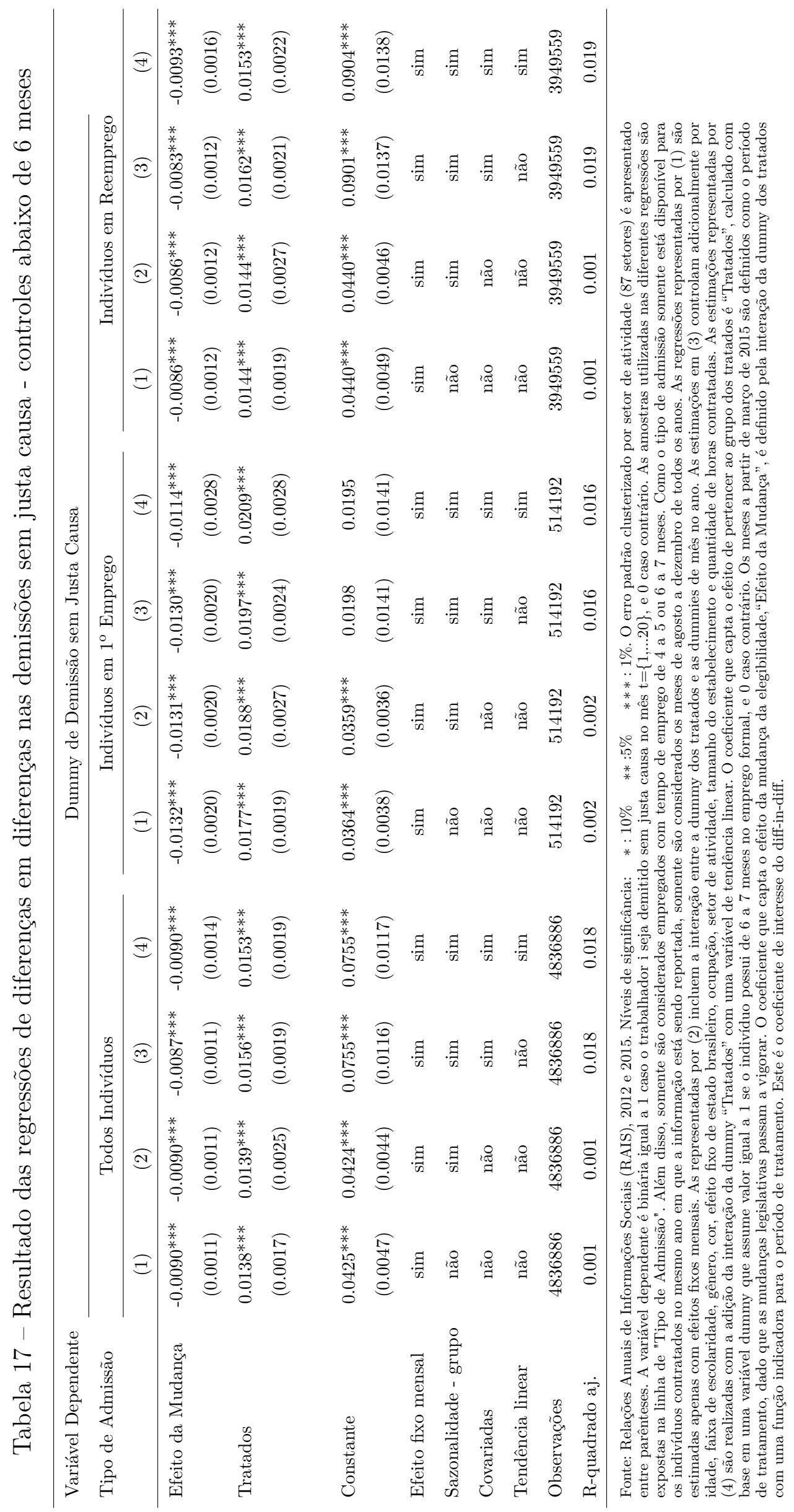


os diferentes tamanhos de firmas. As estimações são realizadas para os diferentes grupos e janelas de tempo de emprego. O grupo definido como base são os indivíduos que estavam ocupados em fimas com até 9 empregados. Logo, os efeitos totais para as firmas maiores são calculados ao somar as interações com o "Efeito da Mudança". A partir da análise dos coeficientes das interações estimados, nota-se que os efeitos são menores para as firmas maiores, ou seja, a probabilidade de demissão diminui menos no período após as alterações legislativas. Por serem mais propensas a serem fiscalizadas, os acordos são relativamente menos importantes para firmas maiores.

Além das heterogeneidades inerentes às firmas, também é possível analisar os efeitos heterogêneos nos indivíduos da mudança nos critérios de elegibilidade. A legislação do seguro-desemprego institui taxas de reposição diferentes de acordo com o salário recebido pelo empregado nos períodos anteriores a sua demissão. O valor das parcelas pagas varia do salário mínimo até um teto estipulado. Assim, a taxa de reposição é decrescente no salário dos trabalhadores, sendo $100 \%$ para quem recebe o salário mínimo. Desse modo, quanto menor o salário do indivíduo, maior o seu incentivo a entrar em algum tipo de acordo para ser demitido.

A variável de salários, entretanto, não pode ser incluída no modelo. As alterações na regra do seguro-desemprego podem de algum modo ter afetado as remunerações pagas no emprego formal. Neste caso, controlar por essa seria utilizar um mau controle, dado que essa seria uma variável de resultado da política. Para contornar esse problema, é possível utilizar a variável de escolaridade como uma aproximação para os salários recebidos. O grau de instrução dos trabalhadores é positivamente correlacionado com seus salários. Logo, espera-se que, para os indivíduos mais escolarizados, os efeitos da mudança na regra do seguro-desemprego sejam menores.

As tabelas 20 e 21 apresentam os efeitos da mudança na legislação de acordo com as diferentes faixas de escolaridade. As estimações são realizadas para os diferentes grupos e janelas de tempo de emprego. O grupo definido como base são os indivíduos que possuem até o ensino fundamental incompleto. Logo, os efeitos totais para as outras faixas de escolaridade são calculados ao somar as interações com o "Efeito da Mudança". A partir da análise dos coeficientes das interações estimados, nota-se que os efeitos são menores para as os indivíduos que possuem maior escolaridade. Os coeficiente são positivos e crescentes na escolaridade. O efeito da mudança nos critérios de elegibilidade é menor para os indíduos mais escolarizados, pois os incentivos para acordos são fracos devido à baixa taxa de reposição do seguro-desemprego para este grupo.

Por fim, a baixa qualidade dos postos de trabalho podem afetar a probabilidade de firmas e empregados entrarem em acordos para a demissão sem justa causa. Os acordos são mais atrativos para os empregados de postos de trabalho que não permitem ascensão salarial. Dessa forma, é possível que os efeitos das mudanças legislativas sejam heterogêneas 
nos setores de atividade econômica. Espera-se que atividade com menor complexidade do serviço sejam mais afetadas pelas alterações do seguro-desemprego.

As estimações do efeito da mudança para os diferentes setores são apresentadas nas tabelas 22 e 23. Os resultados são apresentados para os diferentes grupos e janelas de tempo de emprego. Trabalhadores dos setores da agropecuária, pesca, água, gestão e resíduos e descontaminação são utilizados como base. A partir da análise dos coeficientes estimados, é possível verificar que esses são positivos para todos os setores considerados em relação ao grupo base. O efeito das alterações são consistentementes menores para os indivíduos empregados nos setores de serviços e indústria, sendo que a magnitude dos coeficientes estimados para esses é similar. Os custos comportamentais são mais preponderantes nos setores da agropecuária, pesca, água, gestão e resíduos e descontaminação; construção e comércio. 


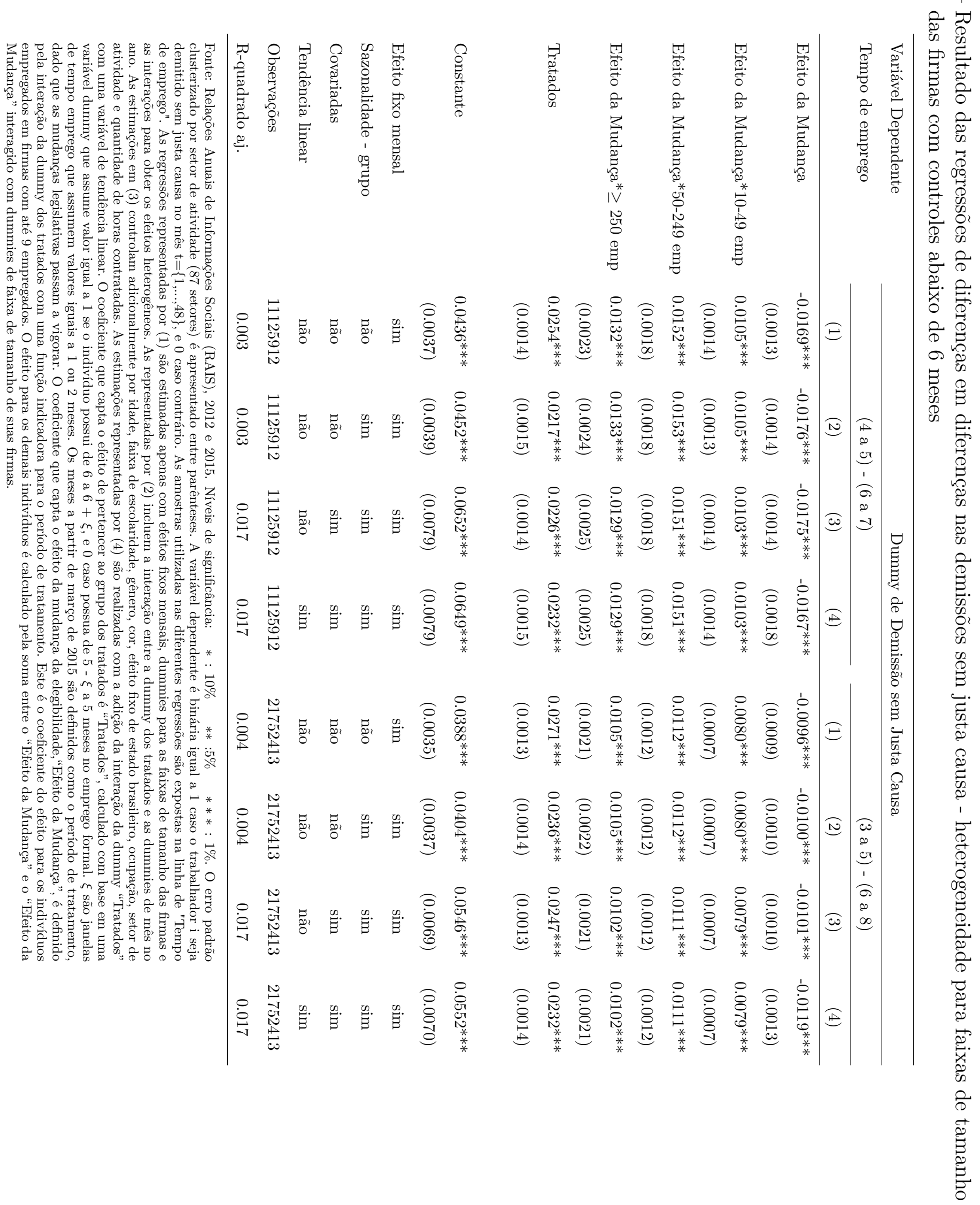




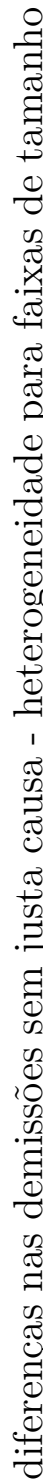

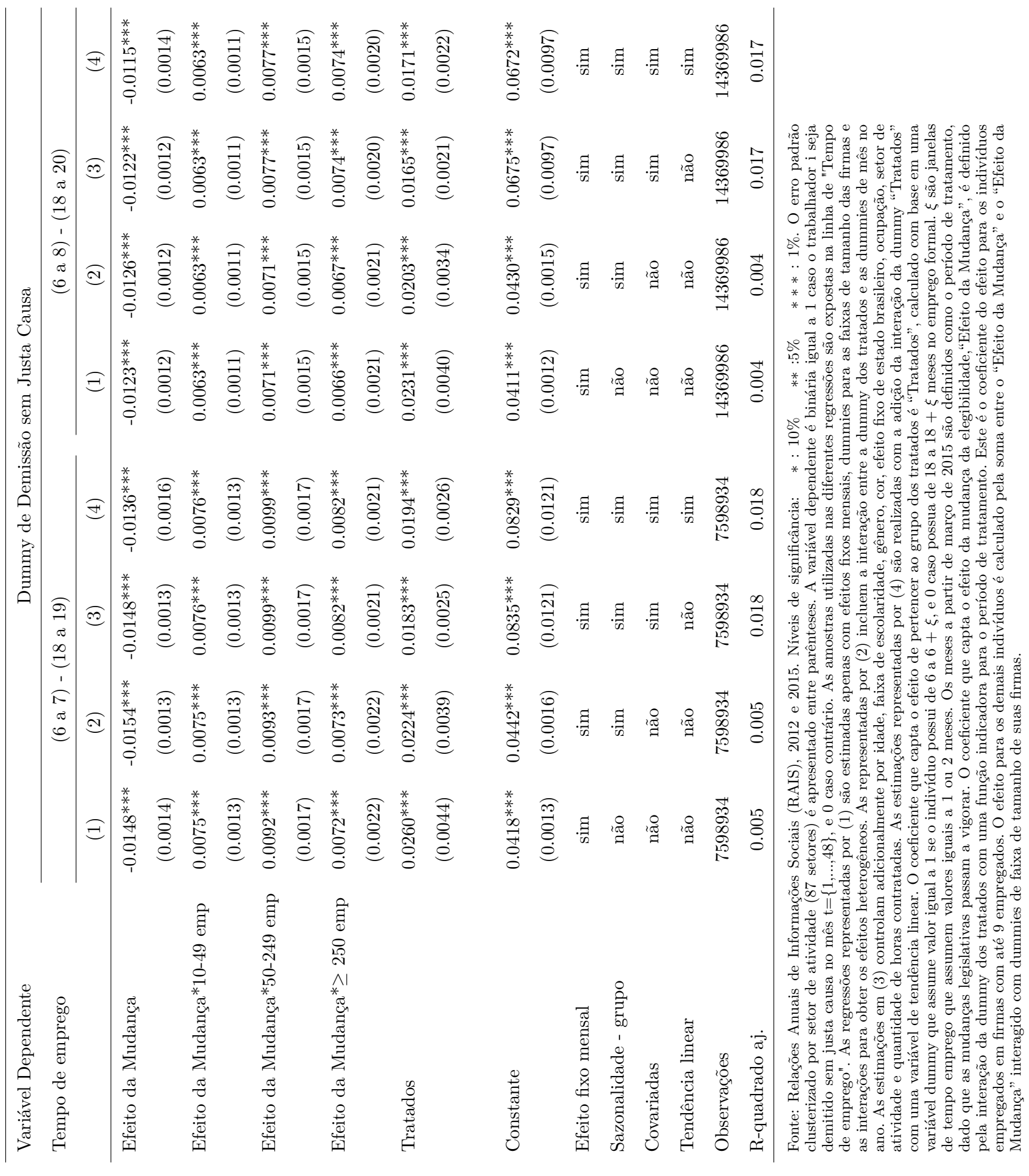




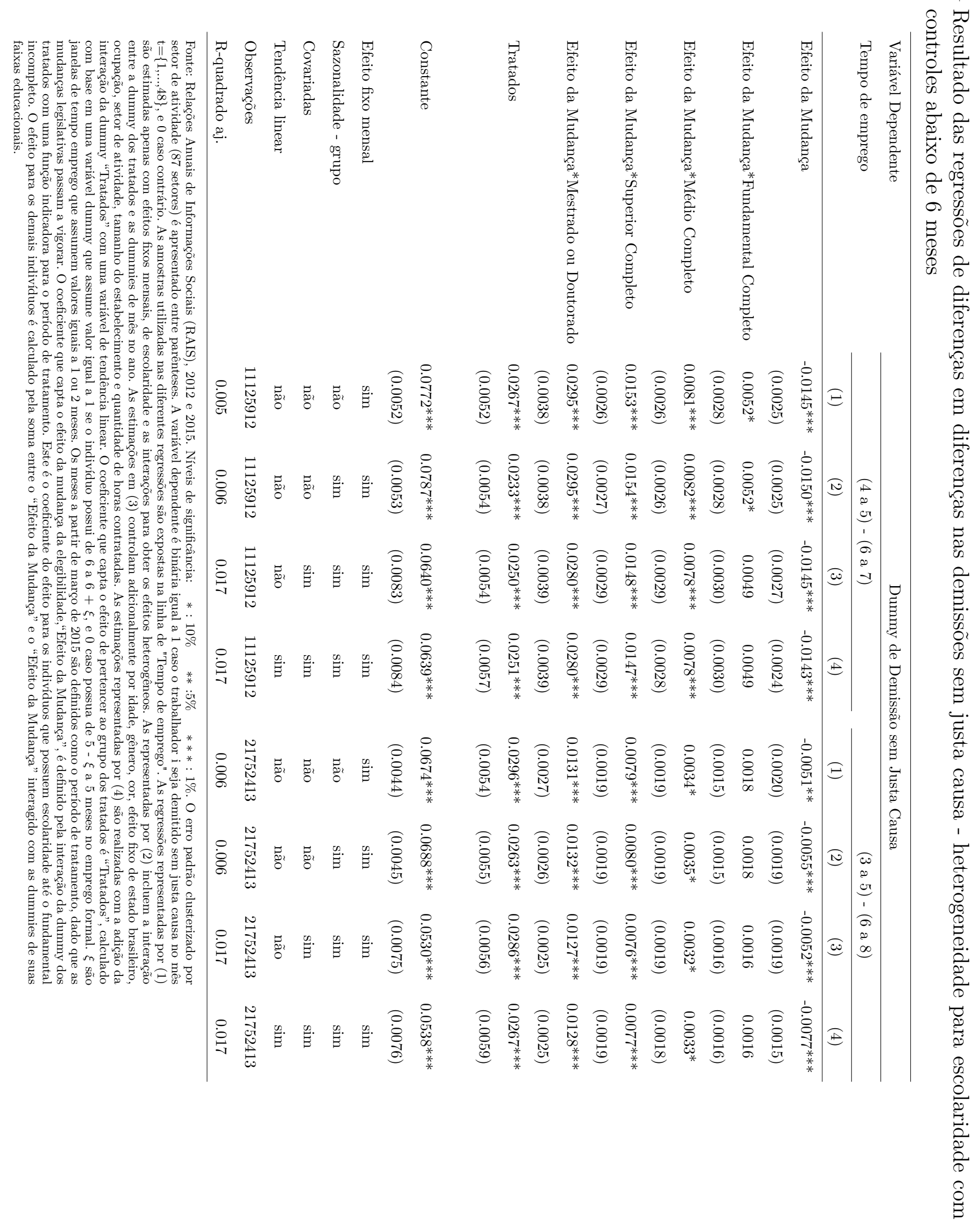




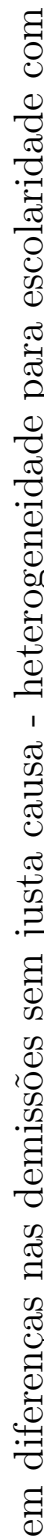

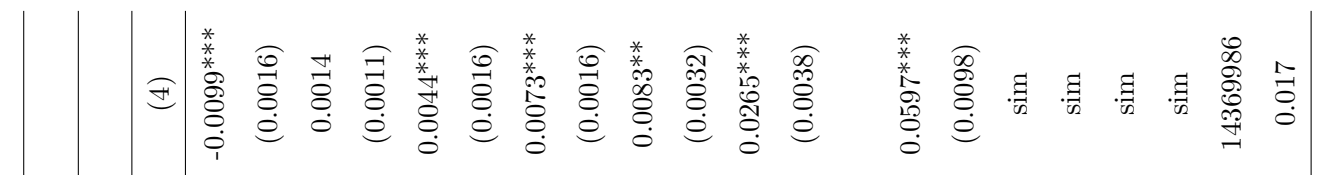

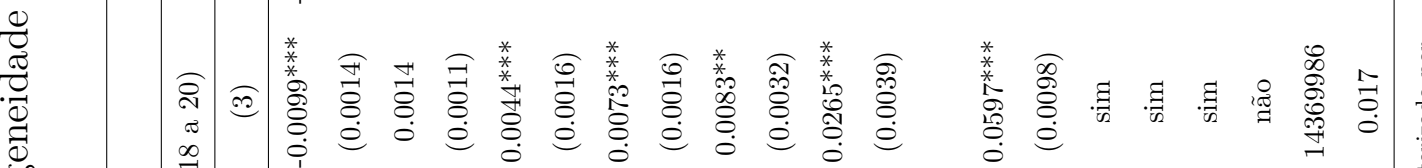

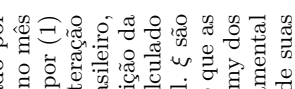

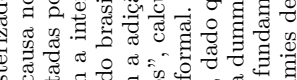

का

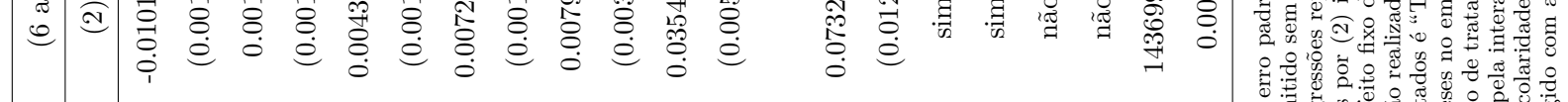

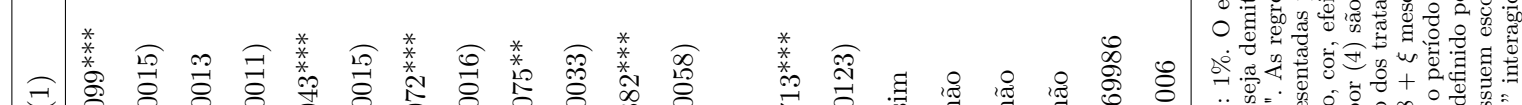

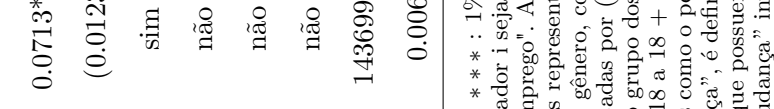

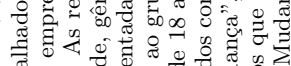
*

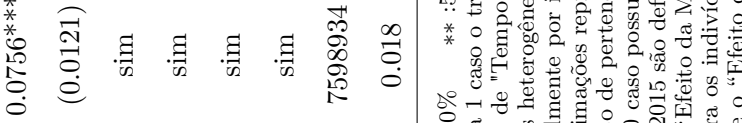

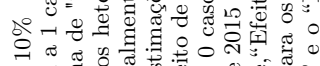

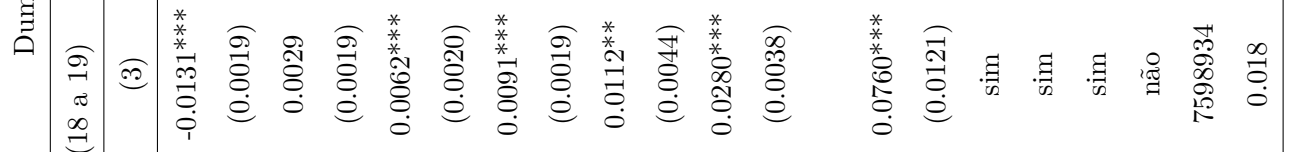
.

త్ర

o

ปै

io

80

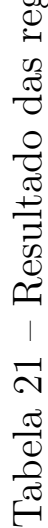




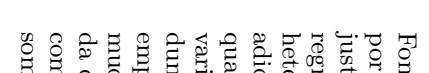

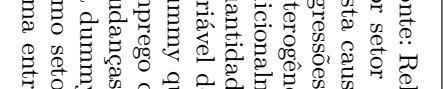

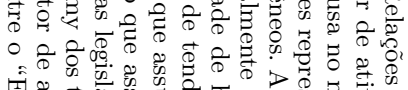

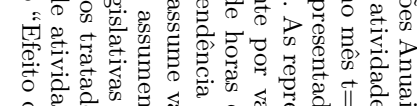
के

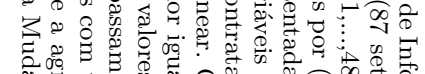

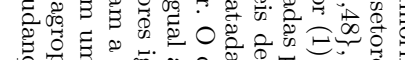

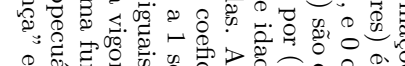

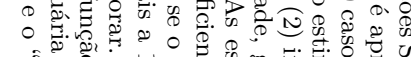

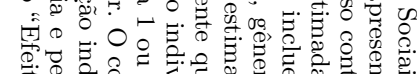

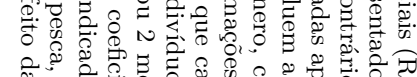

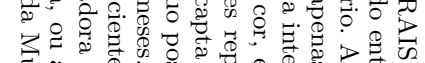

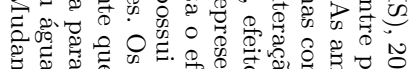

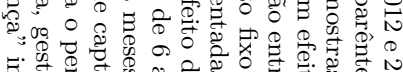

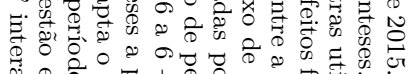

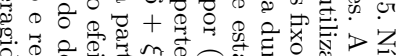

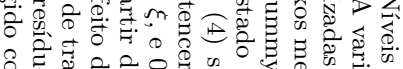

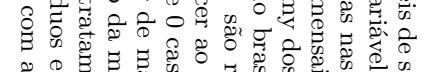

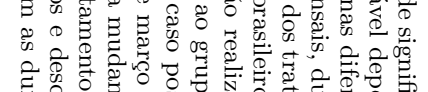
ᄋำ D.

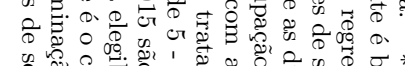

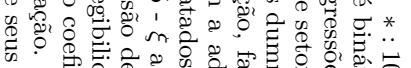

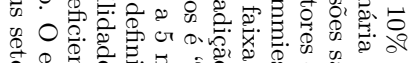

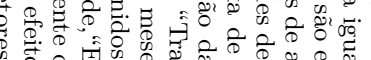
० ₹

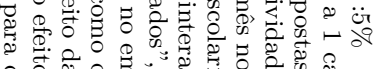

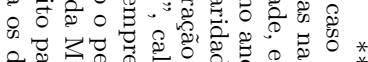
बै

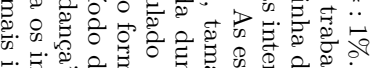
政:

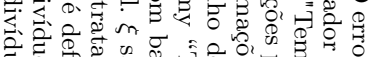

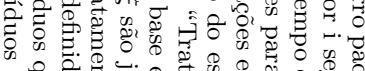

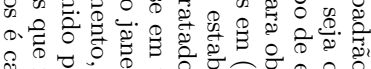

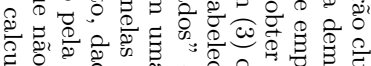

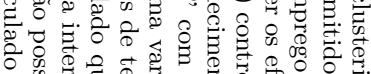

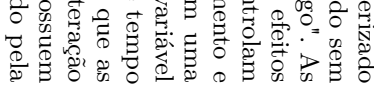

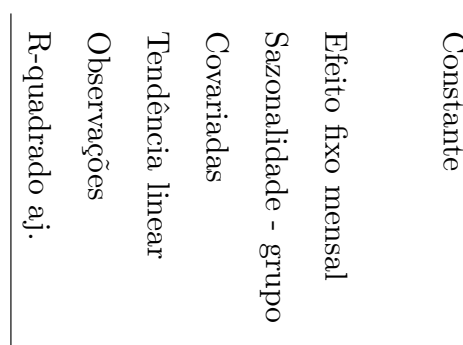

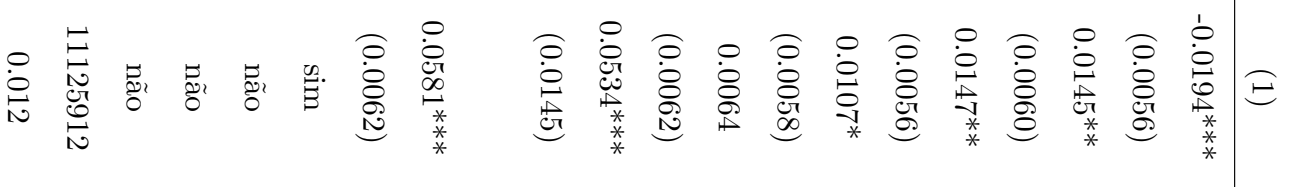

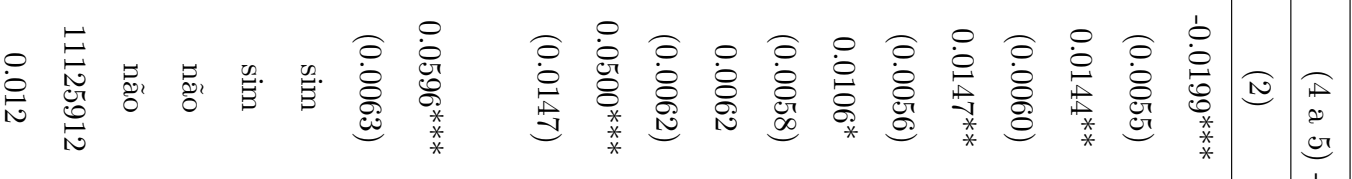

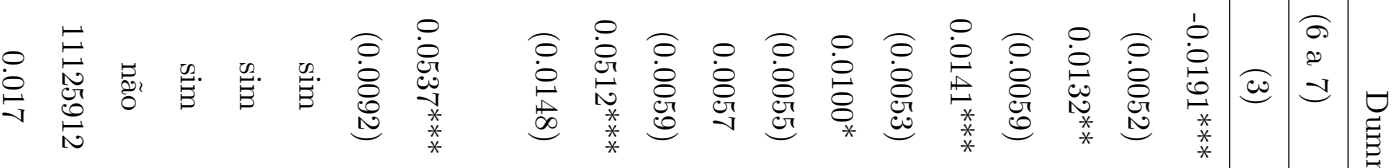

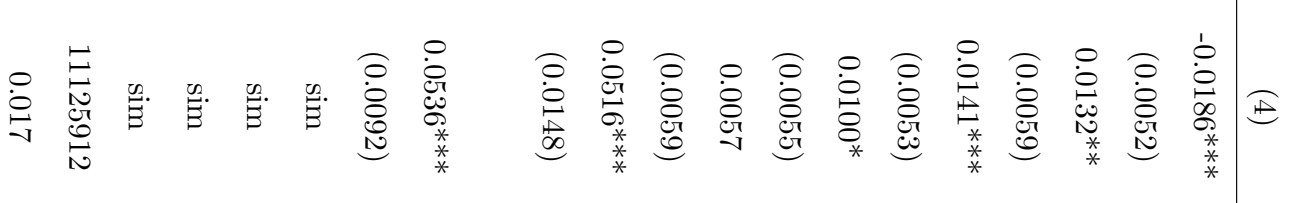

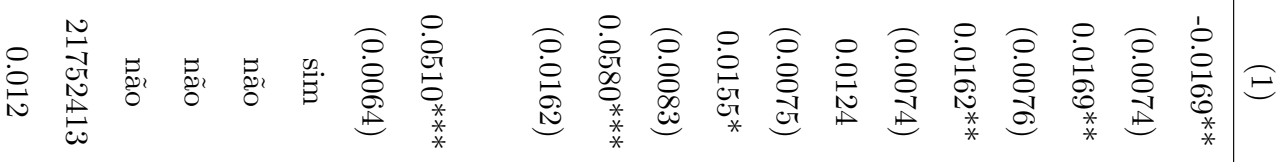

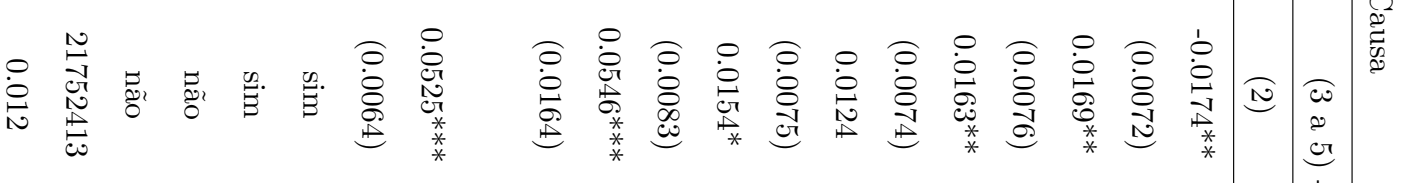

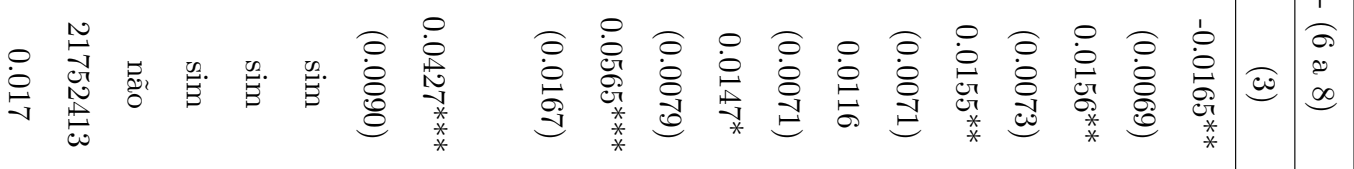

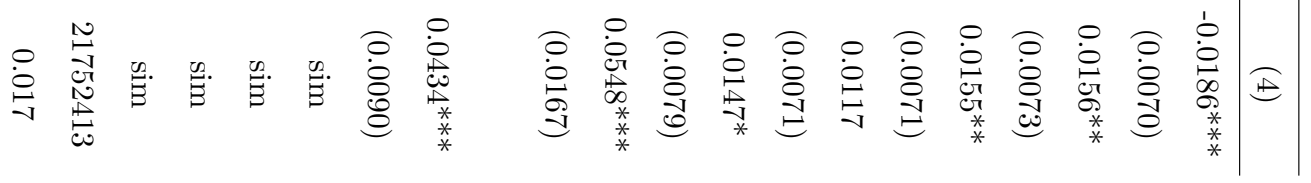





\section{Resultados com a PME}

Para obter uma análise completa, após concluir que a elegibilidade ao segurodesemprego impacta as demissões sem justa causa, utiliza-se a Pesquisa Mensal do Emprego (PME) para verificar o destino do trabalhor deslocado do mercado de trabalho formal. Apesar de não ser realizada uma análise de bem estar, parte-se do pressuposto de que a necessidade de ser segurado varia de acordo com a realocação do trabalhador. Dessa forma, faz-se necessário distinguir entre os indivíduos que vão para a inatividade, para o desemprego e para o setor informal. Assumimos forma similar à equação 4.1:

$$
y_{i, t}=\delta \cdot L_{t \geq \text { março de } 2015} \cdot T_{i}+\lambda \cdot T_{i}+\mu_{t}+\gamma \cdot T_{i} \cdot \text { Mês }+\beta \cdot X_{i, t-1}+\varepsilon_{i, t}
$$

onde $y_{i, t}$ é uma variável binária igual a 1 caso o trabalhador i seja formal em t-1 e deixe o setor formal em $\mathrm{t}=\{1, \ldots, 48\}$, e 0 caso permaneça no setor formal em t. A variável $y_{i, t}$ é desagregada em saída para inatividade, para o desemprego e para o informal (trabalhador sem carteira e conta própria). $T_{i}$ é uma variável binária igual a 1 se o indivíduo pertence ao grupo dos tratados que é definido por: tempo de emprego ${ }_{i, t-1}(\mathrm{em}$ meses $)=6 . T_{i}$ assume valor igual a 0 se o indivíduo possui: tempo de emprego $\operatorname{eg}_{i, t-1}=3^{1} \cdot X_{i, t-1}$ é um grupo de covariadas em t-1, quando o indivíduo está no emprego formal, que controla para idade, faixa de escolaridade, gênero, cor, região metropolitana, ocupação, setor de atividade, tamanho do estabelecimento e número da entrevista no domicílio, e $\varepsilon_{i, t}$ é um termo de erro idiossincrático. Note que os indivíduos contidos na amostra devem ser observados por ao menos dois períodos subsequentes, t-1 e t, e devem ser formais em t-1. As estimações são realizadas utilizando peso amostral.

A partir da análise dos resultados das estimações apresentadas na tabela 24, notase que os padrões verificados se assemelham aos encontrados na regressão principal que utiliza a RAIS. Os indivíduos que deixam de ser elegíveis ao seguro-desemprego saem menos do emprego formal comparativamente aos que se mantêm inelegíveis após a vigoração da MP665. Ao decompor a variável de saída do formal, percebe-se que a queda nas saídas para o setor informal corresponde a parte expressiva do efeito. Considerando que as estimações realizadas permitem isolar o efeito das alterações legislativas, pode-se afirmar que $34 \%$ das demissões causadas pelo seguro-desemprego são de indivíduos que se inserem no setor informal no mês subsequente. Entretanto, dois pontos devem ser considerados. Parte-se do pressuposto de que a queda nas saídas do formal é derivada da queda nas

1 Ao contrário da RAIS, na PME o aviso prévio indenizado não é contabilizado no tempo de emprego. Logo, o tempo de emprego na demissão pode variar de 3 a 5 meses para os controles e de 6 a 8 meses para os tratados. Caso seja demitido logo após a semana de referência em t-1 e cumpra o aviso prévio trabalho, terá o tempo mínimo. Caso seja demitido próximo a semana de referência t e cumpra o aviso prévio indenizado, terá o tempo máximo da janela denifida. 
demissões sem justa causa, porém esta informação não está disponível ${ }^{2}$. Além disso, os coeficientes não possuem significância estatística, o que pode ser atribuído a relativa baixa amostra, aproximadamente 380 indivíduos a cada mês.

Tabela 24 - Resultado das regressões de diferenças em diferenças nas saídas do setor formal - Controles com 3 meses e tratados com 6 em t-1

\begin{tabular}{|c|c|c|c|c|}
\hline \multirow{2}{*}{$\begin{array}{l}\text { Tempo de Emprego } \\
\text { Variável Dependente }\end{array}$} & \multicolumn{4}{|c|}{ Controles com 3 e tratados com 6 meses no emprego formal em t-1 } \\
\hline & $\begin{array}{l}\text { Dummy de saída do Formal } \\
(1)\end{array}$ & $\begin{array}{l}\text { Dummy de Desocupados } \\
(2)\end{array}$ & $\begin{array}{c}\text { Dummy de Inativos } \\
(3)\end{array}$ & $\begin{array}{c}\text { Dummy de Informal } \\
\text { (4) }\end{array}$ \\
\hline Efeito da Mudança & $\begin{array}{l}-0.0236 \\
(0.0147)\end{array}$ & $\begin{array}{c}-0.0080 \\
(0.0078)\end{array}$ & $\begin{array}{c}-0.0074 \\
(0.0088)\end{array}$ & $\begin{array}{l}-0.0080 \\
(0.0095)\end{array}$ \\
\hline Tratados & $\begin{array}{l}-0.0184 \\
(0.0249)\end{array}$ & $\begin{array}{l}-0.0031 \\
(0.0113)\end{array}$ & $\begin{array}{l}-0.0244 \\
(0.0160)\end{array}$ & $\begin{array}{c}0.0034 \\
(0.0170)\end{array}$ \\
\hline Constante & $\begin{array}{l}-0.0858 \\
(0.0809)\end{array}$ & $\begin{array}{l}-0.0210 \\
(0.0277)\end{array}$ & $\begin{array}{l}-0.0837 \\
(0.0603)\end{array}$ & $\begin{array}{c}0.0091 \\
(0.0453)\end{array}$ \\
\hline Efeito fixo mensal & $\operatorname{sim}$ & $\operatorname{sim}$ & $\operatorname{sim}$ & $\operatorname{sim}$ \\
\hline Sazonalidade - grupo & $\operatorname{sim}$ & $\operatorname{sim}$ & $\operatorname{sim}$ & $\operatorname{sim}$ \\
\hline Covariadas & $\operatorname{sim}$ & $\operatorname{sim}$ & $\operatorname{sim}$ & $\operatorname{sim}$ \\
\hline Observações & 18324 & 18324 & 18324 & 18324 \\
\hline R-quadrado aj. & 0.014 & 0.005 & 0.009 & 0.012 \\
\hline $\begin{array}{l}\text { Fonte: Pesquisa Mensal de } \mathrm{F} \\
\text { entre parênteses. A variável } \\
\mathrm{i} \text {, formal em t-1, deixe o se } \\
\text { trabalhador i, formal em t-1 } \\
\text { formal em t-1, esteja inativo } \\
\text { sem carteira ou como contr } \\
\text { Todas as regressões control } \\
\text { controlam adicionalmente } \mathrm{p} \\
\text { atividade, tamanho do estal } \\
\text { capta o efeito de pertencer } \\
\text { possui } 6 \text { meses no emprego } \\
\text { o período de tratamento, de } \\
\text { Mudança", é definido pela i } \\
\text { do diff-in-diff. }\end{array}$ & 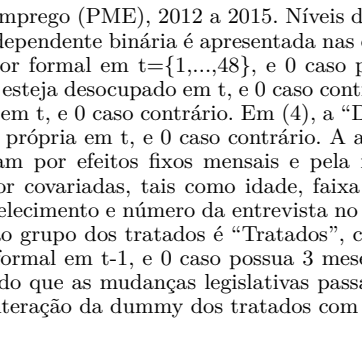 & $\begin{array}{l}\text { significância: } *: 10 \% * * * 5 \% \\
\text { olunas. Em (1), a variável "Dumm } \\
\text { ermaneça no formal. Na coluna (2 } \\
\text { ário. A variável "Dummy de Inativ } \\
\text { ummy de Informal" é igual a } 1 \text { cas } \\
\text { mostra utilizada nas diferentes reg } \\
\text { nteração entre a dummy dos trat } \\
\text { de escolaridade, gênero, cor, efeit } \\
\text { domicílio. Todas covariadas são ref } \\
\text { lculado com base em uma variáve } \\
\text { s no emprego formal em t-1. Os m } \\
\text { m a vigorar. O coeficiente que cap } \\
\text { uma função indicadora para o perí }\end{array}$ & $\begin{array}{l}\text { ***: } 1 \% \text {. O erro padrã } \\
\text { de saída do Formal" é igua } \\
\text {, a "Dummy de Desocupa } \\
\text { os" utilizada em (3) é igual } \\
\text { o trabalhador i, formal em } \\
\text { essões é exposta na linha d } \\
\text { ados e as dummies de mês } \\
\text { fixo de região metropolita } \\
\text { antes ao emprego formal e } \\
\text { dummy que assume valor } \\
\text { eses a partir de março de } 2 \\
\text { ta o efeito da mudança da } \\
\text { do de tratamento. Este é o }\end{array}$ & $\begin{array}{l}\text { robusto é apresentado } \\
1 \text { a } 1 \text { caso o trabalhador } \\
\text { dos" é igual a } 1 \text { caso o } \\
1 \text { caso o trabalhador i, } \\
\text { t-1, esteja trabalhando } \\
\text { e "Tempo de emprego". } \\
\text { no ano. As regressões } \\
\text { na, ocupação, setor de } \\
\text { m t- } 1 \text {. O coeficiente que } \\
\text { gual a } 1 \text { se o indivíduo } \\
015 \text { são definidos como } \\
\text { elegibilidade,"Efeito da } \\
\text { coeficiente de interesse }\end{array}$ \\
\hline
\end{tabular}

Para além da especificação principal, as tabelas 25 e 26 apresentam os resultados das estimações por efeitos heterogêneos de escolaridade e tamanho da firma. A partir da análise dos coeficientes, nota-se que o peso da saída para o setor informal é maior para os indivíduos menos escolarizados e em firmas menores. Tal resultado é condizente com o encontrado nas estimações realizadas utilizando a RAIS, para o qual a queda na demissão sem justa causa é maior para esses grupos. Note que a saída para o setor informal somente é significante para os indivíduos menos escolarizados. No Apêndice C, o mesmo exercício é realizado para trabalhadores informais em t-1, porém, sem verificar a mesma relação. Conclui-se, portanto, que parte dos indivíduos deslocados do emprego formal devido à existência do seguro-desemprego se empregam no setor informal.

2 A PME pergunta aos indivíduos desocupados e inativos qual foi o motivo do encerramento do último emprego, sendo que uma das opções é demissão, porém não é possível verificar se foi sem justa causa. Adicionalmente, esta pergunta não é realizada para os indivíduos ocupados. Logo, não é possível saber se os indivíduos empregados no informal foram demitidos no último emprego. 
Tabela 25 - Resultado das regressões de diferenças em diferenças nas saídas do setor formal - Controles com 3 meses e tratados com 6 em t-1 - Heterogeneidade de escolaridade

\begin{tabular}{|c|c|c|c|c|}
\hline \multirow{2}{*}{$\begin{array}{l}\text { Tempo de Emprego } \\
\text { Variável Dependente }\end{array}$} & \multicolumn{4}{|c|}{ Controles com 3 e tratados com 6 meses no emprego formal em t-1 } \\
\hline & $\begin{array}{l}\text { Dummy de saída do Formal } \\
\text { (1) }\end{array}$ & $\begin{array}{c}\text { Dummy de Desocupados } \\
(2)\end{array}$ & $\begin{array}{c}\text { Dummy de Inativos } \\
\text { (3) }\end{array}$ & $\begin{array}{c}\text { Dummy de Informa } \\
\text { (4) }\end{array}$ \\
\hline Efeito da Mudança & $\begin{array}{l}-0.0405 \\
(0.0263)\end{array}$ & $\begin{array}{l}-0.0023 \\
(0.0151)\end{array}$ & $\begin{array}{c}0.0011 \\
(0.0152)\end{array}$ & $\begin{array}{c}-0.0380^{* *} \\
(0.0173)\end{array}$ \\
\hline Efeito Mudança* $\geq 11$ anos de estudo & $\begin{array}{c}0.0247 \\
(0.0314)\end{array}$ & $\begin{array}{l}-0.0084 \\
(0.0173)\end{array}$ & $\begin{array}{l}-0.0125 \\
(0.0185)\end{array}$ & $\begin{array}{l}0.0439^{* *} \\
(0.0206)\end{array}$ \\
\hline Tratados & $\begin{array}{l}-0.0103 \\
(0.0260)\end{array}$ & $\begin{array}{l}-0.0065 \\
(0.0119)\end{array}$ & $\begin{array}{l}-0.0254 \\
(0.0164)\end{array}$ & $\begin{array}{c}0.0154 \\
(0.0182)\end{array}$ \\
\hline Constante & $\begin{array}{l}-0.0855 \\
(0.0808)\end{array}$ & $\begin{array}{l}-0.0210 \\
(0.0276)\end{array}$ & $\begin{array}{l}-0.0861 \\
(0.0608)\end{array}$ & $\begin{array}{c}0.0121 \\
(0.0450)\end{array}$ \\
\hline Efeito fixo mensal & $\operatorname{sim}$ & $\operatorname{sim}$ & $\operatorname{sim}$ & $\operatorname{sim}$ \\
\hline Sazonalidade - grupo & $\operatorname{sim}$ & $\operatorname{sim}$ & $\operatorname{sim}$ & $\operatorname{sim}$ \\
\hline Covariadas & $\operatorname{sim}$ & $\operatorname{sim}$ & $\operatorname{sim}$ & $\operatorname{sim}$ \\
\hline Observações & 18324 & 18324 & 18324 & 18324 \\
\hline R-quadrado aj. & 0.014 & 0.005 & 0.009 & 0.013 \\
\hline \multicolumn{5}{|c|}{ 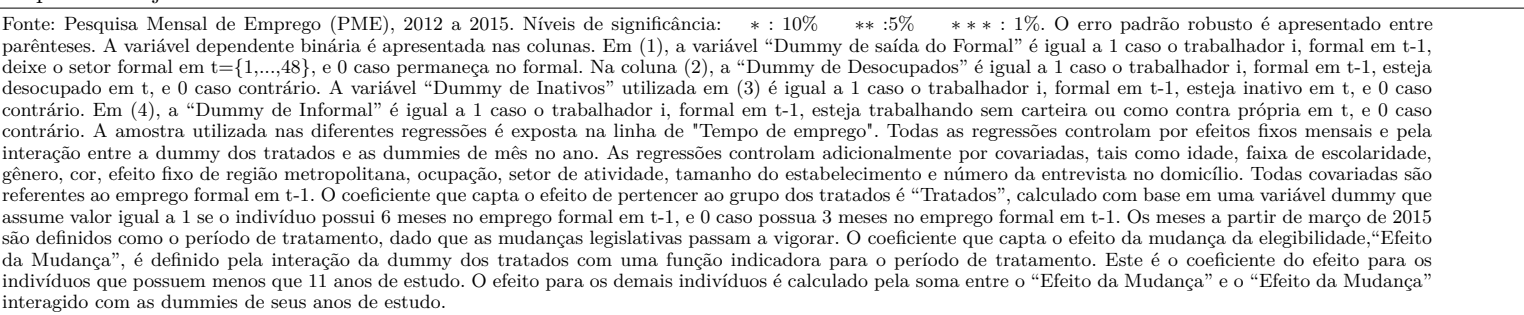 } \\
\hline
\end{tabular}

Tabela 26 - Resultado das regressões de diferenças em diferenças nas saídas do setor formal - Controles com 3 meses e tratados com 6 em t-1 - Heterogeneidade de tamanho da firma

\begin{tabular}{|c|c|c|c|c|}
\hline \multirow{2}{*}{$\begin{array}{l}\text { Tempo de Emprego } \\
\text { Variável Dependente }\end{array}$} & \multicolumn{4}{|c|}{ Controles com 3 e tratados com 6 meses no emprego formal em t-1 } \\
\hline & $\begin{array}{l}\text { Dummy de saída do Formal } \\
\text { (1) }\end{array}$ & $\begin{array}{c}\text { Dummy de Desocupados } \\
(2)\end{array}$ & $\begin{array}{c}\text { Dummy de Inativos } \\
\text { (3) }\end{array}$ & $\begin{array}{c}\text { Dummy de Informal } \\
\text { (4) }\end{array}$ \\
\hline Efeito da Mudança & $\begin{array}{l}-0.0197 \\
(0.0503)\end{array}$ & $\begin{array}{l}-0.0042 \\
(0.0273)\end{array}$ & $\begin{array}{c}0.0233 \\
(0.0226)\end{array}$ & $\begin{array}{l}-0.0524 \\
(0.0379)\end{array}$ \\
\hline Efeito Mudança* $\geq 11$ empregados & $\begin{array}{l}-0.0040 \\
(0.0524)\end{array}$ & $\begin{array}{l}-0.0041 \\
(0.0282)\end{array}$ & $\begin{array}{l}-0.0344 \\
(0.0244)\end{array}$ & $\begin{array}{c}0.0500 \\
(0.0391)\end{array}$ \\
\hline Tratados & $\begin{array}{l}-0.0348 \\
(0.0312)\end{array}$ & $\begin{array}{l}-0.0049 \\
(0.0128)\end{array}$ & $\begin{array}{l}-0.0280 \\
(0.0187)\end{array}$ & $\begin{array}{l}-0.0018 \\
(0.0227)\end{array}$ \\
\hline Constante & $\begin{array}{l}-0.0771 \\
(0.0813)\end{array}$ & $\begin{array}{l}-0.0205 \\
(0.0281)\end{array}$ & $\begin{array}{l}-0.0834 \\
(0.0604)\end{array}$ & $\begin{array}{c}0.0144 \\
(0.0456)\end{array}$ \\
\hline Efeito fixo mensal & $\operatorname{sim}$ & $\operatorname{sim}$ & $\operatorname{sim}$ & $\operatorname{sim}$ \\
\hline Sazonalidade - grupo & $\operatorname{sim}$ & $\operatorname{sim}$ & $\operatorname{sim}$ & $\operatorname{sim}$ \\
\hline Covariadas & $\operatorname{sim}$ & $\operatorname{sim}$ & $\operatorname{sim}$ & $\operatorname{sim}$ \\
\hline Observações & 18324 & 18324 & 18324 & 18324 \\
\hline R-quadrado aj. & 0.014 & 0.005 & 0.009 & 0.012 \\
\hline $\begin{array}{l}\text { Fonte: Pesquisa Mensal de Emprego (PME } \\
\text { parênteses. A variável dependente binária é } \\
\text { deixe o setor formal em } \mathrm{t}=\{1, \ldots, 48\} \text {, e } 0 \text { cas } \\
\text { desocupado em t, e } 0 \text { caso contrário. A vari } \\
\text { contrário. Em (4), a "Dummy de Informal" } \\
\text { contrário. A amostra utilizada nas diferente } \\
\text { interação entre a dummy dos tratados e as } \\
\text { gênero, cor, efeito fixo de região metropolita } \\
\text { referentes ao emprego formal em t-1. O coefic } \\
\text { assume valor igual a } 1 \text { se o indivíduo possui } \\
\text { são definidos como o período de tratamento, } \\
\text { da Mudança", é definido pela interação da } \\
\text { indivíduos que estão em firmas com menos } \\
\text { Mudança" interagido com as dummies de ta }\end{array}$ & $\begin{array}{l}2012 \text { a 2015. Níveis de significância } \\
\text { presentada nas colunas. Em (1), a var } \\
\text { permaneça no formal. Na coluna (2), } \\
\text { vel "Dummy de Inativos" utilizada er } \\
\text { é igual a } 1 \text { caso o trabalhador i, form } \\
\text { regressões é exposta na linha de "Te } \\
\text { ummies de mês no ano. As regressões } \\
\text { a, ocupação, setor de atividade, tama } \\
\text { ente que capta o efeito de pertencer ac } \\
\text { meses no emprego formal em t- } 1 \text {, e } 0 \\
\text { dado que as mudanças legislativas pas } \\
\text { lummy dos tratados com uma função } \\
\text { e } 11 \text { empregados. O efeito para os der } \\
\text { aanho de suas firmas. }\end{array}$ & $\begin{array}{l}*: 10 \% \quad * *: 5 \% \quad * * *: \\
\text { ável "Dummy de saída do Formal" } \\
\text { "Dummy de Desocupados" é igu } \\
\text { a (3) é igual a } 1 \text { caso o trabalhado } \\
\text { al em t-1, esteja trabalhando sem } \\
\text { mpo de emprego". Todas as regres } \\
\text { controlam adicionalmente por co } \\
\text { hho do estabelecimento e número } \\
\text { grupo dos tratados é "Tratados", } \\
\text { aso possua } 3 \text { meses no emprego fol } \\
\text { am a vigorar. O coeficiente que ca } \\
\text { indicadora para o período de tra } \\
\text { aais indivíduos é calculado pela so }\end{array}$ & $\begin{array}{l}\text { \%. O erro padrão robusto } \\
\text { é igual a } 1 \text { caso o trabalhac } \\
\text { l a } 1 \text { caso o trabalhador i, f } \\
\mathrm{r} \text { i, formal em t-1, esteja in } \\
\text { carteira ou como contra pro } \\
\text { sões controlam por efeitos } \\
\text { ariadas, tais como idade, fa } \\
\text { la entrevista no domicílio. T } \\
\text { calculado com base em uma } \\
\text { mal em t-1. Os meses a part } \\
\text { pta o efeito da mudança da } \\
\text { tamento. Este é o coeficien } \\
\text { ma entre o "Efeito da Muda }\end{array}$ & $\begin{array}{l}\text { é apresentado entre } \\
\text { lor i, formal em t-1, } \\
\text { ormal em t-1, esteja } \\
\text { ativo em t, e } 0 \text { caso } \\
\text { fpria em t, e } 0 \text { caso } \\
\text { fixos mensais e pela } \\
\text { ixa de escolaridade, } \\
\text { odas covariadas são } \\
\text { variável dummy que } \\
\text { ir de março de } 2015 \\
\text { elegibilidade,"Efeito } \\
\text { te do efeito para os } \\
\text { inça" e o "Efeito da }\end{array}$ \\
\hline
\end{tabular}





\section{Extensões do Trabalho}

Extensões desse trabalho podem analisar os efeitos da alteração nos critérios de elegibilidade do seguro-desemprego no retorno do trabalhador ao mercado de trabalho. O acesso à RAIS identificada permitirá uma análise mais completa das alterações legislativas como, por exemplo, analisar o tempo de retorno e o salário de reentrada dos indivíduos no emprego formal. O identificador do empregado possibilitaria identificar os indivíduos que mudaram de vínculos.

Além disso, a utilização da Relação Anual de Informações Sociais (RAIS) com os identificadores de indivíduos e firmas permitiria uma filtragem mais precisa da amostra, de modo que sem eles não é possível traçar o histórico dos trabalhadores no mercado de trabalho formal. Adicionalmente, a base não identificada não possui as datas de admissão e demissão dos indivíduos, o que compromete o cálculo do tempo de emprego de acordo com a contagem de meses específica do seguro-desemprego ${ }^{1}$.

O acesso à RAIS identificada também possibilitaria ligá-la com os dados administrativos do seguro-desemprego, disponibilizados pelo Ministério do Trabalho. Essa base de dados possui os registros de todos os requerimentos do seguro-desemprego realizados a partir de um identificador do indivíduo. Informações das datas de requerimento e valores pago estão disponíveis. Adicionalmente, pela base do seguro-desemprego é possível verificar em qual requerimento os indivíduos se encontram, o que permitirá analisar os impactos da legislação de acordo com esta variável.

1 Para fins do recebimento do seguro-desemprego, 15 dias trabalhados em um mês equivale a um mês competo para a contagem de tempo de emprego. 



\section{Conclusão}

Este trabalho se propôs a analisar se os trabalhadores do mercado formal brasileiro são capazes de induzir a própria demissão para receber o seguro-desemprego. À princípio, essa indução ocorreria pois apenas os trabalhadores demitidos involuntariamente e sem justa causa podem usufruir do benefício. A mudança na restrição da elegibilidade para o requerimento a esse auxílio, causada pela Medida Provisória 665 e lei no 13.134, atuou como um experimento quase-natural, o que possibilitou a identificação desse efeito.

Utilizando os dados da RAIS estimou-se a probabilidade dos trabalhadores serem demitidos sem justa causa, considerando o critério de elegibilidade para o segurodesemprego. Os resultados indicam que os trabalhadores elegíveis no período anterior a vigoração da MP665 têm probabilidade 0,73 p.p maior de serem demitidos, em comparação com os não-elegíveis ao seguro, causada pelo existência do seguro-desemprego. Isto equivale a dizer que $13 \%$ da demissões sem justa causa são induzidas por parte dos trabalhadores. Para os indivíduos em primeiro emprego, as demissões causadas pelo seguro desemprego chegam à aproximadamente $24 \%$. Adicionalmente, os acordos são menos relevantes para firmas maiores, indivíduos mais escolarizados e para o setor de serviços e industrial. Em uma análise complementar, utilizando a PME, conclui-se que $34 \%$ dos indivíduos que deixam o setor formal para acessar o seguro-desemprego se reempregam no setor informal no mês subsquente.

A verificação dos resultados é realizada através de testes de falseamento, placebos e análises de robustez. Em todos os casos, os testes não são rejeitados. Não é possível verificar o mesmo impacto nas demissões sem justa causa para outros tipos de demissões. Também não se pode visualizar o mesmo padrão encontrado em 2015, ano da mudança da lei, para o período anterior à política. Dessa forma, as verificações fornecem evidência de que o problema está bem identificado. 



\section{Referências}

BARROS, R. P. d.; CORSEUIL, C. H.; FOGUEL, M. Os incentivos adversos e a focalização dos programas de proteção ao trabalhador no brasil. Planejamento e Políticas Públicas, n. 22, 2009. Citado na página 22.

CARD, D.; LEVINE, P. B. Extended benefits and the duration of ui spells: evidence from the new jersey extended benefit program. Journal of Public economics, Elsevier, v. 78, n. 1, p. 107-138, 2000. Citado na página 23.

CARDOSO, A.; LAGE, T. As Normas e os fatos. Rio de Janeiro: Editora FGV, 2007. Citado na página 62.

CHETTY, R.; FINKELSTEIN, A. Social insurance: Connecting theory to data. Handbook of Public Economics, v. 5, p. 111-193, 2013. Citado na página 21.

DIEESE. Considerações sobre as medidas provisórias 664 e 665. 2015. Citado na página 27.

DOORNIK, B. V.; SCHOENHERR, D.; SKRASTINS, J. Unemployment insurance with informal labor markets: Evidence from brazil. 2017. Citado na página 24.

GERARD, F.; GONZAGA, G. M. Informal labor and the efficiency cost of social programs: evidence from the brazilian unemployment insurance program. National Bureau of Economic Research, 2016. Citado 2 vezes nas páginas 22 e 29.

GERARD, F.; ROKKANEN, M.; ROTHE, C. Bounds on treatment effects in regression discontinuity designs under manipulation of the running variable, with an application to unemployment insurance in brazil. National Bureau of Economic Research, 2016. Citado 3 vezes nas páginas 22,23 e 29.

GONZAGA, G.; MALONEY, W. F.; MIZALA, A. Labor turnover and labor legislation in brazil. Economía, v. 4, n. 1, p. 165-222, 2003. Citado na página 22.

HOPENHAYN, H. A.; NICOLINI, J. P. Optimal unemployment insurance. Journal of Political Economy, v. 105, p. 412-438, 1997. Citado na página 21.

LALIVE, R.; OURS, J. V.; ZWEIMüLLER, J. How changes in financial incentives affect the duration of unemployment. The Review of Economic Studies, Oxford University Press, v. 73, n. 4, p. 1009-1038, 2006. Citado na página 23.

MORTENSEN, D. T. Unemployment insurance and job search decisions. Indus. \& Lab. Rel. Rev., HeinOnline, v. 30, p. 505, 1976. Citado na página 23.

OURS, J. C. V.; VODOPIVEC, M. How shortening the potential duration of unemployment benefits affects the duration of unemployment: Evidence from a natural experiment. Journal of Labor Economics, JSTOR, v. 24, n. 2, p. 351-378, 2006. Citado na página 23. 
OURS, J. C. V.; VODOPIVEC, M. Does reducing unemployment insurance generosity reduce job match quality? Journal of Public Economics, Elsevier, v. 92, n. 3, p. 684-695, 2008. Citado na página 24.

PAVONI, N. On optimal unemployment compensation. Journal of Monetary Economics, v. 54, p. 1612-1630, 2007. Citado na página 21.

PAVONI, N. Optimal unemployment insurance, with human capital depreciation, and duration dependence. International Economic Review, v. 50, p. 323-362, 2009. Citado na página 21.

PAVONI, N.; VIOLANTE, G. Optimal welfare-to-work programs. Review of Economic Studies, v. 74, p. 283-318, 2007. Citado na página 21.

WORLDBAnK. Policy Briefing: Brazil Job Reports. [S.1.], 2002. Citado na página 22. 


\section{APÊNDICE A - Gráficos}

Figura 16 - Probabilidade de demissão com justa causa nos meses de emprego

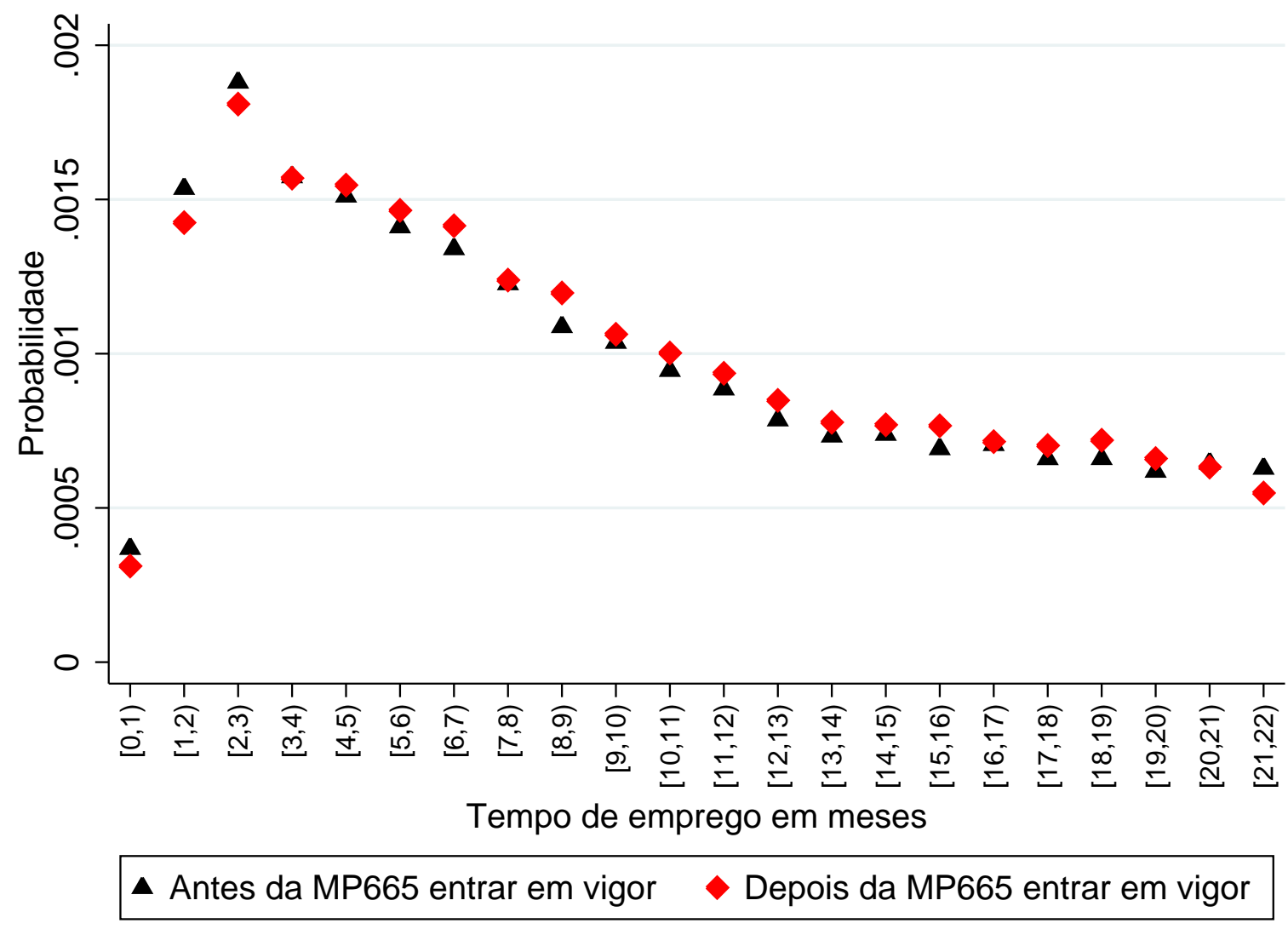

Fonte: RAIS 2012 a 2015.

Os meses anteriores à março de 2015 são definidos como o período "Antes da MP665 entrar em vigor". O período "Depois da MP665 entrar em vigor" compreende os meses após março de 2015. A probabilidade de demissão é calculada como uma média da probabilidade mensal de demissão com justa causa para intervalos de um mês de tempo de emprego. 
Figura 17 - Probabilidade de saída do emprego por iniciativa do trabalhador nos meses de emprego

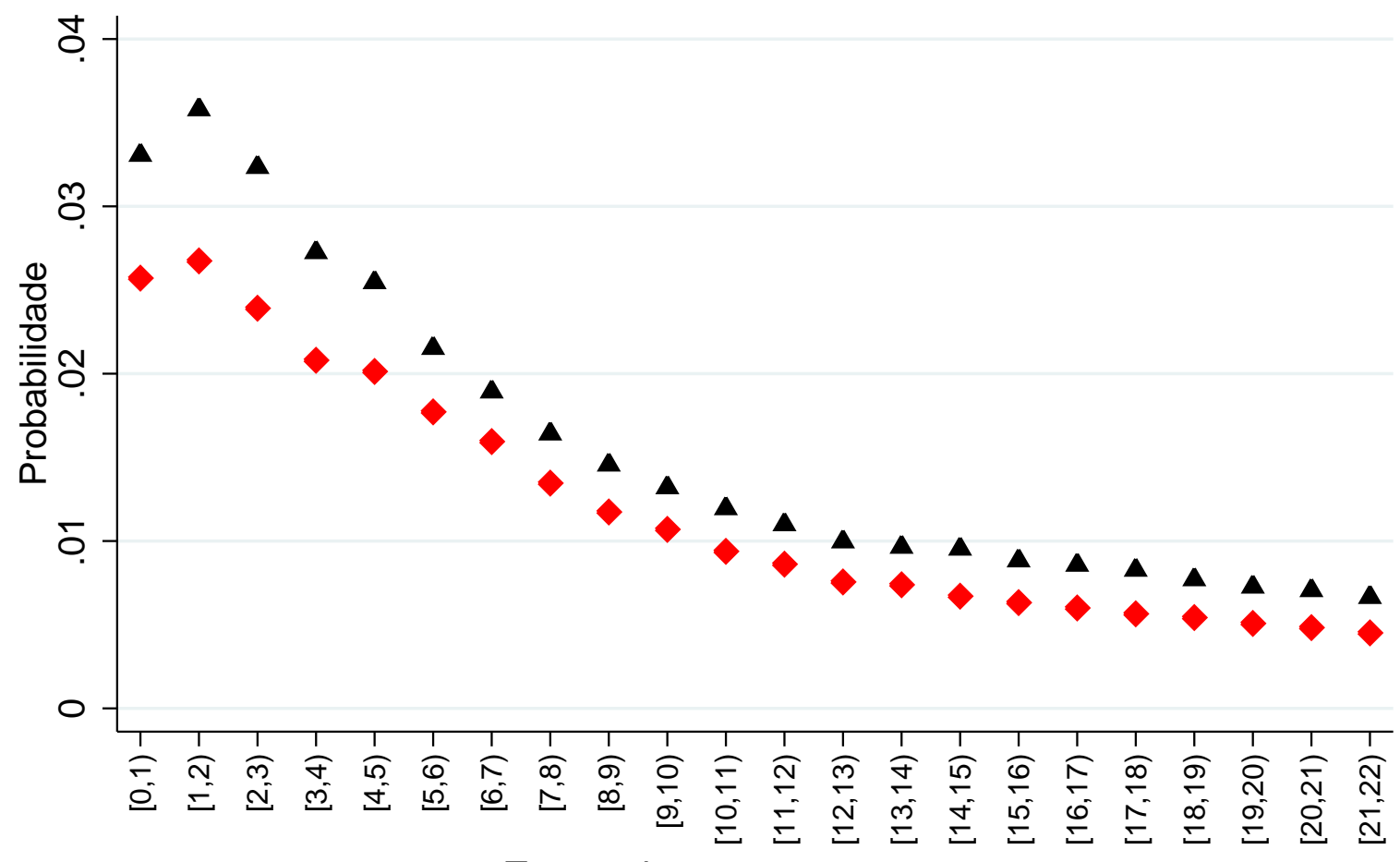

Tempo de emprego em meses

A Antes da MP665 entrar em vigor $\diamond$ Depois da MP665 entrar em vigor

Fonte: RAIS 2012 a 2015.

Os meses anteriores à março de 2015 são definidos como o período "Antes da MP665 entrar em vigor". O período "Depois da MP665 entrar em vigor" compreende os meses após março de 2015. A probabilidade de saída é calculada como uma média da probabilidade mensal de saída do emprego por iniciativa do trabalhador para intervalos de um mês de tempo de emprego. 
Figura 18 - Probabilidade de quebra de vínculo por outros motivos nos meses de emprego

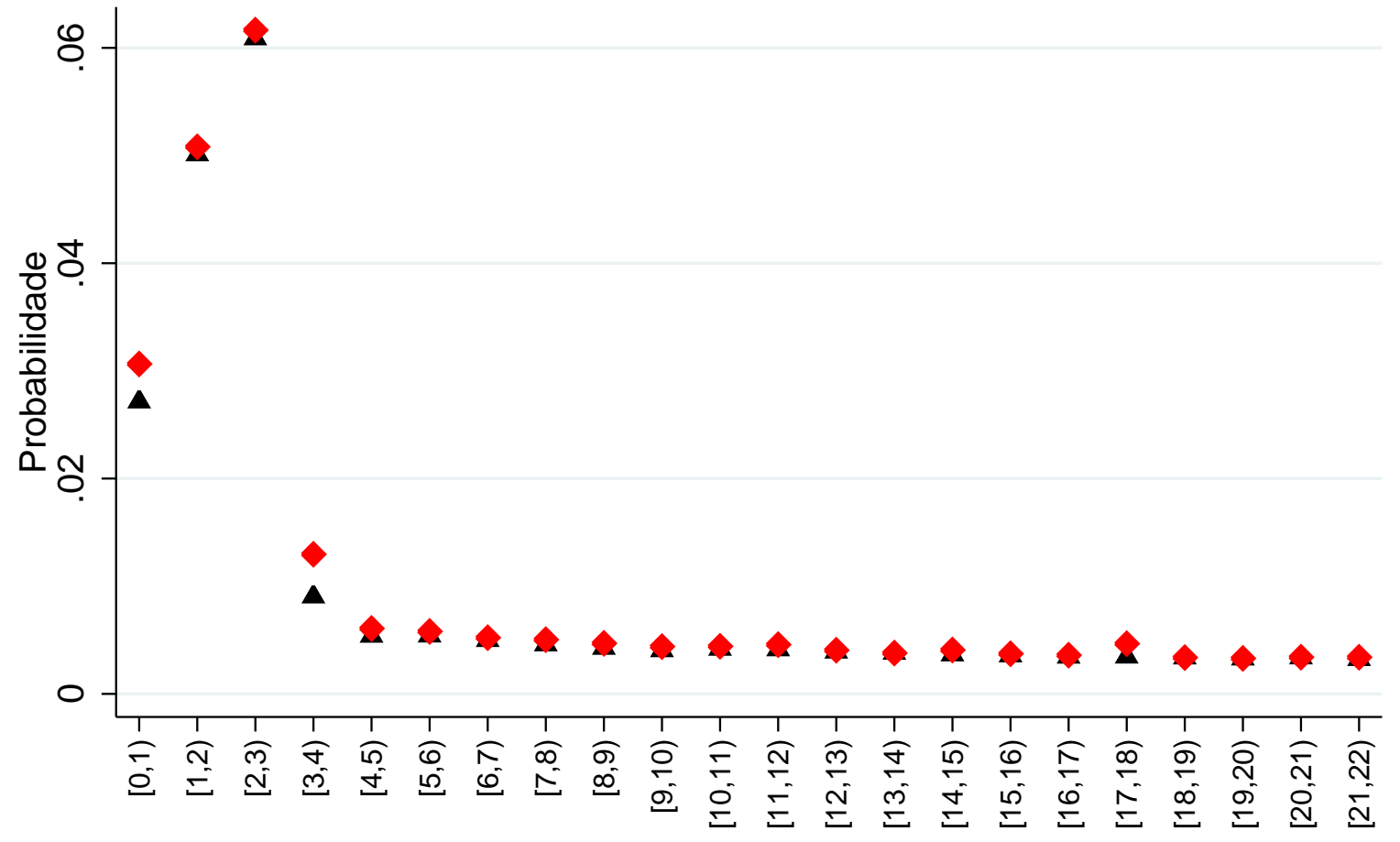

Tempo de emprego em meses

\section{A Antes da MP665 entrar em vigor $\diamond$ Depois da MP665 entrar em vigor}

Fonte: RAIS 2012 a 2015.

Os meses anteriores à março de 2015 são definidos como o período "Antes da MP665 entrar em vigor". O período "Depois da MP665 entrar em vigor" compreende os meses após março de 2015. A probabilidade de quebra por outros motivos é calculada como uma média da probabilidade mensal de quebra por término do contrato, recisão com justa causa por iniciativa do empregado, transferência, falecimento e aposentadoria. Esta probabilidade é calculada para intervalos de um mês de tempo de emprego. 
Figura 19 - Proporção dos indivíduos por tempo de emprego dentre os segurados do programa seguro-desemprego que estavam até o segundo requerimento

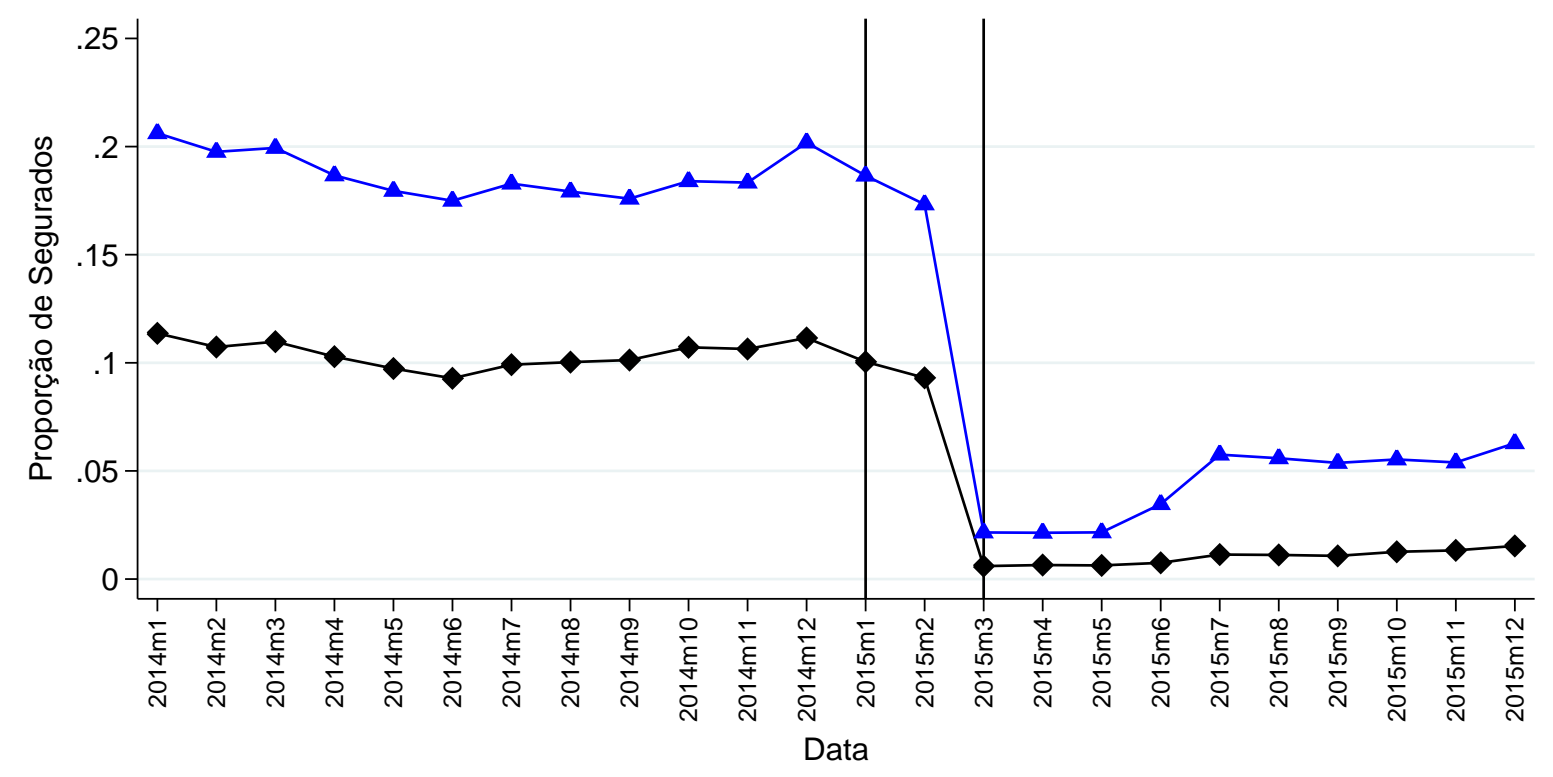

$\longrightarrow$ Até 9 meses $\longleftarrow$ Até 12 meses

Fonte: Base administrativa do seguro-desemprego 2014 a 2015.

O gráfico apresenta a proporção das pessoas até 9 meses e até 12 meses de tempo de emprego dentre os segurados até o segundo requerimento ao longo dos meses. O período considerado inicia-se em janeiro de 2014 indo até dezembro de 2015, englobando os meses em que a MP665 foi promulgada, dezembro de 2014, e que passou a vigorar, fevereiro de 2015. Tendo em vista que tanto o dia da promulgação quanto o dia em que a medida passou a vigorar estão no final do mês, 30 de dezembro e 28 de fevereiro, respectivamente, opta-se por traçar a linha vertical nos meses subsequentes, janeiro e março de 2015. A informação sobre qual requerimento em que o indivíduo se encontra somente está disponível de 2014 em diante. 
Figura 20 - Proporção dos indivíduos por tempo de emprego dentre os segurados do programa seguro-desemprego que estavam até o segundo requerimento

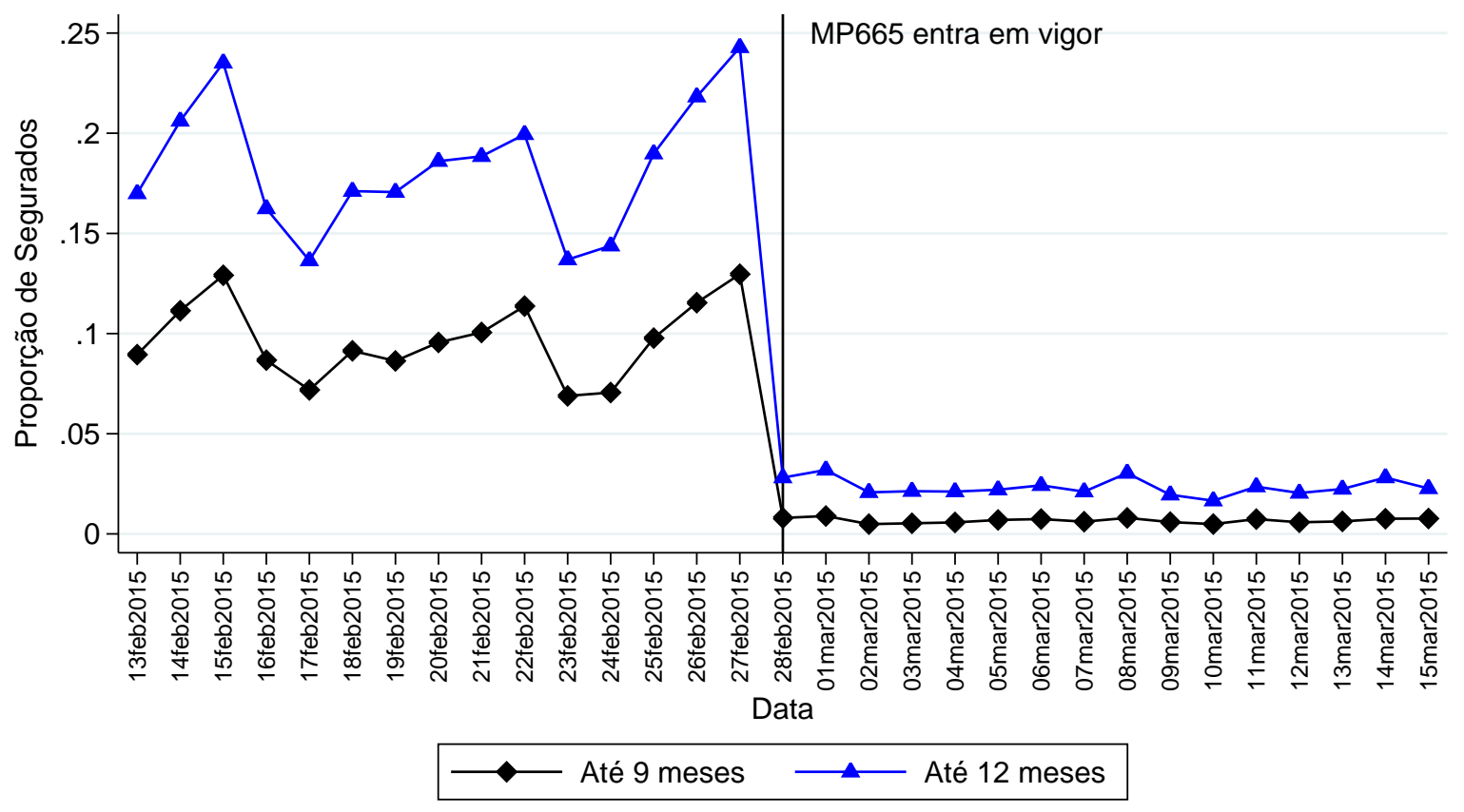

Fonte: Base administrativa do seguro-desemprego 2015.

O gráfico apresenta a proporção das pessoas até 9 meses e até 12 meses de tempo de emprego dentre os segurados até o segundo requerimento ao longo dos meses. O período considerado inicia-se em 13 de fevereiro de 2015, 15 dias antes da MP665 entrar em vigor, indo até 15 de março 2015, 15 dias após a MP665 entrar em vigor. A MP665 entra em vigor em 28 de fevereiro de 2015.

Figura 21 - Tendência da probabilidade de demissão sem justa causa para o grupo dos tratados, 6 a 8 meses, e grupo dos controles, 3 a 5 meses

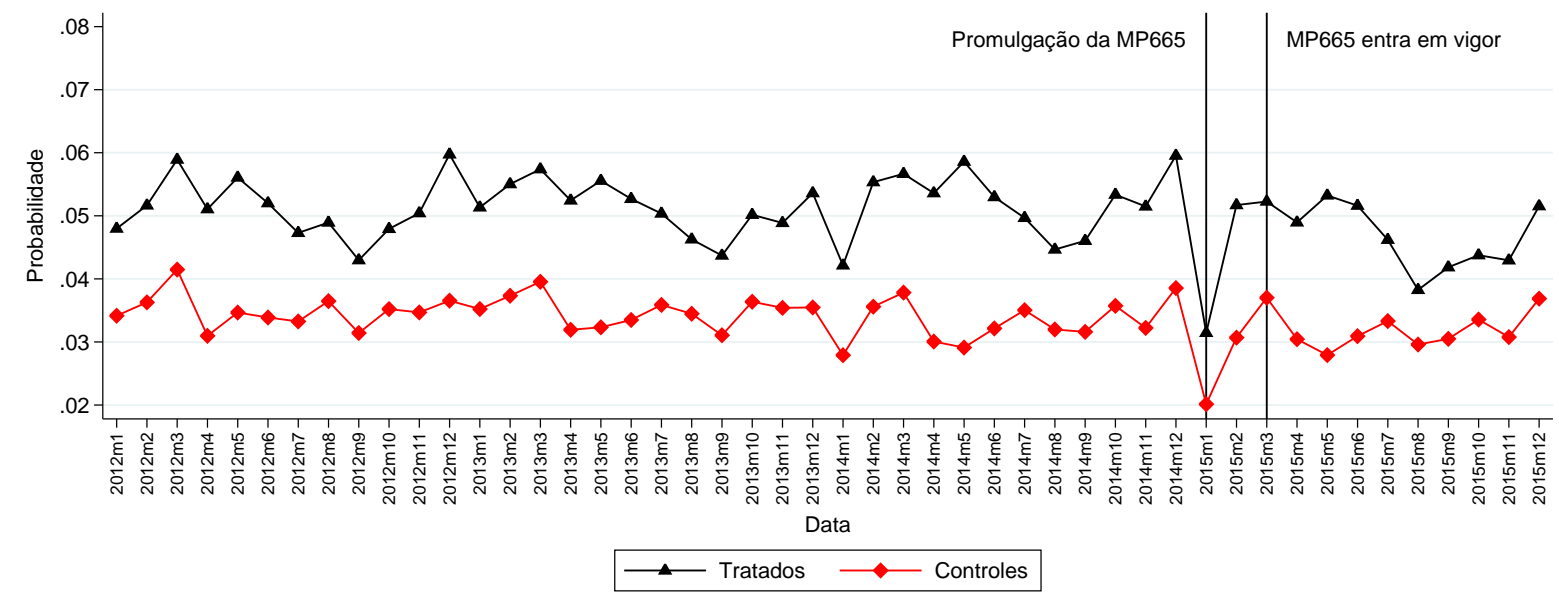

Fonte: RAIS 2012 a 2015.

O gráfico apresenta as probabilidades de demissão sem justa causa mensais para o grupo dos tratados, indivíduos de 6 a 8 meses completos no trabalho formal, e para o grupo dos controles, pessoas que possuem de 3 a 5 meses completos de trabalho no setor formal. O período considerado inicia-se em janeiro de 2012 indo até dezembro de 2015, englobando os meses em que a MP665 foi promulgada, dezembro de 2014, e que passou a vigorar, fevereiro de 2015. Tendo em vista que tanto o dia da promulgação quanto o dia em que a medida passou a vigorar estão no final do mês, 30 de dezembro e 28 de fevereiro, respectivamente, opta-se por traçar a linha vertical nos meses subsequentes, janeiro e março de 2015. 
Figura 22 - Tendência da probabilidade de demissão sem justa causa para o grupo dos tratados, 6 a 8 meses, e grupo dos controles, 18 a 20 meses

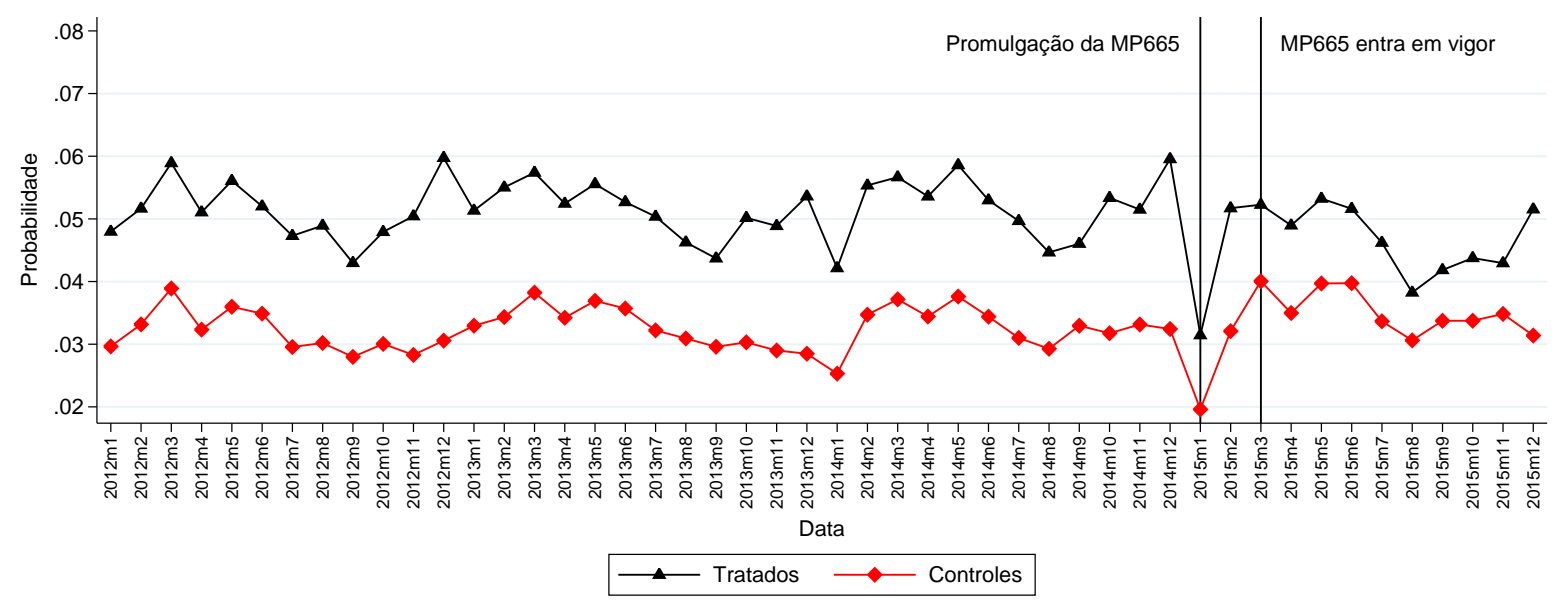

Fonte: RAIS 2012 a 2015.

O gráfico apresenta as probabilidades de demissão sem justa causa mensais para o grupo dos tratados, indivíduos de 6 a 8 meses completos no trabalho formal, e para o grupo dos controles, pessoas que possuem de 18 a 20 meses completos de trabalho no setor formal. O período considerado inicia-se em janeiro de 2012 indo até dezembro de 2015, englobando os meses em que a MP665 foi promulgada, dezembro de 2014, e que passou a vigorar, fevereiro de 2015. Tendo em vista que tanto o dia da promulgação quanto o dia em que a medida passou a vigorar estão no final do mês, 30 de dezembro e 28 de fevereiro, respectivamente, opta-se por traçar a linha vertical nos meses subsequentes, janeiro e março de 2015.

Figura 23 - Tendência da probabilidade de saída por iniciativa do trabalhador para o grupo dos tratados, 6 a 7 meses, e grupo dos controles, 4 a 5 meses

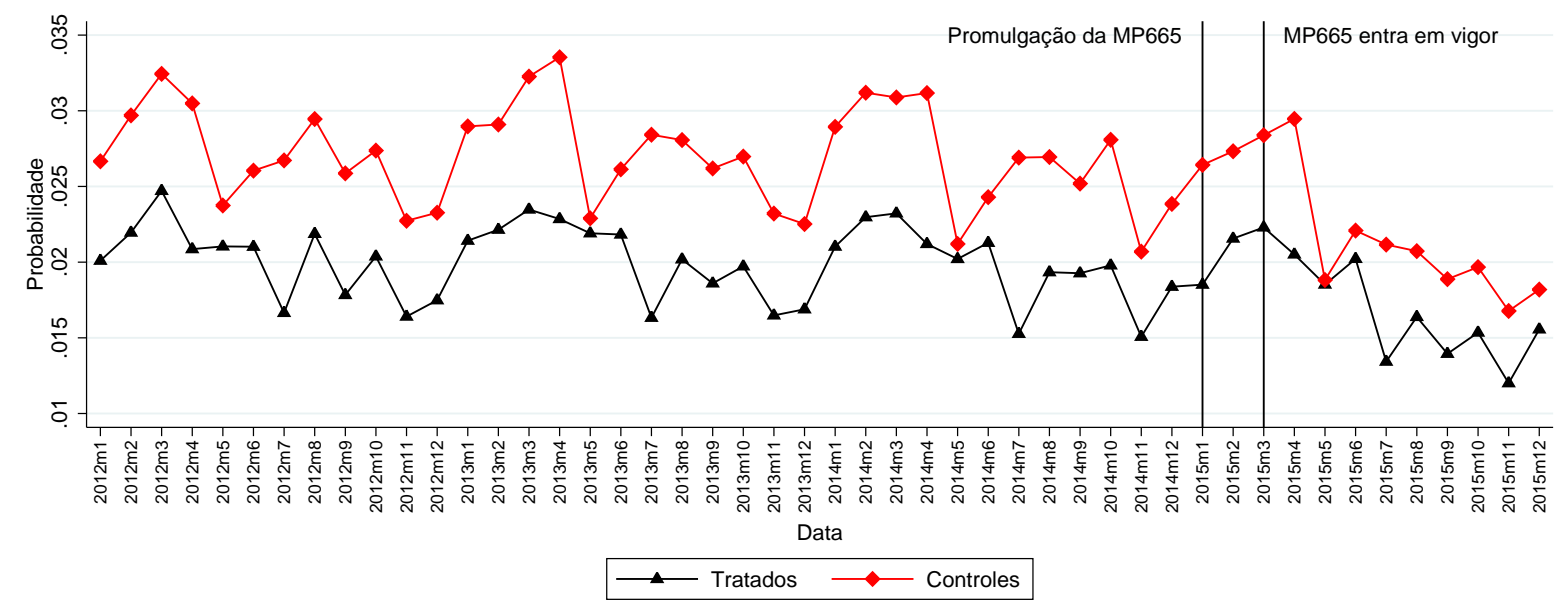

Fonte: RAIS 2012 a 2015.

O gráfico apresenta as probabilidades de saída por iniciativa do trabalhador mensais para o grupo dos tratados, indivíduos de 6 a 7 meses completos no trabalho formal, e para o grupo dos controles, pessoas que possuem de 4 a 5 meses completos de trabalho no setor formal. O período considerado inicia-se em janeiro de 2012 indo até dezembro de 2015, englobando os meses em que a MP665 foi promulgada, dezembro de 2014, e que passou a vigorar, fevereiro de 2015. Tendo em vista que tanto o dia da promulgação quanto o dia em que a medida passou a vigorar estão no final do mês, 30 de dezembro e 28 de fevereiro, respectivamente, opta-se por traçar a linha vertical nos meses subsequentes, janeiro e março de 2015. 
Figura 24 - Tendência da probabilidade de saída por iniciativa do trabalhador para o grupo dos tratados, 6 a 7 meses, e grupo dos controles, 18 a 19 meses

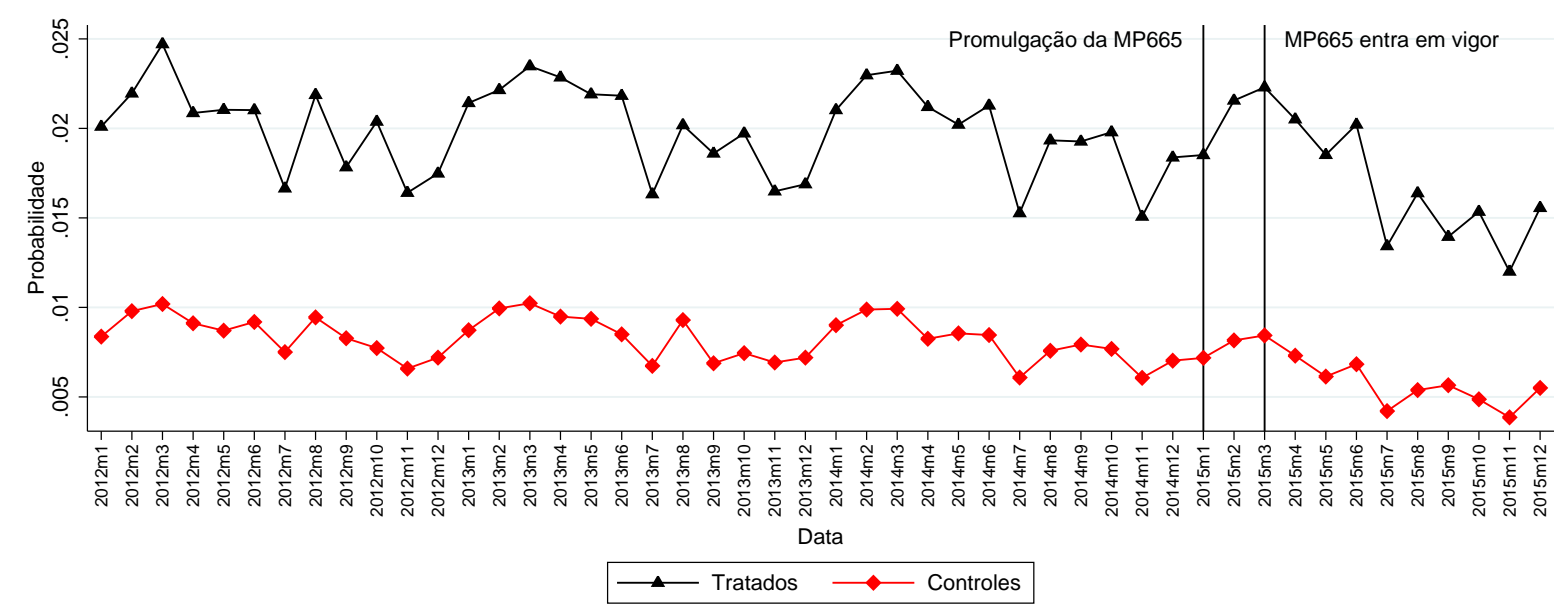

Fonte: RAIS 2012 a 2015.

O gráfico apresenta as probabilidades de saída por iniciativa do trabalhador mensais para o grupo dos tratados, indivíduos de 6 a 7 meses completos no trabalho formal, e para o grupo dos controles, pessoas que possuem de 18 a 19 meses completos de trabalho no setor formal. O período considerado inicia-se em janeiro de 2012 indo até dezembro de 2015, englobando os meses em que a MP665 foi promulgada, dezembro de 2014, e que passou a vigorar, fevereiro de 2015. Tendo em vista que tanto o dia da promulgação quanto o dia em que a medida passou a vigorar estão no final do mês, 30 de dezembro e 28 de fevereiro, respectivamente, opta-se por traçar a linha vertical nos meses subsequentes, janeiro e março de 2015.

Figura 25 - Tendência da probabilidade de demissão por justa causa para o grupo dos tratados, 6 a 7 meses, e grupo dos controles, 4 a 5 meses

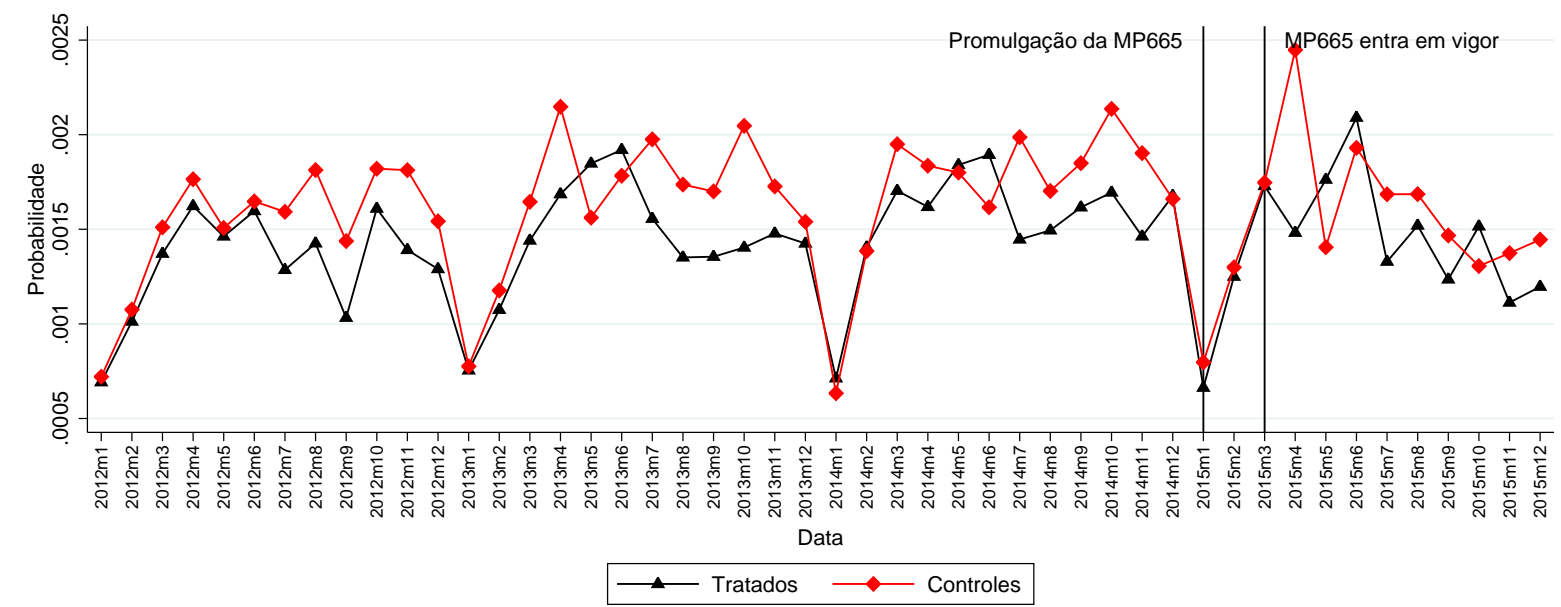

Fonte: RAIS 2012 a 2015.

O gráfico apresenta as probabilidades de demissão por justa causa mensais para o grupo dos tratados, indivíduos de 6 a 7 meses completos no trabalho formal, e para o grupo dos controles, pessoas que possuem de 4 a 5 meses completos de trabalho no setor formal. O período considerado inicia-se em janeiro de 2012 indo até dezembro de 2015, englobando os meses em que a MP665 foi promulgada, dezembro de 2014, e que passou a vigorar, fevereiro de 2015. Tendo em vista que tanto o dia da promulgação quanto o dia em que a medida passou a vigorar estão no final do mês, 30 de dezembro e 28 de fevereiro, respectivamente, opta-se por traçar a linha vertical nos meses subsequentes, janeiro e março de 2015. 
Figura 26 - Tendência da probabilidade de demissão por justa causa para o grupo dos tratados, 6 a 7 meses, e grupo dos controles, 18 a 19 meses

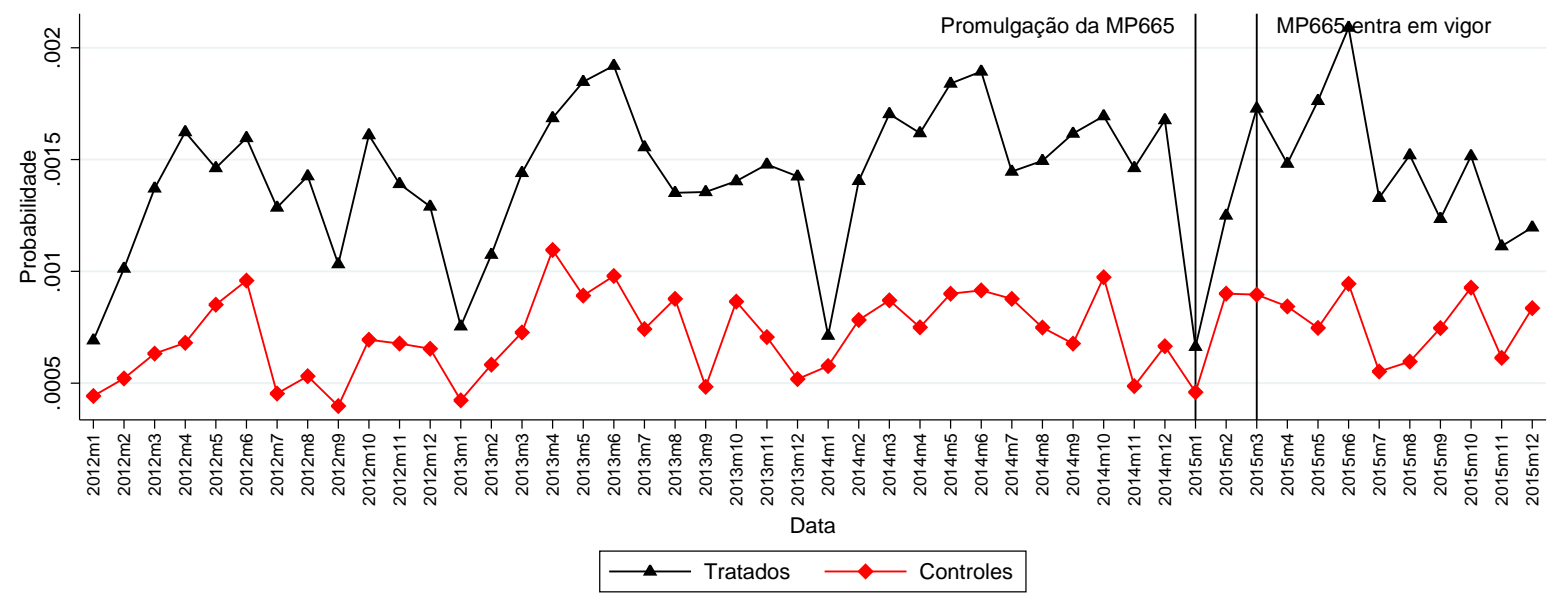

Fonte: RAIS 2012 a 2015.

O gráfico apresenta as probabilidades de demissão por justa causa mensais para o grupo dos tratados, indivíduos de 6 a 7 meses completos no trabalho formal, e para o grupo dos controles, pessoas que possuem de 18 a 19 meses completos de trabalho no setor formal. O período considerado inicia-se em janeiro de 2012 indo até dezembro de 2015, englobando os meses em que a MP665 foi promulgada, dezembro de 2014, e que passou a vigorar, fevereiro de 2015. Tendo em vista que tanto o dia da promulgação quanto o dia em que a medida passou a vigorar estão no final do mês, 30 de dezembro e 28 de fevereiro, respectivamente, opta-se por traçar a linha vertical nos meses subsequentes, janeiro e março de 2015.

Figura 27 - Tendência da probabilidade de quebra de vínculo por outros motivos para o grupo dos tratados, 6 a 7 meses, e grupo dos controles, 4 a 5 meses

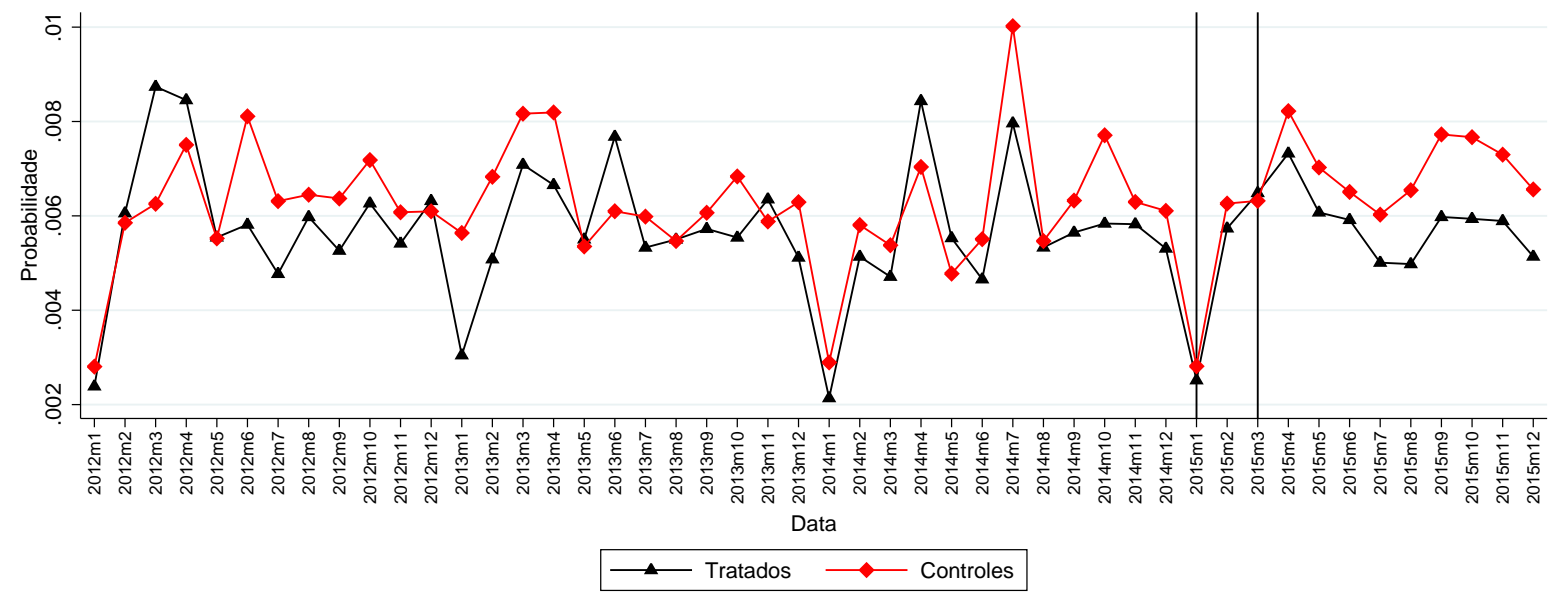

Fonte: RAIS 2012 a 2015.

O gráfico apresenta as probabilidades de quebra de vínculo por outros motivos mensais para o grupo dos tratados, indivíduos de 6 a 7 meses completos no trabalho formal, e para o grupo dos controles, pessoas que possuem de 4 a 5 meses completos de trabalho no setor formal. A probabilidade de quebra por outros motivos é calculada como uma média da probabilidade mensal de quebra por término do contrato, recisão com justa-causa por iniciativa do empregado, transferência, falecimento e aposentadoria. O período considerado inicia-se em janeiro de 2012 indo até dezembro de 2015, englobando os meses em que a MP665 foi promulgada, dezembro de 2014, e que passou a vigorar, fevereiro de 2015. Tendo em vista que tanto o dia da promulgação quanto o dia em que a medida passou a vigorar estão no final do mês, 30 de dezembro e 28 de fevereiro, respectivamente, opta-se por traçar a linha vertical nos meses subsequentes, janeiro e março de 2015. 
Figura 28 - Tendência da probabilidade de quebra de vínculo por outros motivos para o grupo dos tratados, 6 a 7 meses, e grupo dos controles, 18 a 19 meses

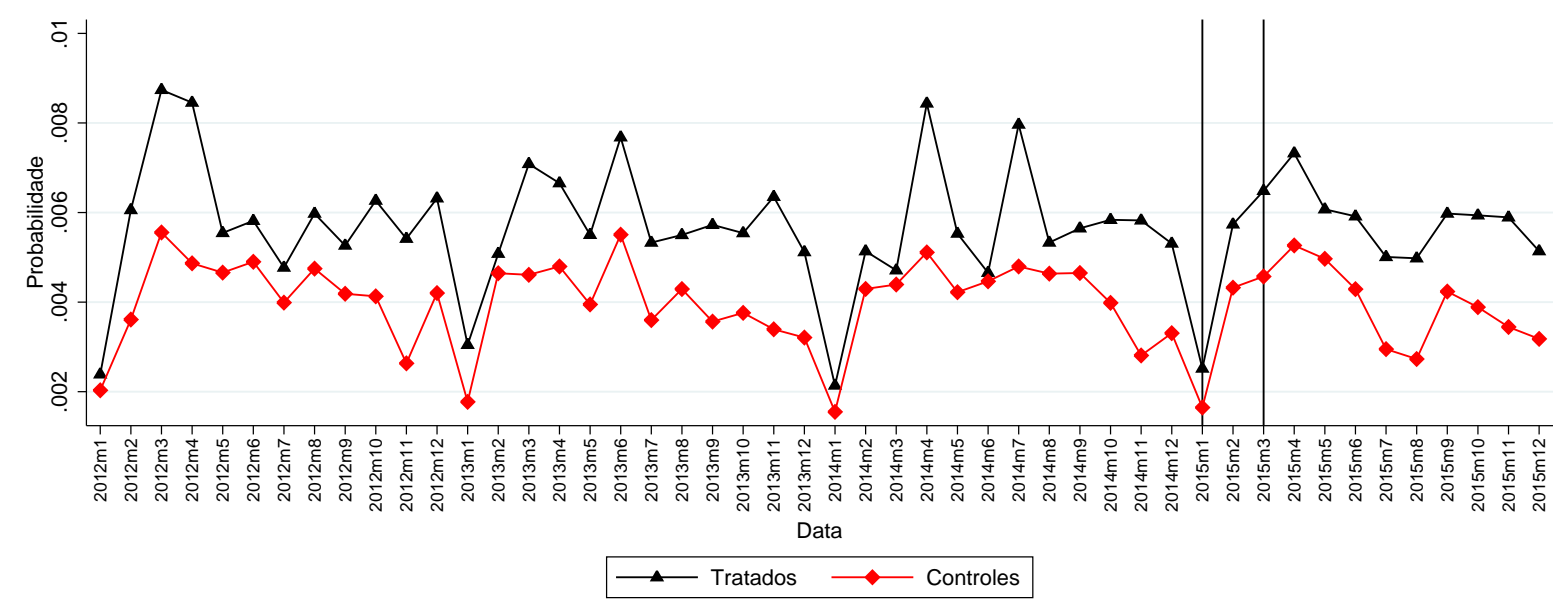

Fonte: RAIS 2012 a 2015.

O gráfico apresenta as probabilidades de quebra de vínculo por outros motivos mensais para o grupo dos tratados, indivíduos de 6 a 7 meses completos no trabalho formal, e para o grupo dos controles, pessoas que possuem de 18 a 19 meses completos de trabalho no setor formal. A probabilidade de quebra por outros motivos é calculada como uma média da probabilidade mensal de quebra por término do contrato, recisão com justa-causa por iniciativa do empregado, transferência, falecimento e aposentadoria. O período considerado inicia-se em janeiro de 2012 indo até dezembro de 2015, englobando os meses em que a MP665 foi promulgada, dezembro de 2014, e que passou a vigorar, fevereiro de 2015. Tendo em vista que tanto o dia da promulgação quanto o dia em que a medida passou a vigorar estão no final do mês, 30 de dezembro e 28 de fevereiro, respectivamente, opta-se por traçar a linha vertical nos meses subsequentes, janeiro e março de 2015 . 



\section{APÊNDICE B - Efeito por Bimestre}

Tabela 27 - Resultado das regressões de diferenças em diferenças nas demissões sem justa causa por bimestre - controles abaixo de 6 meses

\begin{tabular}{|c|c|c|c|c|c|c|c|c|}
\hline \multirow{3}{*}{$\begin{array}{l}\text { Variável Dependente } \\
\text { Tempo de emprego }\end{array}$} & \multicolumn{8}{|c|}{ Dummy de Demissão sem Justa Causa } \\
\hline & \multicolumn{4}{|c|}{$(4$ a 5$)-(6$ a 7$)$} & \multicolumn{4}{|c|}{$(3$ a 5$)-(6$ a 8$)$} \\
\hline & (1) & $(2)$ & (3) & (4) & (1) & $(2)$ & (3) & (4) \\
\hline \multirow[t]{2}{*}{ Tratamento -7} & $-0.0022^{* *}$ & -0.0011 & -0.0009 & -0.0010 & 0.0007 & $0.0012^{*}$ & $0.0018^{* *}$ & 0.0014 \\
\hline & $(0.0009)$ & $(0.0008)$ & $(0.0009)$ & $(0.0013)$ & $(0.0011)$ & $(0.0007)$ & $(0.0008)$ & $(0.0011)$ \\
\hline \multirow[t]{2}{*}{ Tratamento -6} & 0.0001 & -0.0022 & -0.0024 & -0.0024 & $0.0049^{* * *}$ & 0.0022 & 0.0018 & 0.0014 \\
\hline & $(0.0014)$ & $(0.0024)$ & $(0.0023)$ & $(0.0019)$ & $(0.0014)$ & $(0.0019)$ & $(0.0017)$ & $(0.0013)$ \\
\hline \multirow[t]{2}{*}{ Tratamento -5} & $0.0094^{* * *}$ & $0.0030^{* *}$ & $0.0022^{* *}$ & $0.0022^{*}$ & $0.0091^{* * *}$ & $0.0048^{* * *}$ & $0.0040^{* * *}$ & $0.0037^{* *}$ \\
\hline & $(0.0021)$ & $(0.0012)$ & $(0.0010)$ & $(0.0011)$ & $(0.0019)$ & $(0.0012)$ & $(0.0009)$ & $(0.0015)$ \\
\hline \multirow[t]{2}{*}{ Tratamento -4} & $-0.0065^{* * *}$ & $-0.0032^{* * *}$ & $-0.0029^{* * *}$ & $-0.0030^{* *}$ & $-0.0027^{* *}$ & 0.0005 & 0.0005 & 0.0002 \\
\hline & $(0.0014)$ & $(0.0008)$ & $(0.0008)$ & $(0.0013)$ & $(0.0013)$ & $(0.0008)$ & $(0.0008)$ & $(0.0013)$ \\
\hline \multirow[t]{2}{*}{ Tratamento -3} & -0.0010 & $0.0016^{*}$ & $0.0016^{*}$ & 0.0016 & -0.0003 & $0.0033^{* * *}$ & $0.0032^{* * *}$ & $0.0028^{* *}$ \\
\hline & $(0.0013)$ & $(0.0009)$ & $(0.0009)$ & $(0.0014)$ & $(0.0015)$ & $(0.0008)$ & $(0.0008)$ & $(0.0012)$ \\
\hline \multirow[t]{2}{*}{ Tratamento -2} & 0.0017 & $0.0020^{*}$ & 0.0013 & 0.0013 & $0.0038^{* *}$ & $0.0025^{* *}$ & $0.0021^{*}$ & $0.0017^{*}$ \\
\hline & $(0.0018)$ & $(0.0012)$ & $(0.0010)$ & $(0.0014)$ & $(0.0019)$ & $(0.0012)$ & $(0.0011)$ & $(0.0009)$ \\
\hline \multirow[t]{2}{*}{ Tratamento -1} & $-0.0041^{* * *}$ & $-0.0031^{* * *}$ & $-0.0028^{* * *}$ & $-0.0029^{*}$ & -0.0001 & 0.0004 & 0.0009 & 0.0003 \\
\hline & $(0.0009)$ & $(0.0010)$ & $(0.0010)$ & $(0.0015)$ & $(0.0012)$ & $(0.0010)$ & $(0.0010)$ & $(0.0015)$ \\
\hline \multirow[t]{2}{*}{ Tratamento 0} & $-0.0069^{* * *}$ & $-0.0092^{* * *}$ & $-0.0092^{* * *}$ & $-0.0093^{* * *}$ & 0.0005 & -0.0021 & -0.0024 & $-0.0030^{* *}$ \\
\hline & $(0.0014)$ & $(0.0029)$ & $(0.0028)$ & $(0.0026)$ & $(0.0011)$ & $(0.0020)$ & $(0.0018)$ & $(0.0014)$ \\
\hline \multirow[t]{2}{*}{ Tratamento 1} & 0.0022 & $-0.0042^{* *}$ & $-0.0050^{* * *}$ & $-0.0051^{*}$ & $0.0068^{* *}$ & 0.0025 & 0.0013 & 0.0007 \\
\hline & $(0.0028)$ & $(0.0017)$ & $(0.0016)$ & $(0.0026)$ & $(0.0026)$ & $(0.0021)$ & $(0.0019)$ & $(0.0031)$ \\
\hline \multirow[t]{2}{*}{ Tratamento 2} & $-0.0114^{* * *}$ & $-0.0079^{* * *}$ & $-0.0082^{* * *}$ & $-0.0083^{* * *}$ & $-0.0056^{* * *}$ & -0.0025 & $-0.0029^{* *}$ & -0.0035 \\
\hline & $(0.0013)$ & $(0.0014)$ & $(0.0014)$ & $(0.0024)$ & $(0.0012)$ & $(0.0015)$ & $(0.0014)$ & $(0.0024)$ \\
\hline \multirow[t]{2}{*}{ Tratamento 3} & $-0.0111^{* * *}$ & $-0.0085^{* * *}$ & $-0.0082^{* * *}$ & $-0.0082^{* * *}$ & $-0.0055^{* * *}$ & $-0.0019^{*}$ & -0.0016 & -0.0022 \\
\hline & $(0.0014)$ & $(0.0014)$ & $(0.0014)$ & $(0.0025)$ & $(0.0014)$ & $(0.0010)$ & $(0.0011)$ & $(0.0023)$ \\
\hline \multirow[t]{2}{*}{ Tratamento 4} & $-0.0094^{* * *}$ & $-0.0092^{* * *}$ & $-0.0088^{* * *}$ & $-0.0089^{* * *}$ & $-0.0029^{*}$ & $-0.0042^{* *}$ & $-0.0041^{* *}$ & $-0.0047^{* * *}$ \\
\hline & $(0.0014)$ & $(0.0018)$ & $(0.0016)$ & $(0.0023)$ & $(0.0015)$ & $(0.0019)$ & $(0.0017)$ & $(0.0017)$ \\
\hline Efeito fixo mensal & $\operatorname{sim}$ & $\operatorname{sim}$ & $\operatorname{sim}$ & $\operatorname{sim}$ & $\operatorname{sim}$ & $\operatorname{sim}$ & $\operatorname{sim}$ & $\operatorname{sim}$ \\
\hline Sazonalidade - grupo & não & $\operatorname{sim}$ & $\operatorname{sim}$ & $\operatorname{sim}$ & não & $\operatorname{sim}$ & $\operatorname{sim}$ & $\operatorname{sim}$ \\
\hline Covariadas & não & não & $\operatorname{sim}$ & $\operatorname{sim}$ & não & não & $\operatorname{sim}$ & $\operatorname{sim}$ \\
\hline Tendência linear & não & não & não & $\operatorname{sim}$ & não & não & não & $\operatorname{sim}$ \\
\hline Observações & 11125912 & 11125912 & 11125912 & 11125912 & 21752413 & 21752413 & 21752413 & 21752413 \\
\hline R-quadrado aj. & 0.002 & 0.002 & 0.017 & 0.017 & 0.002 & 0.002 & 0.016 & 0.016 \\
\hline \multicolumn{9}{|c|}{ 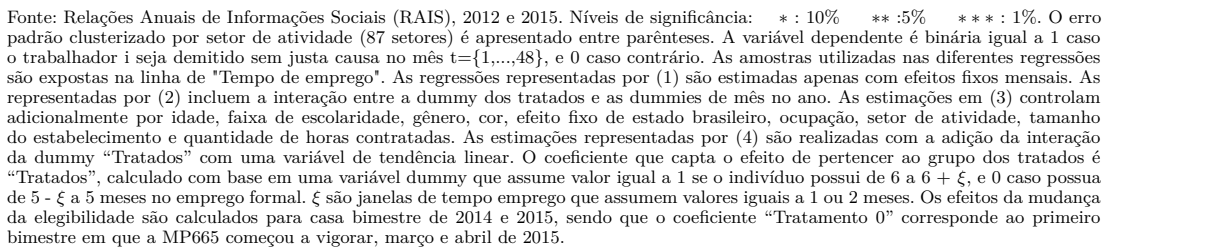 } \\
\hline
\end{tabular}


Tabela 28 - Resultado das regressões de diferenças em diferenças nas demissões sem justa causa por bimestre - controles acima de 18 meses

\begin{tabular}{|c|c|c|c|c|c|c|c|c|}
\hline \multirow{3}{*}{$\begin{array}{l}\text { Variável Dependente } \\
\text { Tempo de emprego }\end{array}$} & \multicolumn{8}{|c|}{ Dummy de Demissão sem Justa Causa } \\
\hline & \multicolumn{4}{|c|}{$(6$ a 7$)-(18$ a 19$)$} & \multicolumn{4}{|c|}{$(6$ a 8$)-(18$ a 20$)$} \\
\hline & (1) & (2) & (3) & (4) & (1) & (2) & (3) & (4) \\
\hline \multirow[t]{2}{*}{ Tratamento -7} & $-0.0028^{* * *}$ & $-0.0023^{* *}$ & $-0.0023^{* *}$ & $-0.0026^{*}$ & -0.0003 & -0.0002 & 0.0001 & 0.0006 \\
\hline & $(0.0009)$ & $(0.0011)$ & $(0.0010)$ & $(0.0014)$ & $(0.0010)$ & $(0.0008)$ & $(0.0007)$ & $(0.0009)$ \\
\hline \multirow[t]{2}{*}{ Tratamento -6} & -0.0003 & -0.0019 & -0.0023 & -0.0027 & 0.0002 & 0.0003 & -0.0001 & 0.0003 \\
\hline & $(0.0013)$ & $(0.0023)$ & $(0.0021)$ & $(0.0018)$ & $(0.0008)$ & $(0.0016)$ & $(0.0015)$ & $(0.0012)$ \\
\hline \multirow[t]{2}{*}{ Tratamento -5} & 0.0010 & 0.0010 & 0.0008 & 0.0004 & 0.0008 & $0.0016^{*}$ & 0.0010 & 0.0015 \\
\hline & $(0.0013)$ & $(0.0014)$ & $(0.0012)$ & $(0.0012)$ & $(0.0010)$ & $(0.0008)$ & $(0.0007)$ & $(0.0012)$ \\
\hline \multirow[t]{2}{*}{ Tratamento -4} & $-0.0029^{* *}$ & -0.0009 & -0.0006 & -0.0010 & $-0.0023^{*}$ & -0.0006 & -0.0004 & 0.0000 \\
\hline & $(0.0013)$ & $(0.0012)$ & $(0.0012)$ & $(0.0017)$ & $(0.0012)$ & $(0.0012)$ & $(0.0011)$ & $(0.0015)$ \\
\hline \multirow[t]{2}{*}{ Tratamento -3 } & -0.0025 & -0.0004 & 0.0001 & -0.0002 & -0.0018 & 0.0006 & 0.0009 & 0.0014 \\
\hline & $(0.0015)$ & $(0.0012)$ & $(0.0012)$ & $(0.0015)$ & $(0.0013)$ & $(0.0007)$ & $(0.0007)$ & $(0.0011)$ \\
\hline \multirow[t]{2}{*}{ Tratamento -2} & 0.0036 & 0.0003 & -0.0001 & -0.0005 & $0.0035^{*}$ & -0.0014 & -0.0014 & -0.0010 \\
\hline & $(0.0023)$ & $(0.0014)$ & $(0.0013)$ & $(0.0013)$ & $(0.0019)$ & $(0.0012)$ & $(0.0010)$ & $(0.0008)$ \\
\hline \multirow[t]{2}{*}{ Tratamento -1 } & $-0.0055^{* * *}$ & $-0.0050^{* * *}$ & $-0.0041^{* * *}$ & $-0.0047^{* * *}$ & $-0.0033^{* * *}$ & $-0.0032 * * *$ & $-0.0024^{* * *}$ & -0.0016 \\
\hline & $(0.0011)$ & $(0.0008)$ & $(0.0006)$ & $(0.0017)$ & $(0.0011)$ & $(0.0008)$ & $(0.0006)$ & $(0.0015)$ \\
\hline \multirow[t]{2}{*}{ Tratamento 0} & $-0.0066^{* * *}$ & $-0.0082^{* * *}$ & $-0.0076^{* * *}$ & $-0.0082^{* * *}$ & $-0.0060^{* * *}$ & $-0.0060^{* * *}$ & $-0.0055^{* * *}$ & $-0.0048^{* * *}$ \\
\hline & $(0.0017)$ & $(0.0026)$ & $(0.0025)$ & $(0.0025)$ & $(0.0011)$ & $(0.0017)$ & $(0.0017)$ & $(0.0014)$ \\
\hline \multirow[t]{2}{*}{ Tratamento 1} & $-0.0077^{* * *}$ & $-0.0077^{* * *}$ & $-0.0071^{* * *}$ & $-0.0077^{* * *}$ & $-0.0063^{* * *}$ & $-0.0055^{* * *}$ & $-0.0054^{* * *}$ & $-0.0047^{*}$ \\
\hline & $(0.0015)$ & $(0.0013)$ & $(0.0013)$ & $(0.0023)$ & $(0.0015)$ & $(0.0017)$ & $(0.0016)$ & $(0.0026)$ \\
\hline \multirow[t]{2}{*}{ Tratamento 2} & $-0.0119^{* * *}$ & $-0.0099^{* * *}$ & $-0.0093^{* * *}$ & $-0.0099^{* * *}$ & $-0.0093^{* * *}$ & $-0.0076^{* * *}$ & $-0.0073^{* * *}$ & $-0.0066^{* * *}$ \\
\hline & $(0.0015)$ & $(0.0014)$ & $(0.0013)$ & $(0.0026)$ & $(0.0015)$ & $(0.0013)$ & $(0.0011)$ & $(0.0022)$ \\
\hline \multirow[t]{2}{*}{ Tratamento 3} & $-0.0127^{* * *}$ & $-0.0106^{* * *}$ & $-0.0092^{* * *}$ & $-0.0098^{* * *}$ & $-0.0101 * * *$ & $-0.0076^{* * *}$ & $-0.0065^{* * *}$ & $-0.0057^{* * *}$ \\
\hline & $(0.0015)$ & $(0.0013)$ & $(0.0011)$ & $(0.0023)$ & $(0.0012)$ & $(0.0009)$ & $(0.0009)$ & $(0.0019)$ \\
\hline \multirow[t]{2}{*}{ Tratamento 4} & $-0.0068^{* * *}$ & $-0.0100^{* * *}$ & $-0.0093^{* * *}$ & $-0.0099^{* * *}$ & $-0.0051^{* * *}$ & $-0.0100^{* * *}$ & $-0.0092^{* * *}$ & $-0.0085^{* * *}$ \\
\hline & $(0.0016)$ & $(0.0013)$ & $(0.0013)$ & $(0.0023)$ & $(0.0016)$ & $(0.0015)$ & $(0.0014)$ & $(0.0018)$ \\
\hline Efeito fixo mensal & $\operatorname{sim}$ & $\operatorname{sim}$ & $\operatorname{sim}$ & $\operatorname{sim}$ & $\operatorname{sim}$ & $\operatorname{sim}$ & $\operatorname{sim}$ & $\operatorname{sim}$ \\
\hline Sazonalidade - grupo & não & $\operatorname{sim}$ & $\operatorname{sim}$ & $\operatorname{sim}$ & não & $\operatorname{sim}$ & $\operatorname{sim}$ & $\operatorname{sim}$ \\
\hline Covariadas & não & não & $\operatorname{sim}$ & $\operatorname{sim}$ & não & não & $\operatorname{sim}$ & $\operatorname{sim}$ \\
\hline Tendência linear & não & não & não & $\operatorname{sim}$ & não & não & não & $\operatorname{sim}$ \\
\hline Observações & 7598934 & 7598934 & 7598934 & 7598934 & 14369986 & 14369986 & 14369986 & 14369986 \\
\hline R-quadrado aj. & 0.003 & 0.003 & 0.018 & 0.018 & 0.002 & 0.002 & 0.017 & 0.017 \\
\hline \multicolumn{9}{|c|}{ 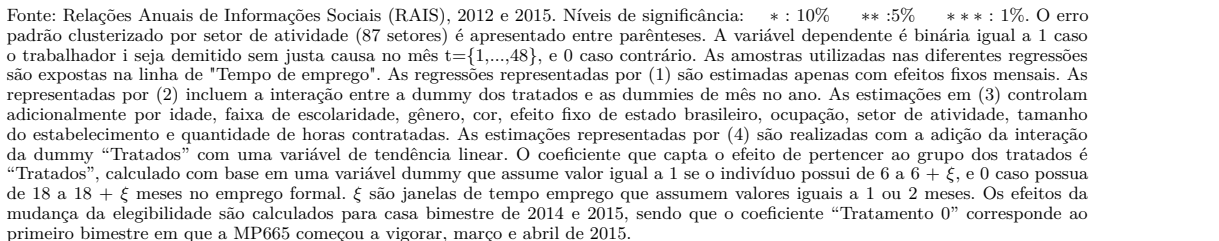 } \\
\hline
\end{tabular}


Tabela 29 - Resultado das regressões de diferenças em diferenças nas saídas por iniciativa do empregado por bimestre - controles abaixo de 6 meses

\begin{tabular}{|c|c|c|c|c|c|c|c|c|}
\hline \multirow{3}{*}{$\begin{array}{l}\text { Variável Dependente } \\
\text { Tempo de emprego }\end{array}$} & \multicolumn{8}{|c|}{ Dummy de Saída por Iniciativa do Trabalhador } \\
\hline & \multicolumn{4}{|c|}{$(4$ a 5$)-(6$ a 7$)$} & \multicolumn{4}{|c|}{$(3$ a 5$)-(6$ a 8$)$} \\
\hline & $(1)$ & $(2)$ & (3) & (4) & (1) & $(2)$ & (3) & $(4)$ \\
\hline \multirow[t]{2}{*}{ Tratamento -7} & $-0.0009^{* *}$ & $-0.0009^{* *}$ & $-0.0011^{* * *}$ & -0.0008 & $-0.0008^{* *}$ & -0.0002 & -0.0005 & -0.0007 \\
\hline & $(0.0004)$ & $(0.0004)$ & $(0.0004)$ & $(0.0005)$ & $(0.0004)$ & $(0.0004)$ & $(0.0003)$ & $(0.0004)$ \\
\hline \multirow[t]{2}{*}{ Tratamento -6} & $-0.0016^{*}$ & 0.0004 & 0.0003 & 0.0006 & $0.0010^{* *}$ & $0.0015^{* * *}$ & $0.0013^{* * *}$ & $0.0011^{* *}$ \\
\hline & $(0.0009)$ & $(0.0007)$ & $(0.0007)$ & $(0.0009)$ & $(0.0005)$ & $(0.0004)$ & $(0.0004)$ & $(0.0005)$ \\
\hline \multirow[t]{2}{*}{ Tratamento -5} & $0.0052^{* * *}$ & $0.0012^{* *}$ & $0.0013^{* *}$ & $0.0016^{* *}$ & $0.0031^{* * *}$ & $0.0008^{* *}$ & $0.0011^{* * *}$ & $0.0009^{* *}$ \\
\hline & $(0.0007)$ & $(0.0005)$ & $(0.0005)$ & $(0.0006)$ & $(0.0005)$ & $(0.0004)$ & $(0.0004)$ & $(0.0004)$ \\
\hline \multirow[t]{2}{*}{ Tratamento -4} & $-0.0024^{* * *}$ & -0.0002 & 0.0001 & 0.0004 & $-0.0010^{* *}$ & $0.0010^{* * *}$ & $0.0012^{* * *}$ & $0.0010^{* *}$ \\
\hline & $(0.0006)$ & $(0.0005)$ & $(0.0005)$ & $(0.0007)$ & $(0.0004)$ & $(0.0003)$ & $(0.0003)$ & $(0.0004)$ \\
\hline \multirow[t]{2}{*}{ Tratamento -3} & 0.0000 & 0.0004 & 0.0003 & 0.0006 & $-0.0008^{* * *}$ & -0.0005 & -0.0004 & -0.0006 \\
\hline & $(0.0006)$ & $(0.0007)$ & $(0.0006)$ & $(0.0007)$ & $(0.0003)$ & $(0.0003)$ & $(0.0003)$ & $(0.0004)$ \\
\hline \multirow[t]{2}{*}{ Tratamento -2 } & $0.0016^{* * *}$ & 0.0006 & $0.0009^{* *}$ & $0.0012^{* *}$ & $0.0021^{* * *}$ & $0.0010^{* * *}$ & $0.0012^{* * *}$ & $0.0010^{* * *}$ \\
\hline & $(0.0003)$ & $(0.0004)$ & $(0.0004)$ & $(0.0005)$ & $(0.0003)$ & $(0.0003)$ & $(0.0003)$ & $(0.0003)$ \\
\hline \multirow[t]{2}{*}{ Tratamento -1 } & 0.0003 & 0.0004 & 0.0003 & 0.0008 & $0.0011^{* * *}$ & $0.0017^{* * *}$ & $0.0015^{* * *}$ & $0.0012^{*}$ \\
\hline & $(0.0005)$ & $(0.0005)$ & $(0.0006)$ & $(0.0009)$ & $(0.0003)$ & $(0.0004)$ & $(0.0004)$ & $(0.0006)$ \\
\hline \multirow[t]{2}{*}{ Tratamento 0} & -0.0003 & $0.0017^{* *}$ & $0.0017^{* *}$ & $0.0022^{* *}$ & $0.0022^{* * *}$ & $0.0028^{* * *}$ & $0.0027^{* * *}$ & $0.0024^{* * *}$ \\
\hline & $(0.0005)$ & $(0.0007)$ & $(0.0007)$ & $(0.0009)$ & $(0.0005)$ & $(0.0006)$ & $(0.0005)$ & $(0.0007)$ \\
\hline \multirow[t]{2}{*}{ Tratamento 1} & $0.0061^{* * *}$ & $0.0021^{* * *}$ & $0.0022^{* * *}$ & $0.0027^{* * *}$ & $0.0048^{* * *}$ & $0.0026^{* * *}$ & $0.0027^{* * *}$ & $0.0023^{* * *}$ \\
\hline & $(0.0007)$ & $(0.0005)$ & $(0.0005)$ & $(0.0008)$ & $(0.0008)$ & $(0.0005)$ & $(0.0005)$ & $(0.0007)$ \\
\hline \multirow{2}{*}{ Tratamento 2} & $0.0011^{*}$ & $0.0034^{* * *}$ & $0.0035^{* * *}$ & $0.0040^{* * *}$ & $0.0017^{* * *}$ & $0.0037^{* * *}$ & $0.0037^{* * *}$ & $0.0034^{* * *}$ \\
\hline & $(0.0006)$ & $(0.0005)$ & $(0.0005)$ & $(0.0009)$ & $(0.0006)$ & $(0.0005)$ & $(0.0005)$ & $(0.0007)$ \\
\hline \multirow[t]{2}{*}{ Tratamento 3} & $0.0025^{* * *}$ & $0.0028^{* * *}$ & $0.0027^{* * *}$ & $0.0032^{* * *}$ & $0.0030^{* * *}$ & $0.0033^{* * *}$ & $0.0032^{* * *}$ & $0.0028^{* * *}$ \\
\hline & $(0.0004)$ & $(0.0005)$ & $(0.0005)$ & $(0.0008)$ & $(0.0004)$ & $(0.0004)$ & $(0.0004)$ & $(0.0006)$ \\
\hline \multirow[t]{2}{*}{ Tratamento 4} & $0.0034^{* * *}$ & $0.0024^{* * *}$ & $0.0024^{* * *}$ & $0.0029^{* * *}$ & $0.0044^{* * *}$ & $0.0034^{* * *}$ & $0.0034^{* * *}$ & $0.0030^{* * *}$ \\
\hline & $(0.0007)$ & $(0.0007)$ & $(0.0007)$ & $(0.0010)$ & $(0.0007)$ & $(0.0008)$ & $(0.0007)$ & $(0.0009)$ \\
\hline Efeito fixo mensal & $\operatorname{sim}$ & $\operatorname{sim}$ & $\operatorname{sim}$ & $\operatorname{sim}$ & $\operatorname{sim}$ & $\operatorname{sim}$ & $\operatorname{sim}$ & $\operatorname{sim}$ \\
\hline Sazonalidade - grupo & não & $\operatorname{sim}$ & $\operatorname{sim}$ & $\operatorname{sim}$ & não & $\operatorname{sim}$ & $\operatorname{sim}$ & $\operatorname{sim}$ \\
\hline Covariadas & não & não & $\operatorname{sim}$ & $\operatorname{sim}$ & não & não & $\operatorname{sim}$ & $\operatorname{sim}$ \\
\hline Tendência linear & não & não & não & $\operatorname{sim}$ & não & não & não & $\operatorname{sim}$ \\
\hline Observações & 11125912 & 11125912 & 11125912 & 11125912 & 21752413 & 21752413 & 21752413 & 21752413 \\
\hline R-quadrado aj. & 0.001 & 0.001 & 0.006 & 0.006 & 0.001 & 0.001 & 0.006 & 0.006 \\
\hline \multicolumn{9}{|c|}{ 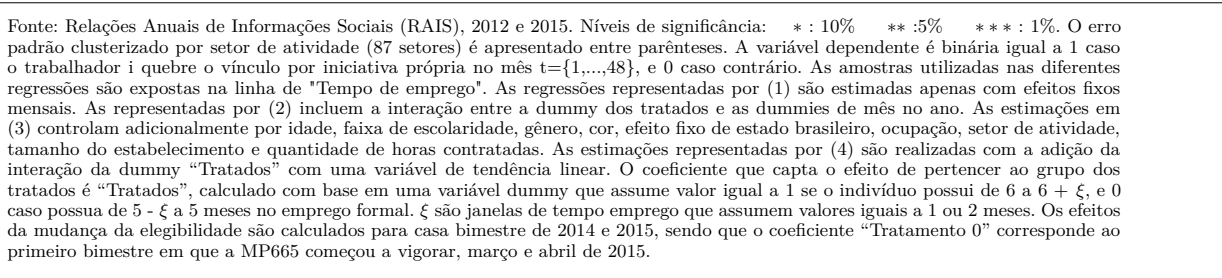 } \\
\hline
\end{tabular}


Tabela 30 - Resultado das regressões de diferenças em diferenças nas saídas por iniciativa do empregado por bimestre - controles acima de 18 meses

\begin{tabular}{|c|c|c|c|c|c|c|c|c|}
\hline \multirow{3}{*}{$\begin{array}{l}\text { Variável Dependente } \\
\text { Tempo de emprego }\end{array}$} & \multicolumn{8}{|c|}{ Dummy de Saída por Iniciativa do Trabalhador } \\
\hline & \multicolumn{4}{|c|}{$(6$ a 7$)-(18$ a 19$)$} & \multicolumn{4}{|c|}{$(6$ a 8$)-(18$ a 20$)$} \\
\hline & (1) & $(2)$ & (3) & (4) & (1) & $(2)$ & (3) & (4) \\
\hline \multirow[t]{2}{*}{ Tratamento -7} & $0.0010^{*}$ & 0.0004 & 0.0003 & 0.0000 & $0.0015^{* * *}$ & $0.0007^{*}$ & $0.0006^{*}$ & 0.0006 \\
\hline & $(0.0005)$ & $(0.0006)$ & $(0.0005)$ & $(0.0006)$ & $(0.0004)$ & $(0.0004)$ & $(0.0004)$ & $(0.0004)$ \\
\hline \multirow[t]{2}{*}{ Tratamento -6} & $0.0015^{* * *}$ & -0.0001 & 0.0001 & -0.0002 & $0.0012^{* * *}$ & -0.0003 & -0.0002 & -0.0002 \\
\hline & $(0.0006)$ & $(0.0006)$ & $(0.0005)$ & $(0.0006)$ & $(0.0005)$ & $(0.0005)$ & $(0.0005)$ & $(0.0004)$ \\
\hline \multirow[t]{2}{*}{ Tratamento -5} & 0.0006 & -0.0003 & -0.0001 & -0.0003 & 0.0001 & -0.0003 & -0.0000 & -0.0001 \\
\hline & $(0.0006)$ & $(0.0007)$ & $(0.0007)$ & $(0.0006)$ & $(0.0005)$ & $(0.0005)$ & $(0.0005)$ & $(0.0004)$ \\
\hline \multirow[t]{2}{*}{ Tratamento -4} & $-0.0011^{* * *}$ & -0.0000 & 0.0001 & -0.0001 & $-0.0011^{* * *}$ & -0.0003 & -0.0001 & -0.0002 \\
\hline & $(0.0004)$ & $(0.0004)$ & $(0.0004)$ & $(0.0006)$ & $(0.0003)$ & $(0.0003)$ & $(0.0003)$ & $(0.0004)$ \\
\hline \multirow[t]{2}{*}{ Tratamento -3} & 0.0001 & 0.0002 & 0.0001 & -0.0001 & -0.0003 & -0.0000 & -0.0001 & -0.0001 \\
\hline & $(0.0006)$ & $(0.0007)$ & $(0.0006)$ & $(0.0006)$ & $(0.0003)$ & $(0.0003)$ & $(0.0003)$ & $(0.0005)$ \\
\hline \multirow[t]{2}{*}{ Tratamento -2 } & $-0.0015^{* * *}$ & 0.0003 & 0.0003 & 0.0001 & $-0.0014^{* * *}$ & 0.0001 & 0.0000 & -0.0000 \\
\hline & $(0.0005)$ & $(0.0004)$ & $(0.0004)$ & $(0.0005)$ & $(0.0003)$ & $(0.0003)$ & $(0.0003)$ & $(0.0004)$ \\
\hline \multirow[t]{2}{*}{ Tratamento -1 } & $0.0008^{*}$ & 0.0002 & -0.0001 & -0.0004 & $0.0011^{* * *}$ & 0.0003 & 0.0001 & -0.0001 \\
\hline & $(0.0004)$ & $(0.0004)$ & $(0.0005)$ & $(0.0007)$ & $(0.0004)$ & $(0.0004)$ & $(0.0004)$ & $(0.0006)$ \\
\hline \multirow[t]{2}{*}{ Tratamento 0} & $0.0019^{* * *}$ & 0.0003 & 0.0001 & -0.0002 & $0.0017^{* * *}$ & 0.0002 & 0.0001 & -0.0000 \\
\hline & $(0.0005)$ & $(0.0006)$ & $(0.0006)$ & $(0.0007)$ & $(0.0004)$ & $(0.0005)$ & $(0.0005)$ & $(0.0006)$ \\
\hline \multirow[t]{2}{*}{ Tratamento 1} & $0.0012^{* *}$ & 0.0003 & 0.0001 & -0.0003 & 0.0002 & -0.0002 & -0.0004 & -0.0005 \\
\hline & $(0.0006)$ & $(0.0006)$ & $(0.0007)$ & $(0.0007)$ & $(0.0004)$ & $(0.0005)$ & $(0.0005)$ & $(0.0005)$ \\
\hline \multirow[t]{2}{*}{ Tratamento 2} & $-0.0015^{* * *}$ & -0.0004 & -0.0007 & -0.0010 & $-0.0015^{* * *}$ & $-0.0007^{*}$ & $-0.0009^{* *}$ & $-0.0011^{*}$ \\
\hline & $(0.0005)$ & $(0.0004)$ & $(0.0004)$ & $(0.0007)$ & $(0.0004)$ & $(0.0004)$ & $(0.0004)$ & $(0.0006)$ \\
\hline \multirow[t]{2}{*}{ Tratamento 3} & $-0.0022^{* * *}$ & $-0.0022^{* * *}$ & $-0.0023^{* * *}$ & $-0.0026^{* * *}$ & $-0.0020^{* * *}$ & $-0.0017^{* * *}$ & $-0.0018^{* * *}$ & $-0.0019^{* *}$ \\
\hline & $(0.0004)$ & $(0.0005)$ & $(0.0005)$ & $(0.0010)$ & $(0.0003)$ & $(0.0003)$ & $(0.0003)$ & $(0.0008)$ \\
\hline \multirow[t]{2}{*}{ Tratamento 4} & $-0.0025^{* * *}$ & -0.0008 & $-0.0008^{*}$ & -0.0012 & $-0.0020^{* * *}$ & -0.0005 & $-0.0006^{*}$ & -0.0007 \\
\hline & $(0.0005)$ & $(0.0005)$ & $(0.0005)$ & $(0.0010)$ & $(0.0004)$ & $(0.0003)$ & $(0.0003)$ & $(0.0007)$ \\
\hline
\end{tabular}

\begin{tabular}{|c|c|c|c|c|c|c|c|c|}
\hline Efeito fixo mensal & $\operatorname{sim}$ & $\operatorname{sim}$ & $\operatorname{sim}$ & $\operatorname{sim}$ & $\operatorname{sim}$ & $\operatorname{sim}$ & $\operatorname{sim}$ & $\operatorname{sim}$ \\
\hline Sazonalidade - grupo & não & $\operatorname{sim}$ & $\operatorname{sim}$ & $\operatorname{sim}$ & não & $\operatorname{sim}$ & $\operatorname{sim}$ & $\operatorname{sim}$ \\
\hline Covariadas & não & não & $\operatorname{sim}$ & $\operatorname{sim}$ & não & não & $\operatorname{sim}$ & $\operatorname{sim}$ \\
\hline Tendência linear & não & não & não & $\operatorname{sim}$ & não & não & não & $\operatorname{sim}$ \\
\hline Observações & 7598934 & 7598934 & 7598934 & 7598934 & 14369986 & 14369986 & 14369986 & 14369986 \\
\hline R-quadrado aj. & 0.002 & 0.002 & 0.006 & 0.006 & 0.002 & 0.002 & 0.006 & 0.006 \\
\hline \multicolumn{9}{|c|}{ 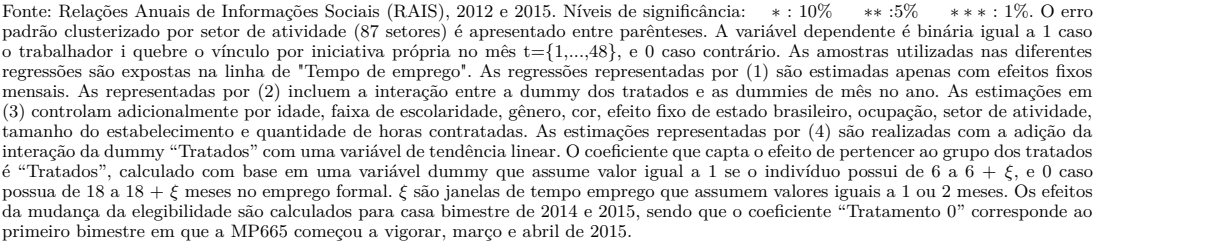 } \\
\hline
\end{tabular}


Tabela 31 - Resultado das regressões de diferenças em diferenças nas demissões com justa causa por bimestre - controles abaixo de 6 meses

\begin{tabular}{|c|c|c|c|c|c|c|c|c|}
\hline \multirow{3}{*}{$\begin{array}{l}\text { Variável Dependente } \\
\text { Tempo de emprego }\end{array}$} & \multicolumn{8}{|c|}{ Dummy de Demissão com Justa Causa } \\
\hline & \multicolumn{4}{|c|}{$(4$ a 5$)-(6$ a 7$)$} & \multicolumn{4}{|c|}{$(3$ a 5$)-(6$ a 8$)$} \\
\hline & $(1)$ & $(2)$ & $(3)$ & (4) & $(1)$ & $(2)$ & $(3)$ & (4) \\
\hline \multirow[t]{2}{*}{ Tratamento -7} & $0.0003^{* * *}$ & 0.0001 & 0.0001 & 0.0001 & $0.0002^{* *}$ & -0.0000 & -0.0000 & -0.0000 \\
\hline & $(0.0001)$ & $(0.0001)$ & $(0.0001)$ & $(0.0001)$ & $(0.0001)$ & $(0.0001)$ & $(0.0001)$ & $(0.0001)$ \\
\hline \multirow[t]{2}{*}{ Tratamento -6} & -0.0000 & -0.0000 & 0.0000 & 0.0000 & -0.0000 & -0.0000 & -0.0000 & -0.0000 \\
\hline & $(0.0001)$ & $(0.0002)$ & $(0.0002)$ & $(0.0002)$ & $(0.0001)$ & $(0.0001)$ & $(0.0001)$ & $(0.0001)$ \\
\hline \multirow[t]{2}{*}{ Tratamento -5} & $0.0004^{* * *}$ & 0.0001 & 0.0001 & 0.0001 & $0.0002^{*}$ & 0.0001 & 0.0001 & 0.0001 \\
\hline & $(0.0001)$ & $(0.0001)$ & $(0.0001)$ & $(0.0002)$ & $(0.0001)$ & $(0.0001)$ & $(0.0001)$ & $(0.0001)$ \\
\hline \multirow{2}{*}{ Tratamento -4} & -0.0001 & 0.0000 & -0.0000 & 0.0000 & -0.0001 & 0.0000 & 0.0000 & 0.0000 \\
\hline & $(0.0001)$ & $(0.0002)$ & $(0.0002)$ & $(0.0002)$ & $(0.0001)$ & $(0.0002)$ & $(0.0002)$ & $(0.0002)$ \\
\hline \multirow[t]{2}{*}{ Tratamento -3} & -0.0001 & 0.0001 & 0.0001 & 0.0001 & -0.0001 & 0.0001 & 0.0001 & 0.0001 \\
\hline & $(0.0002)$ & $(0.0001)$ & $(0.0001)$ & $(0.0001)$ & $(0.0001)$ & $(0.0001)$ & $(0.0001)$ & $(0.0001)$ \\
\hline \multirow[t]{2}{*}{ Tratamento -2 } & 0.0000 & 0.0000 & 0.0001 & 0.0001 & -0.0001 & -0.0001 & -0.0000 & -0.0000 \\
\hline & $(0.0001)$ & $(0.0001)$ & $(0.0001)$ & $(0.0002)$ & $(0.0001)$ & $(0.0001)$ & $(0.0001)$ & $(0.0001)$ \\
\hline \multirow[t]{2}{*}{ Tratamento -1 } & 0.0001 & -0.0000 & -0.0001 & -0.0001 & $0.0002^{* *}$ & -0.0001 & -0.0001 & -0.0001 \\
\hline & $(0.0001)$ & $(0.0001)$ & $(0.0001)$ & $(0.0002)$ & $(0.0001)$ & $(0.0001)$ & $(0.0001)$ & $(0.0002)$ \\
\hline \multirow[t]{2}{*}{ Tratamento 0} & -0.0002 & -0.0002 & -0.0002 & -0.0002 & $-0.0002^{* *}$ & $-0.0002^{*}$ & $-0.0003^{*}$ & $-0.0002^{*}$ \\
\hline & $(0.0001)$ & $(0.0002)$ & $(0.0002)$ & $(0.0002)$ & $(0.0001)$ & $(0.0001)$ & $(0.0001)$ & $(0.0001)$ \\
\hline \multirow[t]{2}{*}{ Tratamento 1} & $0.0005^{* * *}$ & 0.0002 & 0.0002 & 0.0002 & 0.0001 & 0.0000 & 0.0000 & 0.0001 \\
\hline & $(0.0001)$ & $(0.0001)$ & $(0.0001)$ & $(0.0002)$ & $(0.0001)$ & $(0.0001)$ & $(0.0001)$ & $(0.0002)$ \\
\hline \multirow[t]{2}{*}{ Tratamento 2} & -0.0000 & 0.0001 & 0.0001 & 0.0001 & 0.0001 & 0.0002 & 0.0002 & 0.0002 \\
\hline & $(0.0001)$ & $(0.0001)$ & $(0.0001)$ & $(0.0001)$ & $(0.0001)$ & $(0.0001)$ & $(0.0001)$ & $(0.0002)$ \\
\hline \multirow[t]{2}{*}{ Tratamento 3} & 0.0002 & 0.0004 & 0.0004 & 0.0004 & 0.0002 & $0.0003^{* *}$ & $0.0003^{* *}$ & $0.0003^{*}$ \\
\hline & $(0.0002)$ & $(0.0002)$ & $(0.0002)$ & $(0.0003)$ & $(0.0002)$ & $(0.0002)$ & $(0.0002)$ & $(0.0002)$ \\
\hline \multirow[t]{2}{*}{ Tratamento 4} & -0.0000 & 0.0000 & 0.0000 & 0.0000 & 0.0000 & 0.0001 & 0.0001 & 0.0001 \\
\hline & $(0.0001)$ & $(0.0001)$ & $(0.0001)$ & $(0.0002)$ & $(0.0001)$ & $(0.0001)$ & $(0.0001)$ & $(0.0001)$ \\
\hline Efeito fixo mensal & $\operatorname{sim}$ & $\operatorname{sim}$ & $\operatorname{sim}$ & $\operatorname{sim}$ & $\operatorname{sim}$ & $\operatorname{sim}$ & $\operatorname{sim}$ & $\operatorname{sim}$ \\
\hline Sazonalidade - grupo & não & $\operatorname{sim}$ & $\operatorname{sim}$ & $\operatorname{sim}$ & não & $\operatorname{sim}$ & $\operatorname{sim}$ & $\operatorname{sim}$ \\
\hline Covariadas & não & não & $\operatorname{sim}$ & $\operatorname{sim}$ & não & não & $\operatorname{sim}$ & $\operatorname{sim}$ \\
\hline Tendência linear & não & não & não & $\operatorname{sim}$ & não & não & não & $\operatorname{sim}$ \\
\hline Observações & 11125912 & 11125912 & 11125912 & 11125912 & 21752413 & 21752413 & 21752413 & 21752413 \\
\hline R-quadrado aj. & 0.000 & 0.000 & 0.001 & 0.001 & 0.000 & 0.000 & 0.001 & 0.001 \\
\hline \multicolumn{9}{|c|}{ 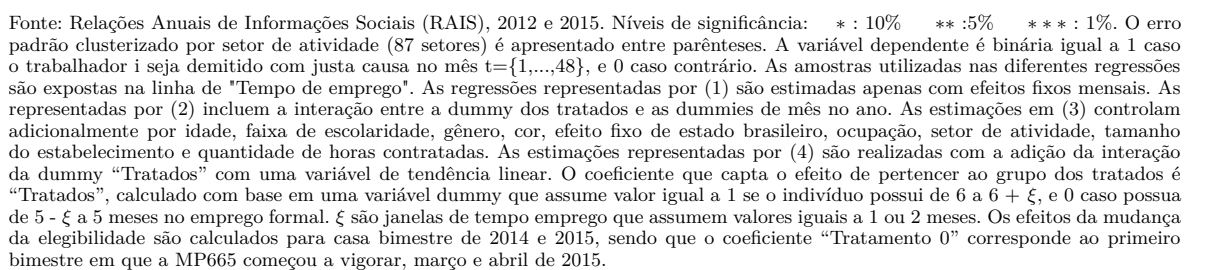 } \\
\hline
\end{tabular}


Tabela 32 - Resultado das regressões de diferenças em diferenças nas demissões com justa causa por bimestre - controles acima de 18 meses

\begin{tabular}{|c|c|c|c|c|c|c|c|c|}
\hline \multirow{3}{*}{$\begin{array}{l}\text { Variável Dependente } \\
\text { Tempo de emprego }\end{array}$} & \multicolumn{8}{|c|}{ Dummy de Demissão com Justa Causa } \\
\hline & \multicolumn{4}{|c|}{$(6$ a 7$)-(18$ a 19$)$} & \multicolumn{4}{|c|}{$(6$ a 8$)-(18$ a 20$)$} \\
\hline & (1) & $(2)$ & (3) & (4) & (1) & $(2)$ & (3) & (4) \\
\hline \multirow[t]{2}{*}{ Tratamento -7} & $-0.0003^{* *}$ & -0.0000 & 0.0000 & -0.0000 & $-0.0003^{* * *}$ & -0.0000 & -0.0000 & -0.0000 \\
\hline & $(0.0001)$ & $(0.0001)$ & $(0.0001)$ & $(0.0002)$ & $(0.0001)$ & $(0.0001)$ & $(0.0001)$ & $(0.0001)$ \\
\hline \multirow[t]{2}{*}{ Tratamento -6} & 0.0002 & 0.0001 & 0.0001 & 0.0001 & $0.0002^{* *}$ & 0.0000 & 0.0001 & 0.0001 \\
\hline & $(0.0001)$ & $(0.0001)$ & $(0.0001)$ & $(0.0002)$ & $(0.0001)$ & $(0.0001)$ & $(0.0001)$ & $(0.0001)$ \\
\hline \multirow[t]{2}{*}{ Tratamento -5} & $0.0003^{* *}$ & 0.0002 & 0.0002 & 0.0002 & $0.0002^{*}$ & 0.0002 & 0.0002 & 0.0002 \\
\hline & $(0.0001)$ & $(0.0002)$ & $(0.0001)$ & $(0.0002)$ & $(0.0001)$ & $(0.0001)$ & $(0.0001)$ & $(0.0002)$ \\
\hline \multirow[t]{2}{*}{ Tratamento -4} & -0.0000 & -0.0001 & -0.0001 & -0.0001 & -0.0001 & $-0.0002^{*}$ & $-0.0002^{*}$ & $-0.0002^{*}$ \\
\hline & $(0.0001)$ & $(0.0002)$ & $(0.0002)$ & $(0.0002)$ & $(0.0001)$ & $(0.0001)$ & $(0.0001)$ & $(0.0001)$ \\
\hline \multirow[t]{2}{*}{ Tratamento -3} & 0.0001 & 0.0001 & 0.0001 & 0.0001 & 0.0001 & 0.0001 & 0.0001 & 0.0001 \\
\hline & $(0.0002)$ & $(0.0002)$ & $(0.0002)$ & $(0.0002)$ & $(0.0001)$ & $(0.0001)$ & $(0.0001)$ & $(0.0001)$ \\
\hline \multirow[t]{2}{*}{ Tratamento -2 } & $0.0003^{* *}$ & $0.0002^{*}$ & $0.0002^{*}$ & 0.0002 & 0.0001 & 0.0001 & 0.0001 & 0.0001 \\
\hline & $(0.0001)$ & $(0.0001)$ & $(0.0001)$ & $(0.0002)$ & $(0.0001)$ & $(0.0001)$ & $(0.0001)$ & $(0.0002)$ \\
\hline \multirow[t]{2}{*}{ Tratamento -1 } & $-0.0004^{* * *}$ & -0.0001 & -0.0002 & -0.0002 & $-0.0004^{* * *}$ & -0.0002 & $-0.0002^{*}$ & $-0.0002^{*}$ \\
\hline & $(0.0001)$ & $(0.0001)$ & $(0.0001)$ & $(0.0002)$ & $(0.0001)$ & $(0.0001)$ & $(0.0001)$ & $(0.0001)$ \\
\hline \multirow[t]{2}{*}{ Tratamento 0} & 0.0000 & -0.0000 & -0.0000 & -0.0000 & 0.0000 & -0.0001 & -0.0001 & -0.0001 \\
\hline & $(0.0001)$ & $(0.0002)$ & $(0.0002)$ & $(0.0002)$ & $(0.0001)$ & $(0.0001)$ & $(0.0001)$ & $(0.0001)$ \\
\hline \multirow[t]{2}{*}{ Tratamento 1} & $0.0004^{* *}$ & $0.0003^{*}$ & $0.0003^{*}$ & 0.0002 & 0.0002 & 0.0001 & 0.0001 & 0.0001 \\
\hline & $(0.0002)$ & $(0.0001)$ & $(0.0001)$ & $(0.0002)$ & $(0.0001)$ & $(0.0001)$ & $(0.0001)$ & $(0.0001)$ \\
\hline \multirow[t]{2}{*}{ Tratamento 2} & 0.0002 & 0.0001 & 0.0001 & 0.0001 & $0.0002^{* *}$ & 0.0001 & 0.0001 & 0.0001 \\
\hline & $(0.0001)$ & $(0.0002)$ & $(0.0001)$ & $(0.0002)$ & $(0.0001)$ & $(0.0001)$ & $(0.0001)$ & $(0.0002)$ \\
\hline \multirow[t]{2}{*}{ Tratamento 3} & -0.0002 & -0.0002 & -0.0002 & -0.0002 & -0.0001 & -0.0001 & -0.0001 & -0.0001 \\
\hline & $(0.0001)$ & $(0.0002)$ & $(0.0001)$ & $(0.0002)$ & $(0.0001)$ & $(0.0001)$ & $(0.0001)$ & $(0.0002)$ \\
\hline \multirow[t]{2}{*}{ Tratamento 4} & $-0.0003^{* *}$ & $-0.0003^{* * *}$ & $-0.0003^{* *}$ & -0.0003 & $-0.0003^{* * *}$ & $-0.0003^{* * *}$ & $-0.0002^{* * *}$ & $-0.0003^{*}$ \\
\hline & $(0.0001)$ & $(0.0001)$ & $(0.0001)$ & $(0.0002)$ & $(0.0001)$ & $(0.0001)$ & $(0.0001)$ & $(0.0001)$ \\
\hline Efeito fixo mensal & $\operatorname{sim}$ & $\operatorname{sim}$ & $\operatorname{sim}$ & $\operatorname{sim}$ & $\operatorname{sim}$ & $\operatorname{sim}$ & $\operatorname{sim}$ & $\operatorname{sim}$ \\
\hline Sazonalidade - grupo & não & $\operatorname{sim}$ & $\operatorname{sim}$ & $\operatorname{sim}$ & não & $\operatorname{sim}$ & $\operatorname{sim}$ & $\operatorname{sim}$ \\
\hline Covariadas & não & não & $\operatorname{sim}$ & $\operatorname{sim}$ & não & não & $\operatorname{sim}$ & $\operatorname{sim}$ \\
\hline Tendência linear & não & não & não & $\operatorname{sim}$ & não & não & não & $\operatorname{sim}$ \\
\hline Observações & 7598934 & 7598934 & 7598934 & 7598934 & 14369986 & 14369986 & 14369986 & 14369986 \\
\hline R-quadrado aj. & 0.000 & 0.000 & 0.001 & 0.001 & 0.000 & 0.000 & 0.001 & 0.001 \\
\hline \multicolumn{9}{|c|}{ 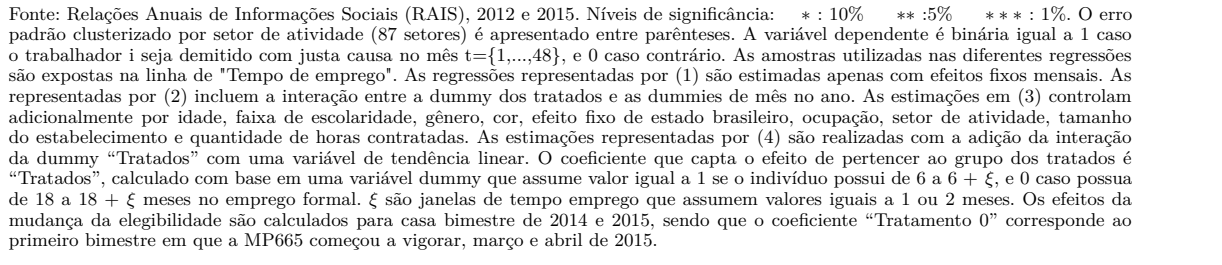 } \\
\hline
\end{tabular}


Tabela 33 - Resultado das regressões de diferenças em diferenças nas quebra por outros tipos por bimestre - controles abaixo de 6 meses

\begin{tabular}{|c|c|c|c|c|c|c|c|c|}
\hline \multirow{3}{*}{$\begin{array}{l}\text { Variável Dependente } \\
\text { Tempo de emprego }\end{array}$} & \multicolumn{8}{|c|}{ Dummy de Outros Tipos de Quebra } \\
\hline & \multicolumn{4}{|c|}{$(4$ a 5$)-(6$ a 7$)$} & \multicolumn{4}{|c|}{$(3$ a 5$)-(6$ a 8$)$} \\
\hline & $(1)$ & (2) & (3) & $(4)$ & (1) & (2) & (3) & (4) \\
\hline \multirow[t]{2}{*}{ Tratamento -7} & -0.0002 & 0.0004 & 0.0004 & 0.0009 & $0.0009^{* *}$ & 0.0004 & 0.0005 & $0.0034^{* * *}$ \\
\hline & $(0.0004)$ & $(0.0006)$ & $(0.0006)$ & $(0.0010)$ & $(0.0004)$ & $(0.0004)$ & $(0.0004)$ & $(0.0007)$ \\
\hline \multirow[t]{2}{*}{ Tratamento -6} & 0.0008 & 0.0000 & 0.0001 & 0.0007 & 0.0008 & -0.0001 & -0.0001 & $0.0028^{* * *}$ \\
\hline & $(0.0015)$ & $(0.0009)$ & $(0.0009)$ & $(0.0011)$ & $(0.0009)$ & $(0.0006)$ & $(0.0006)$ & $(0.0008)$ \\
\hline \multirow[t]{2}{*}{ Tratamento -5} & 0.0005 & 0.0001 & -0.0000 & 0.0005 & $-0.0113^{* * *}$ & $-0.0064^{* * *}$ & $-0.0065^{* * *}$ & $-0.0037^{* * *}$ \\
\hline & $(0.0003)$ & $(0.0006)$ & $(0.0005)$ & $(0.0008)$ & $(0.0008)$ & $(0.0007)$ & $(0.0007)$ & $(0.0008)$ \\
\hline \multirow[t]{2}{*}{ Tratamento -4} & -0.0005 & -0.0004 & -0.0004 & 0.0001 & $0.0011^{* * *}$ & -0.0000 & -0.0000 & $0.0029^{* * *}$ \\
\hline & $(0.0005)$ & $(0.0006)$ & $(0.0006)$ & $(0.0008)$ & $(0.0004)$ & $(0.0004)$ & $(0.0004)$ & $(0.0006)$ \\
\hline \multirow[t]{2}{*}{ Tratamento -3} & -0.0008 & -0.0004 & -0.0004 & 0.0001 & 0.0001 & -0.0000 & -0.0000 & $0.0029^{* * *}$ \\
\hline & $(0.0010)$ & $(0.0008)$ & $(0.0008)$ & $(0.0008)$ & $(0.0007)$ & $(0.0004)$ & $(0.0004)$ & $(0.0005)$ \\
\hline \multirow[t]{2}{*}{ Tratamento -2} & -0.0001 & -0.0004 & -0.0002 & 0.0003 & $0.0014^{* *}$ & -0.0003 & -0.0002 & $0.0027^{* * *}$ \\
\hline & $(0.0006)$ & $(0.0006)$ & $(0.0006)$ & $(0.0010)$ & $(0.0006)$ & $(0.0004)$ & $(0.0004)$ & $(0.0007)$ \\
\hline \multirow[t]{2}{*}{ Tratamento - 1} & 0.0001 & 0.0007 & 0.0006 & 0.0014 & 0.0005 & 0.0000 & -0.0000 & $0.0048^{* * *}$ \\
\hline & $(0.0004)$ & $(0.0008)$ & $(0.0007)$ & $(0.0014)$ & $(0.0006)$ & $(0.0007)$ & $(0.0007)$ & $(0.0011)$ \\
\hline \multirow[t]{2}{*}{ Tratamento 0} & 0.0002 & -0.0006 & -0.0005 & 0.0004 & 0.0000 & $-0.0009^{*}$ & $-0.0008^{*}$ & $0.0040^{* * *}$ \\
\hline & $(0.0005)$ & $(0.0007)$ & $(0.0006)$ & $(0.0009)$ & $(0.0004)$ & $(0.0005)$ & $(0.0005)$ & $(0.0009)$ \\
\hline \multirow[t]{2}{*}{ Tratamento 1} & -0.0003 & -0.0007 & -0.0006 & 0.0002 & $-0.0121^{* * *}$ & $-0.0074^{* * *}$ & $-0.0074^{* * *}$ & $-0.0026^{* * *}$ \\
\hline & $(0.0004)$ & $(0.0005)$ & $(0.0004)$ & $(0.0010)$ & $(0.0007)$ & $(0.0005)$ & $(0.0006)$ & $(0.0009)$ \\
\hline \multirow[t]{2}{*}{ Tratamento 2} & $-0.0008^{* *}$ & -0.0006 & -0.0007 & 0.0001 & 0.0004 & $-0.0007^{*}$ & $-0.0008^{*}$ & $0.0040^{* * *}$ \\
\hline & $(0.0004)$ & $(0.0005)$ & $(0.0006)$ & $(0.0011)$ & $(0.0003)$ & $(0.0004)$ & $(0.0004)$ & $(0.0010)$ \\
\hline \multirow[t]{2}{*}{ Tratamento 3} & -0.0012 & -0.0008 & -0.0008 & 0.0000 & -0.0007 & $-0.0008^{*}$ & $-0.0008^{*}$ & $0.0040^{* * *}$ \\
\hline & $(0.0008)$ & $(0.0007)$ & $(0.0007)$ & $(0.0011)$ & $(0.0007)$ & $(0.0005)$ & $(0.0005)$ & $(0.0008)$ \\
\hline \multirow[t]{2}{*}{ Tratamento 4} & $-0.0009^{*}$ & $-0.0011^{* *}$ & $-0.0010^{* *}$ & -0.0001 & $0.0009^{* * *}$ & $-0.0007^{* *}$ & $-0.0006^{*}$ & $0.0042^{* * *}$ \\
\hline & $(0.0005)$ & $(0.0005)$ & $(0.0005)$ & $(0.0010)$ & $(0.0003)$ & $(0.0004)$ & $(0.0003)$ & $(0.0008)$ \\
\hline
\end{tabular}

\begin{tabular}{lcccccccc} 
Efeito fixo mensal & $\operatorname{sim}$ & $\operatorname{sim}$ & $\operatorname{sim}$ & $\operatorname{sim}$ & $\operatorname{sim}$ & $\operatorname{sim}$ & $\operatorname{sim}$ & $\operatorname{sim}$ \\
Sazonalidade - grupo & não & $\operatorname{sim}$ & $\operatorname{sim}$ & $\operatorname{sim}$ & não & $\operatorname{sim}$ & $\operatorname{sim}$ & $\operatorname{sim}$ \\
Covariadas & não & não & $\operatorname{sim}$ & $\operatorname{sim}$ & não & não & $\operatorname{sim}$ & $\operatorname{sim}$ \\
Tendência linear & não & não & não & $\operatorname{sim}$ & não & não & não & sim \\
Observações & 11125912 & 11125912 & 11125912 & 11125912 & 21752413 & 21752413 & 21752413 & 21752413 \\
R-quadrado aj. & 0.000 & 0.000 & 0.004 & 0.004 & 0.003 & 0.003 & 0.006 & 0.006 \\
\hline
\end{tabular}

Fonte: Relações Anuais de Informações Sociais (RAIS), 2012 e 2015. Níveis de significância: $\quad *: 10 \% \quad * *: 5 \% \quad * * *: 1 \%$. O erro

padrão clusterizado por setor de atividade (87 setores) é apresentado entre parênteses. A variável dependente é binária igual a 1 caso o vínculo do trabalhador i seja quebrado por término do contrato, recisão com justa causa por iniciativa do empregado, transferência, falecimento ou aposentadoria no mês $\mathrm{t}=\{1, \ldots, 48\}$, e 0 caso contrário. As amostras utilizadas nas diferentes regressões são expostas na linha de "Tempo de emprego". As regressões representadas por (1) são estimadas apenas com efeitos fixos mensais. As representadas por (2) incluem a interação entre a dummy dos tratados e as dummies de mês no ano. As estimações em (3) controlam adicionalmente por idade, faixa de escolaridade, gênero, cor, efeito fixo de estado brasileiro, ocupação, setor de atividade, tamanho do estabelecimento e quantidade de horas contratadas. As estimaçoes representadas por (4) são realizadas com a adição da interação da dummy "Tratados" base em uma variável dummy que assume valor igual a 1 se o indivíduo possui de 6 a $6+\xi$, e 0 caso possua de $5-\xi$ a 5 meses no emprego formal. $\xi$ são janelas de tempo emprego que assumem valores iguais a 1 ou 2 meses. Os efeitos da mudança da elegibilidade são calculados para casa bimestre de 2014 e 2015, sendo que o coeficiente "Tratamento 0" corresponde ao primeiro bimestre em que a MP665 começou a vigorar, março e abril de 2015 . 
Tabela 34 - Resultado das regressões de diferenças em diferenças nas quebra por outros tipos por bimestre - controles acima de 18 meses

\begin{tabular}{|c|c|c|c|c|c|c|c|c|}
\hline \multirow{3}{*}{$\begin{array}{l}\text { Variável Dependente } \\
\text { Tempo de emprego }\end{array}$} & \multicolumn{8}{|c|}{ Dummy de Outros Tipos de Quebra } \\
\hline & \multicolumn{4}{|c|}{$(6$ a 7$)-(18$ a 19$)$} & \multicolumn{4}{|c|}{$(6$ a 8$)-(18$ a 20$)$} \\
\hline & (1) & $(2)$ & $(3)$ & (4) & (1) & $(2)$ & $(3)$ & $(4)$ \\
\hline \multirow[t]{2}{*}{ Tratamento -7} & $-0.0011^{* * *}$ & -0.0004 & -0.0004 & -0.0005 & $-0.0007^{* * *}$ & 0.0003 & 0.0003 & 0.0002 \\
\hline & $(0.0004)$ & $(0.0005)$ & $(0.0005)$ & $(0.0006)$ & $(0.0002)$ & $(0.0003)$ & $(0.0003)$ & $(0.0005)$ \\
\hline \multirow[t]{2}{*}{ Tratamento -6} & 0.0000 & -0.0010 & -0.0011 & -0.0011 & -0.0003 & -0.0008 & -0.0009 & -0.0010 \\
\hline & $(0.0016)$ & $(0.0009)$ & $(0.0009)$ & $(0.0011)$ & $(0.0009)$ & $(0.0005)$ & $(0.0005)$ & $(0.0008)$ \\
\hline \multirow[t]{2}{*}{ Tratamento -5} & $-0.0010^{* *}$ & -0.0005 & -0.0006 & -0.0007 & $-0.0007^{* *}$ & -0.0005 & -0.0006 & -0.0007 \\
\hline & $(0.0005)$ & $(0.0006)$ & $(0.0006)$ & $(0.0009)$ & $(0.0003)$ & $(0.0005)$ & $(0.0005)$ & $(0.0008)$ \\
\hline \multirow[t]{2}{*}{ Tratamento -4} & 0.0001 & 0.0007 & 0.0007 & 0.0006 & 0.0005 & 0.0006 & 0.0006 & 0.0004 \\
\hline & $(0.0009)$ & $(0.0009)$ & $(0.0009)$ & $(0.0009)$ & $(0.0008)$ & $(0.0008)$ & $(0.0008)$ & $(0.0010)$ \\
\hline \multirow[t]{2}{*}{ Tratamento -3} & -0.0004 & -0.0004 & -0.0004 & -0.0005 & -0.0005 & -0.0002 & -0.0002 & -0.0004 \\
\hline & $(0.0005)$ & $(0.0004)$ & $(0.0004)$ & $(0.0006)$ & $(0.0004)$ & $(0.0003)$ & $(0.0003)$ & $(0.0005)$ \\
\hline \multirow[t]{2}{*}{ Tratamento -2} & 0.0007 & 0.0001 & 0.0001 & 0.0000 & 0.0009 & -0.0001 & -0.0000 & -0.0002 \\
\hline & $(0.0004)$ & $(0.0004)$ & $(0.0004)$ & $(0.0006)$ & $(0.0006)$ & $(0.0003)$ & $(0.0003)$ & $(0.0006)$ \\
\hline \multirow{2}{*}{ Tratamento -1 } & -0.0006 & 0.0000 & -0.0000 & -0.0001 & $-0.0010^{* *}$ & -0.0001 & -0.0001 & -0.0003 \\
\hline & $(0.0005)$ & $(0.0004)$ & $(0.0005)$ & $(0.0008)$ & $(0.0005)$ & $(0.0005)$ & $(0.0006)$ & $(0.0008)$ \\
\hline \multirow[t]{2}{*}{ Tratamento 0} & 0.0002 & -0.0008 & -0.0009 & -0.0010 & 0.0002 & -0.0003 & -0.0004 & -0.0006 \\
\hline & $(0.0008)$ & $(0.0006)$ & $(0.0006)$ & $(0.0009)$ & $(0.0005)$ & $(0.0005)$ & $(0.0005)$ & $(0.0008)$ \\
\hline \multirow[t]{2}{*}{ Tratamento 1} & -0.0005 & -0.0000 & -0.0001 & -0.0002 & -0.0003 & -0.0001 & -0.0002 & -0.0004 \\
\hline & $(0.0004)$ & $(0.0006)$ & $(0.0006)$ & $(0.0011)$ & $(0.0004)$ & $(0.0005)$ & $(0.0005)$ & $(0.0010)$ \\
\hline \multirow[t]{2}{*}{ Tratamento 2} & 0.0004 & $0.0009^{* * *}$ & $0.0008^{* *}$ & 0.0007 & 0.0004 & 0.0005 & 0.0003 & 0.0001 \\
\hline & $(0.0005)$ & $(0.0003)$ & $(0.0003)$ & $(0.0008)$ & $(0.0004)$ & $(0.0004)$ & $(0.0004)$ & $(0.0008)$ \\
\hline \multirow[t]{2}{*}{ Tratamento 3} & 0.0001 & 0.0001 & 0.0001 & -0.0000 & 0.0002 & 0.0004 & 0.0005 & 0.0003 \\
\hline & $(0.0005)$ & $(0.0004)$ & $(0.0004)$ & $(0.0008)$ & $(0.0004)$ & $(0.0004)$ & $(0.0004)$ & $(0.0007)$ \\
\hline \multirow[t]{2}{*}{ Tratamento 4} & 0.0004 & -0.0002 & -0.0002 & -0.0003 & $0.0012^{* * *}$ & 0.0002 & 0.0002 & 0.0000 \\
\hline & $(0.0004)$ & $(0.0005)$ & $(0.0005)$ & $(0.0009)$ & $(0.0004)$ & $(0.0003)$ & $(0.0003)$ & $(0.0008)$ \\
\hline Efeito fixo mensal & $\operatorname{sim}$ & $\operatorname{sim}$ & $\operatorname{sim}$ & $\operatorname{sim}$ & $\operatorname{sim}$ & $\operatorname{sim}$ & $\operatorname{sim}$ & $\operatorname{sim}$ \\
\hline Sazonalidade - grupo & não & $\operatorname{sim}$ & $\operatorname{sim}$ & $\operatorname{sim}$ & não & $\operatorname{sim}$ & $\operatorname{sim}$ & $\operatorname{sim}$ \\
\hline Covariadas & não & não & $\operatorname{sim}$ & $\operatorname{sim}$ & não & não & $\operatorname{sim}$ & $\operatorname{sim}$ \\
\hline Tendência linear & não & não & não & $\operatorname{sim}$ & não & não & não & $\operatorname{sim}$ \\
\hline Observações & 7598934 & 7598934 & 7598934 & 7598934 & 14369986 & 14369986 & 14369986 & 14369986 \\
\hline R-quadrado aj. & 0.000 & 0.000 & 0.004 & 0.004 & 0.000 & 0.000 & 0.003 & 0.003 \\
\hline \multicolumn{9}{|c|}{ 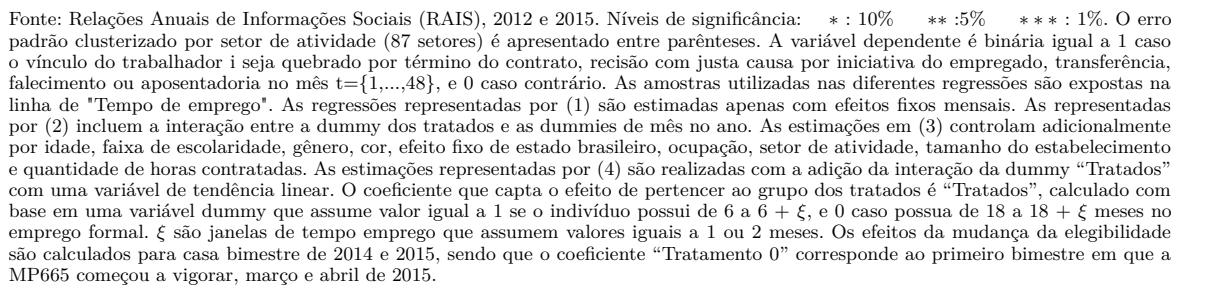 } \\
\hline
\end{tabular}




\section{APÊNDICE C - Resultados PME}

Tabela 35 - Resultado das regressões de diferenças em diferenças nas saídas do setor informal - Controles com 3 meses e tratados com 6 em t-1

\begin{tabular}{|c|c|c|c|c|}
\hline \multirow{2}{*}{$\begin{array}{l}\text { Tempo de Emprego } \\
\text { Variável Dependente }\end{array}$} & \multicolumn{4}{|c|}{ Controles com 3 e tratados com 6 meses no emprego informal em t-1 } \\
\hline & $\begin{array}{l}\text { Dummy de saída do Informal } \\
(1)\end{array}$ & $\begin{array}{l}\text { Dummy de Desocupados } \\
(2)\end{array}$ & $\begin{array}{c}\text { Dummy de Inativos } \\
(3)\end{array}$ & $\begin{array}{c}\text { Dummy de Formal } \\
(4)\end{array}$ \\
\hline \multirow[t]{2}{*}{ Efeito da Mudança } & -0.0119 & 0.0220 & -0.0159 & -0.0006 \\
\hline & $(0.0370)$ & $(0.0165)$ & $(0.0207)$ & $(0.0292)$ \\
\hline \multirow[t]{2}{*}{ Tratados } & -0.0385 & $0.0606^{* *}$ & $-0.0561^{* *}$ & -0.0520 \\
\hline & $(0.0597)$ & $(0.0280)$ & $(0.0257)$ & $(0.0512)$ \\
\hline \multirow[t]{2}{*}{ Constante } & 0.1056 & 0.0257 & $0.1925^{* * *}$ & -0.0480 \\
\hline & $(0.1171)$ & $(0.0330)$ & $(0.0680)$ & $(0.0987)$ \\
\hline Efeito fixo mensal & $\operatorname{sim}$ & $\operatorname{sim}$ & $\operatorname{sim}$ & $\operatorname{sim}$ \\
\hline Sazonalidade - grupo & $\operatorname{sim}$ & $\operatorname{sim}$ & $\operatorname{sim}$ & $\operatorname{sim}$ \\
\hline Covariadas & $\operatorname{sim}$ & $\operatorname{sim}$ & $\operatorname{sim}$ & $\operatorname{sim}$ \\
\hline Observações & 6100 & 6100 & 6100 & 6100 \\
\hline R-quadrado aj. & 0.068 & 0.009 & 0.038 & 0.050 \\
\hline \multicolumn{5}{|c|}{ 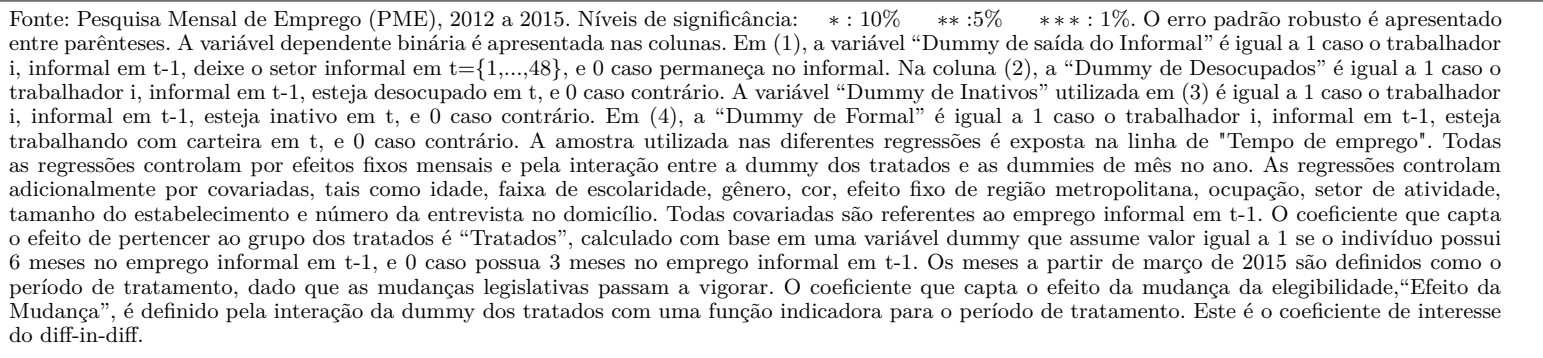 } \\
\hline
\end{tabular}

Tabela 36 - Resultado das regressões de diferenças em diferenças nas saídas do setor informal - Controles com 3 meses e tratados com 6 em t-1 - Heterogeneidade de escolaridade

\begin{tabular}{|c|c|c|c|c|}
\hline \multirow{2}{*}{$\begin{array}{l}\text { Tempo de Emprego } \\
\text { Variável Dependente }\end{array}$} & \multicolumn{4}{|c|}{ Controles com 3 e tratados com 6 meses no emprego informal em t-1 } \\
\hline & $\begin{array}{c}\text { Dummy de saída do Informal } \\
(1)\end{array}$ & $\begin{array}{c}\text { Dummy de Desocupados } \\
(2)\end{array}$ & $\begin{array}{c}\text { Dummy de Inativos } \\
(3)\end{array}$ & $\begin{array}{l}\text { Dummy de Formal } \\
\text { (4) }\end{array}$ \\
\hline Efeito da Mudança & $\begin{array}{l}-0.0046 \\
(0.0573)\end{array}$ & $\begin{array}{c}0.0157 \\
(0.0275)\end{array}$ & $\begin{array}{l}-0.0227 \\
(0.0313)\end{array}$ & $\begin{array}{c}0.0310 \\
(0.0441)\end{array}$ \\
\hline Efeito Mudança* $\geq 11$ anos de estudo & $\begin{array}{l}-0.0127 \\
(0.0734)\end{array}$ & $\begin{array}{c}0.0112 \\
(0.0341)\end{array}$ & $\begin{array}{c}0.0115 \\
(0.0406)\end{array}$ & $\begin{array}{l}-0.0553 \\
(0.0565)\end{array}$ \\
\hline Tratados & $\begin{array}{l}-0.0403 \\
(0.0620)\end{array}$ & $\begin{array}{l}0.0643^{* *} \\
(0.0279)\end{array}$ & $\begin{array}{c}-0.0575^{* *} \\
(0.0276)\end{array}$ & $\begin{array}{l}-0.0491 \\
(0.0528)\end{array}$ \\
\hline Constante & $\begin{array}{c}0.1040 \\
(0.1173)\end{array}$ & $\begin{array}{c}0.0249 \\
(0.0329)\end{array}$ & $\begin{array}{c}0.1943^{* * *} \\
(0.0680)\end{array}$ & $\begin{array}{l}-0.0480 \\
(0.0990)\end{array}$ \\
\hline Efeito fixo mensal & $\operatorname{sim}$ & $\operatorname{sim}$ & $\operatorname{sim}$ & $\operatorname{sim}$ \\
\hline Sazonalidade - grupo & $\operatorname{sim}$ & $\operatorname{sim}$ & $\operatorname{sim}$ & $\operatorname{sim}$ \\
\hline Covariadas & $\operatorname{sim}$ & $\operatorname{sim}$ & $\operatorname{sim}$ & $\operatorname{sim}$ \\
\hline Observações & 6100 & 6100 & 6100 & 6100 \\
\hline R-quadrado aj. & 0.067 & 0.009 & 0.038 & 0.050 \\
\hline $\begin{array}{l}\text { Fonte: Pesquisa Mensal de Emprego (PME), } 201 \\
\text { A variável dependente binária é apresentada nas } \\
\text { informal em } t=\{1, \ldots, 48\} \text {, e } 0 \text { caso permaneça no } \\
\text { em t, e } 0 \text { caso contrário. A variável "Dummy de } \\
\text { "Dummy de Formal" é igual a } 1 \text { caso o trabalhad } \\
\text { exposta na linha de "Tempo de emprego". Todas } \\
\text { As regressões controlam adicionalmente por cova } \\
\text { tamanho do estabelecimento e número da entrev } \\
\text { ao grupo dos tratados é "Tratados", calculado cc } \\
\text { caso possua } 3 \text { meses no emprego informal em t-1. } \\
\text { vigorar. O coeficiente que capta o efeito da muda } \\
\text { o período de tratamento. Este é o coeficiente do } \\
\text { entre o "Efeito da Mudança" e o "Efeito da Mud }\end{array}$ & $\begin{array}{l}2 \text { a 2015. Níveis de significância: * *: } \\
\text { colunas. Em (1), a variável "Dummy d } \\
\text { informal. Na coluna (2), a "Dummy de } \\
\text { Inativos" utilizada em (3) é igual a } 1 \text { cas } \\
\text { or i, informal em t-1, esteja trabalhando } \\
\text { as regressões controlam por efeitos fixos } \\
\text { riadas, tais como idade, faixa de escolar } \\
\text { ista no domicílio. Todas covariadas são } \\
\text { m base em uma variável dummy que as } \\
\text { Os meses a partir de março de } 2015 \text { são } \\
\text { nça da elegibilidade,"Efeito da Mudança } \\
\text { feito para os indivíduos que possuem me } \\
\text { ança" interagido com as dummies de seu }\end{array}$ & $\begin{array}{l}0 \% \text { * * : } 5 \% \quad * * *: 1 \% \text {. O er } \\
\text { e saída do Informal" é igual a } 1 \mathrm{cc} \\
\text { Desocupados" é igual a } 1 \text { caso o } \\
\text { o o trabalhador i, informal em t-1 } \\
\text { com carteira em t, e } 0 \text { caso contrá } \\
\text { mensais e pela interação entre a } \\
\text { idade, gênero, cor, efeito fixo de r } \\
\text { referentes ao emprego informal em } \\
\text { sume valor igual a } 1 \text { se o indivídu } \\
\text { definidos como o período de tratar } \\
\text { ", é definido pela interação da dum } \\
\text { nos que } 11 \text { anos de estudo. O efeit } \\
\text { s anos de estudo. }\end{array}$ & $\begin{array}{l}\text { To padrão robusto é apresen } \\
\text { so o trabalhador i, informa } \\
\text { trabalhador i, informal em } \\
\text { esteja inativo em t, e } 0 \text { cas } \\
\text { io. A amostra utilizada nas } \\
\text { lummy dos tratados e as du } \\
\text { gião metropolitana, ocupaç } \\
\text { t-1. O coeficiente que capt } \\
\text { o possui } 6 \text { meses no empreg } \\
\text { nento, dado que as mudança } \\
\text { imy dos tratados com uma f } \\
\text { o para os demais indivíduos }\end{array}$ & $\begin{array}{l}\text { tado entre parênteses. } \\
1 \text { em t-1, deixe o setor } \\
\text { t-1, esteja desocupado } \\
\text { o contrário. Em (4), a } \\
\text { diferentes regressões é } \\
\text { mmies de mês no ano. } \\
\text { âo, setor de atividade, } \\
\text { a o efeito de pertencer } \\
\text { o informal em t-1, e 0 } \\
\text { s legislativas passam a } \\
\text { unção indicadora para } \\
\text { é calculado pela soma }\end{array}$ \\
\hline
\end{tabular}


Tabela 37 - Resultado das regressões de diferenças em diferenças nas saídas do setor informal - Controles com 3 meses e tratados com 6 em t- 1 - Heterogeneidade de tamanho da firma

\begin{tabular}{|c|c|c|c|c|}
\hline \multirow{2}{*}{$\begin{array}{l}\text { Tempo de Emprego } \\
\text { Variável Dependente }\end{array}$} & \multicolumn{4}{|c|}{ Controles com 3 e tratados com 6 meses no emprego informal em t- 1} \\
\hline & $\begin{array}{l}\text { Dummy de saída do Informal } \\
\text { (1) }\end{array}$ & $\begin{array}{l}\text { Dummy de Desocupados } \\
(2)\end{array}$ & $\begin{array}{c}\text { Dummy de Inativos } \\
(3)\end{array}$ & $\begin{array}{c}\text { Dummy de Formal } \\
\text { (4) }\end{array}$ \\
\hline \multirow[t]{2}{*}{ Efeito da Mudança } & 0.0359 & 0.0343 & 0.0012 & 0.0216 \\
\hline & $(0.0554)$ & $(0.0260)$ & $(0.0301)$ & $(0.0412)$ \\
\hline \multirow{2}{*}{ Efeito Mudança* $\geq$ que 11 empregados } & -0.0869 & -0.0221 & -0.0285 & -0.0438 \\
\hline & $(0.0727)$ & $(0.0336)$ & $(0.0390)$ & $(0.0561)$ \\
\hline \multirow[t]{2}{*}{ Tratados } & -0.0376 & $0.0623^{* *}$ & $-0.0671^{* *}$ & -0.0335 \\
\hline & $(0.0615)$ & $(0.0279)$ & $(0.0275)$ & $(0.0520)$ \\
\hline \multirow[t]{2}{*}{ Constante } & 0.1058 & 0.0238 & $0.2023^{* * *}$ & -0.0642 \\
\hline & $(0.1186)$ & $(0.0337)$ & $(0.0693)$ & $(0.0997)$ \\
\hline Efeito fixo mensal & $\operatorname{sim}$ & $\operatorname{sim}$ & $\operatorname{sim}$ & $\operatorname{sim}$ \\
\hline Sazonalidade - grupo & $\operatorname{sim}$ & $\operatorname{sim}$ & $\operatorname{sim}$ & $\operatorname{sim}$ \\
\hline Covariadas & $\operatorname{sim}$ & $\operatorname{sim}$ & $\operatorname{sim}$ & $\operatorname{sim}$ \\
\hline Observações & 6100 & 6100 & 6100 & 6100 \\
\hline R-quadrado aj. & 0.068 & 0.009 & 0.038 & 0.051 \\
\hline \multicolumn{5}{|c|}{ 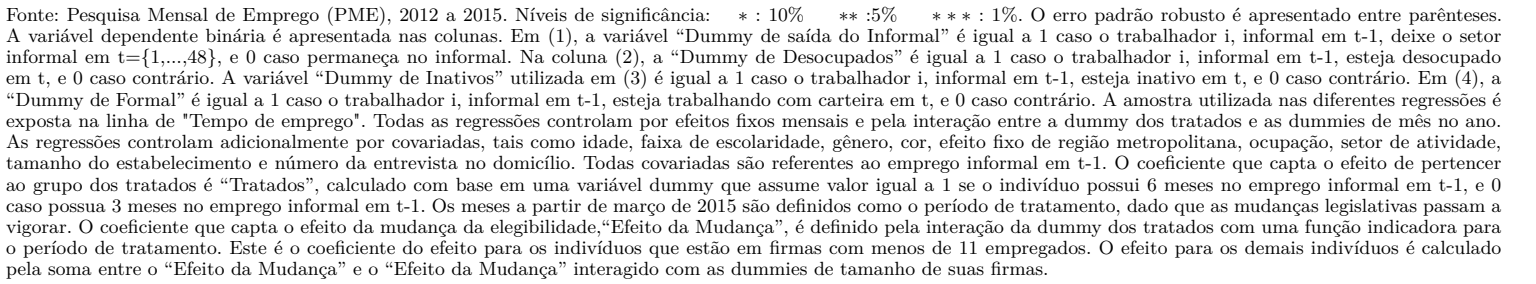 } \\
\hline
\end{tabular}

